\title{
Elucidating disease dynamics in the biocontrol of Ailanthus altissima while confirming the host specificity of the vascular wilt pathogen Verticillium nonalfalfae
}

\author{
Kristen L. Wickert \\ klw5421@gmail.com
}

Follow this and additional works at: https://researchrepository.wvu.edu/etd

Part of the Other Forestry and Forest Sciences Commons

\section{Recommended Citation \\ Wickert, Kristen L., "Elucidating disease dynamics in the biocontrol of Ailanthus altissima while confirming the host specificity of the vascular wilt pathogen Verticillium nonalfalfae" (2019). Graduate Theses, Dissertations, and Problem Reports. 3854. \\ https://researchrepository.wvu.edu/etd/3854}

This Dissertation is protected by copyright and/or related rights. It has been brought to you by the The Research Repository @ WVU with permission from the rights-holder(s). You are free to use this Dissertation in any way that is permitted by the copyright and related rights legislation that applies to your use. For other uses you must obtain permission from the rights-holder(s) directly, unless additional rights are indicated by a Creative Commons license in the record and/ or on the work itself. This Dissertation has been accepted for inclusion in WVU Graduate Theses, Dissertations, and Problem Reports collection by an authorized administrator of The Research Repository @ WVU. For more information, please contact researchrepository@mail.wvu.edu. 
Elucidating disease dynamics in the biocontrol of Ailanthus altissima while confirming the host specificity of the vascular wilt pathogen Verticillium nonalfalfae

\author{
Kristen L. Wickert \\ Dissertation submitted \\ to the Davis College of Agriculture, Natural Resources and Design \\ at West Virginia University \\ in partial fulfillment of the requirements for the degree of \\ PhD in \\ Plant Pathology
}

Matthew T. Kasson, Ph.D., Chair

Ember Morrissey, Ph.D.

Daniel G. Panaccione, Ph.D.

Scott Salom, Ph.D.

Donald Davis, Ph. D.

Division of Plant and Soil Sciences

Morgantown, West Virginia

2019

Keywords: Verticillium nonalfalfae, tree-of-heaven, biocontrol, Ailanthus

Copyright 2019 Kristen Wickert 


\section{ABSTRACT \\ Elucidating disease dynamics in the biocontrol of Ailanthus altissima while confirming the host specificity of the vascular wilt pathogen Verticillium nonalfalfae}

\section{Kristen L. Wickert}

Ailanthus altissima is a highly invasive exotic tree species entrenched throughout the United States. Since the discovery of a vascular wilt disease of Ailanthus in 2002, caused by the fungus Verticillium nonalfalfae, many studies are investigating its potential as a biocontrol focusing on efficacy, host specificity and disease transmission. This study addresses: the reproductive potential of Ailanthus; if $V$. dahliae alters Verticillium wilt progression; if hardiness zones influence the individual contributions of two Verticillium spp.; can a unique habitat affect biocontrol efficacy; and can the fungal proteome of $V$. nonalfalfae allow us to explain differences in host specificity? Cumulative seed production in individual Ailanthus reached ca. 10 and 52 million seeds over a 40-year and 100-year period, respectively. Forested sites inoculated with both Ailanthus pathogenic species of Verticillium experienced the same mortality rates as sites with just $V$. nonalfalfae alone. When comparing mortality caused by Verticillium wilt in three hardiness zones, it was found that there was no difference in disease progression. Ailanthus established on previous strip mine sites displayed resistance to the pathogen. Tree ring observations and X-ray fluorescence mineral assays indicated high concentrations of iron which inhibited Verticillium infection. Isolates of Verticillium species and strains from different plant hosts displayed differences in pathogenicity to Ailanthus seedlings and had distinct proteomes from each other when analyzed with MALDI-TOF-MS, indicating Verticillium isolates from different sources respond to their host environment differently. 


\section{Dedication}

This dissertation is dedicated to my mother and my close friends. 


\section{Acknowledgements}

I would like to express my intense gratitude to my committee for their advice, knowledge, and support through my efforts to complete my PhD. Dr. Daniel Panaccione, Dr. Ember Morrissey, Dr. Scott Salom, Dr. Don Davis and Dr. Matthew Kasson have all been valuable academic mentors to my future and have taught me many life lessons. Thank you to Amy Metheny and Cameron Stauder, along with his wife Laura. Chansotheary Dang and Jeth Walkup have been some of the best office mates a graduate student could ask for. 


\section{Table of Contents}

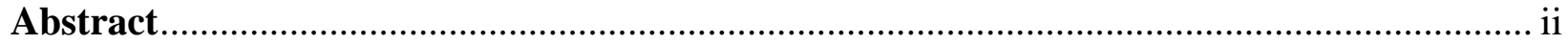

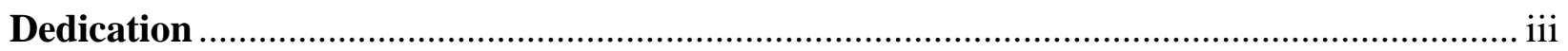

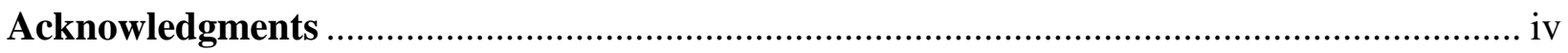

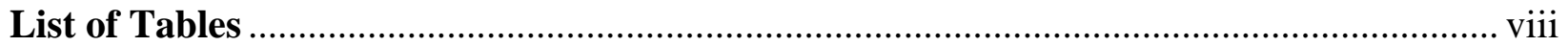

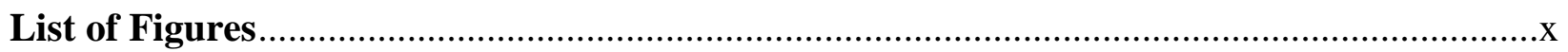

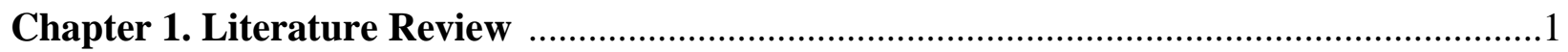

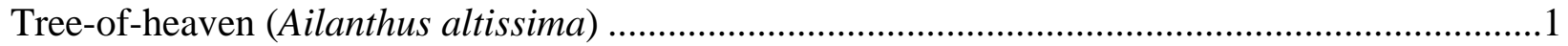

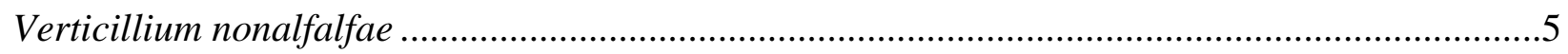

Taxonomy and Phylogenetics of the genus Verticillium ...........................................................6

History of Verticillium wilt caused by $V$. nonalfalfae and $V$. dahliae ..........................................

Examples of Successful Biocontrol efforts ...............................................................................11

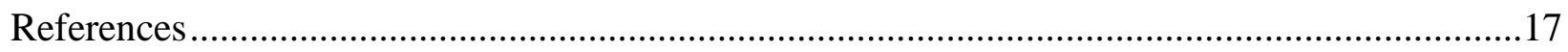

Chapter 2. Seed Production, Viability and Reproductive Limits of the Invasive Ailanthus altissima (tree-of-heaven) within Invaded Environments

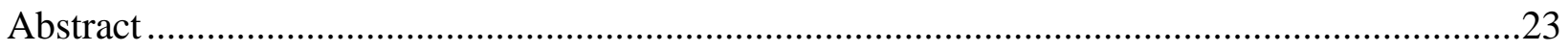

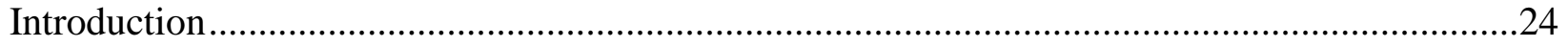

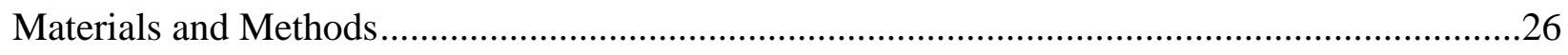

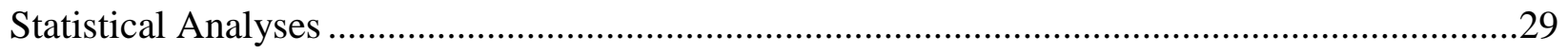

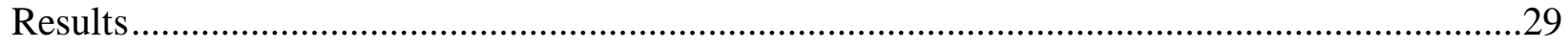

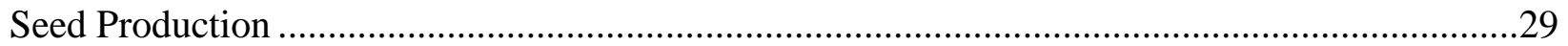

Germination Studies to Assess Seed Viability Based on Seed and Tree Age ...............................32

Tetrazolium Assay to Evaluate Seed Viability ……………….......................................................32

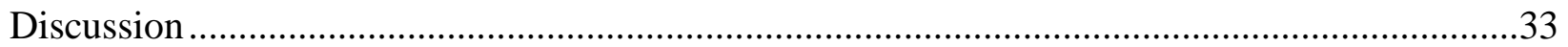

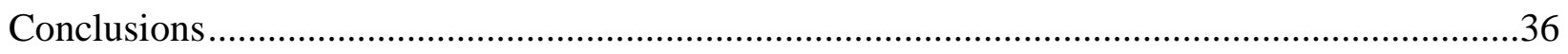

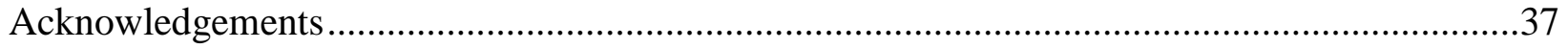

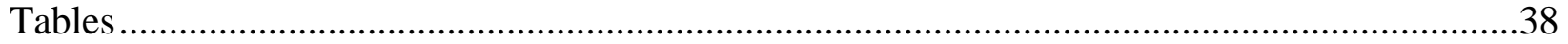

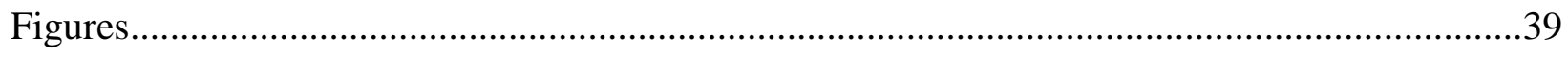

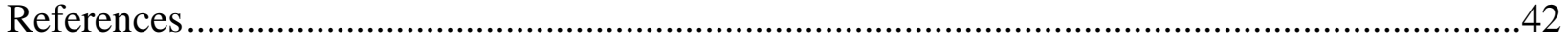


Chapter 3. Disease progression of Verticillium nonalfalfae and $V$. dahliae, causal agents of Verticillium wilt of Ailanthus, in different hardiness zones of Pennsylvania, USA

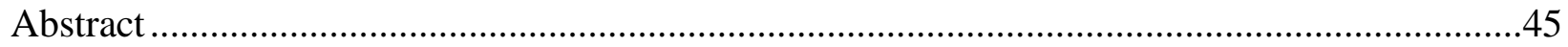

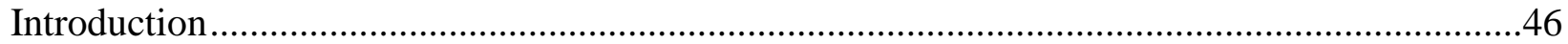

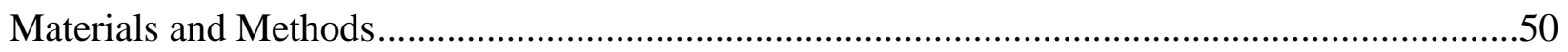

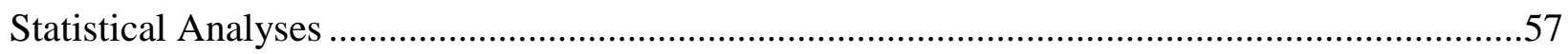

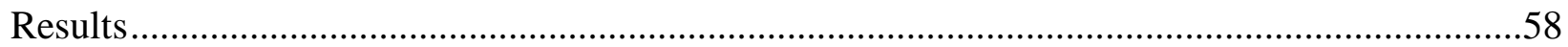

Viability of $V$. nonalfalfae and $V$. dahliae in Long Term Storage ...............................................58

Efficacy of $V$. nonalfalfae-inoculated soil and rye grain on Ailanthus seedlings in a controlled environment

Comparisons among direct and indirect $V$. nonalfalfae inoculations in a newly regenerated forest

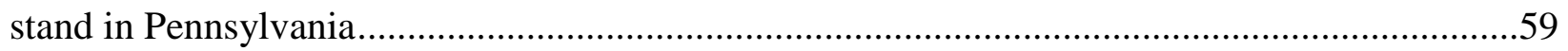

The influence of $V$. dahliae on the efficacy of $V$. nonalfalfae inoculations in three hardiness zone groups of Pennsylvania .

Comparisons among individual and mixed inoculations of $V$. nonalfalfae and $V$. dahliae on greenhouse Ailanthus .....................................................................................................6

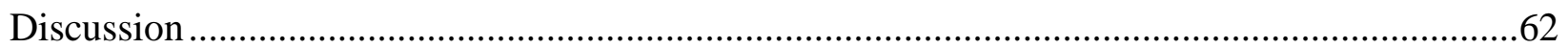

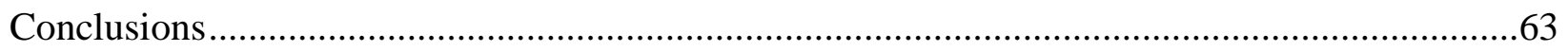

Acknowledgements .........................................................................................................6

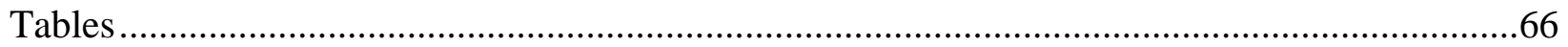

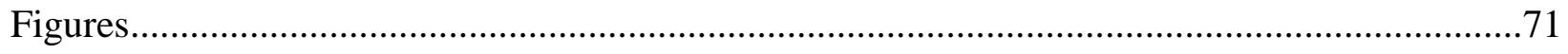

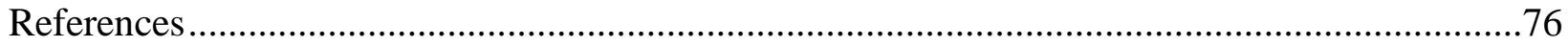

Chapter 4. Iron Hyperaccumulation in Ailanthus altissima Confers Tolerance to the Vascular Wilt Pathogen Verticillium nonalfalfae at a Reclaimed Surface Mine in Ohio

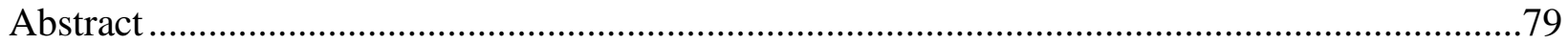

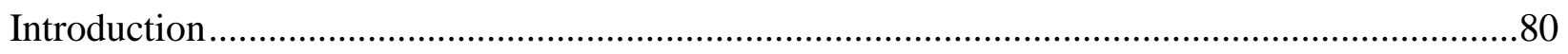

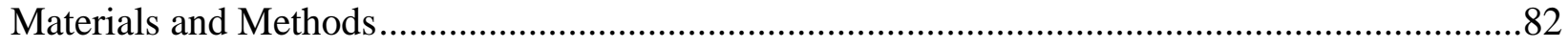

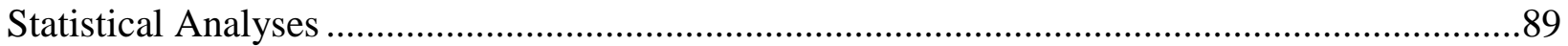

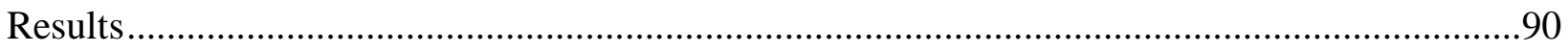


Two-year evaluation of outward symptoms and radial growth responses following artificial

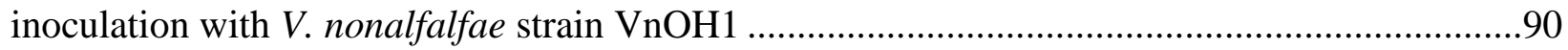

Evaluation of outward symptoms following 2018 re-inoculation with $V$. nonalfalfae ................91

Elemental assessment of Ailanthus radial cores using X-ray fluorescence (XRF) spectrometry..91

Growth and Conidiation of $V$. nonalfalfae across an Iron Gradient ........................................92

Iron Inundation to Suppress Verticillium wilt in Ailanthus seedlings .....................................93

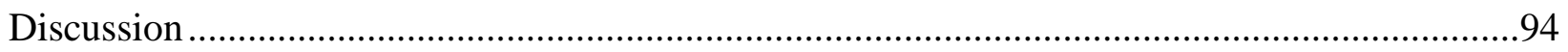

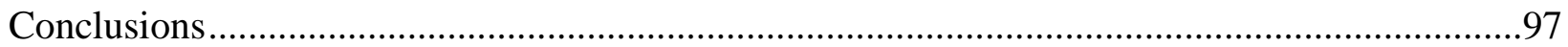

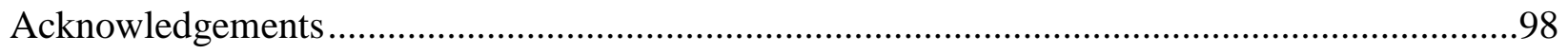

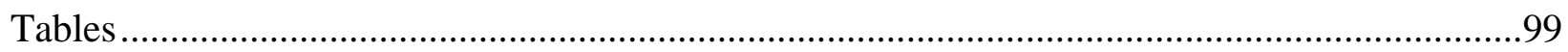

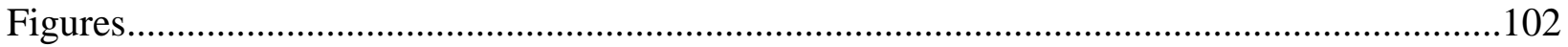

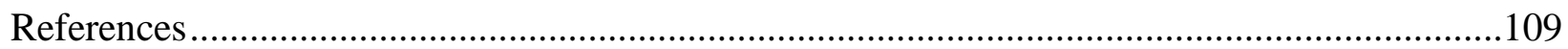

Chapter 5. Resolving inter- and intra-species boundaries in phytopathogenic Verticillium spp. by MALDI-TOF mass spectrometry

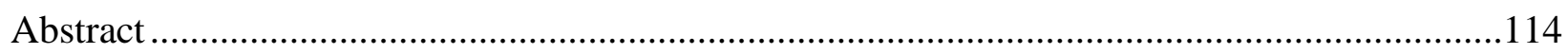

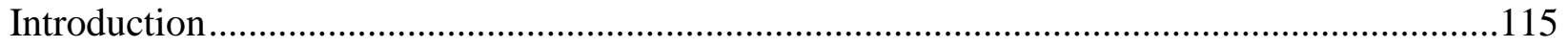

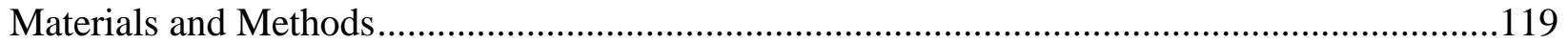

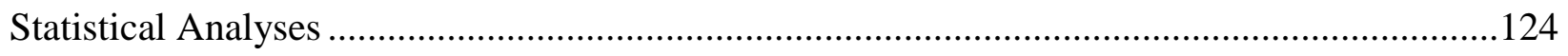

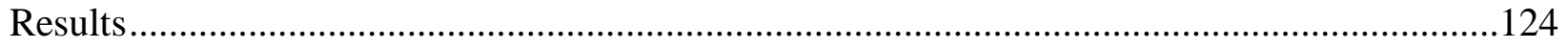

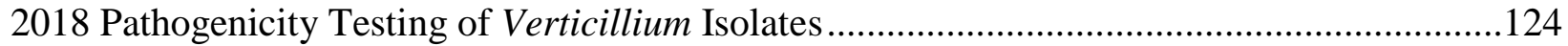

Phylogenetic Resolution via PCR Methods ..................................................................125

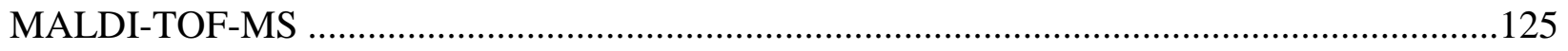

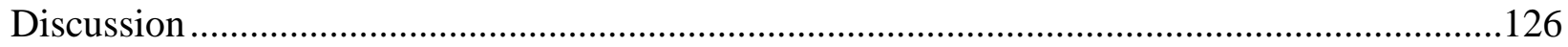

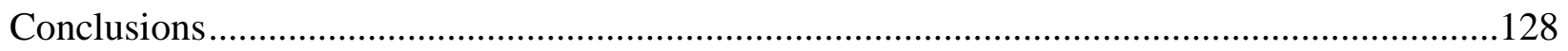

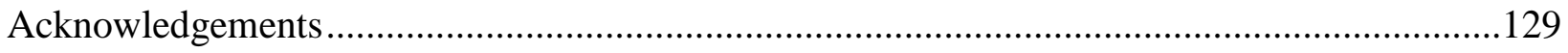

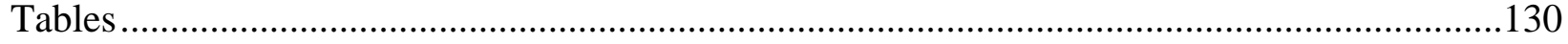

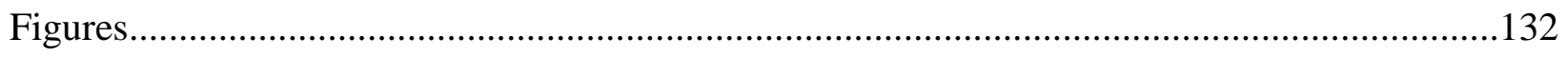

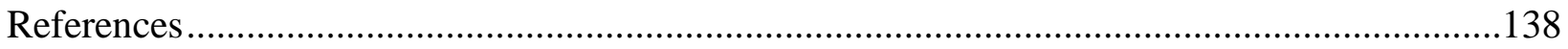

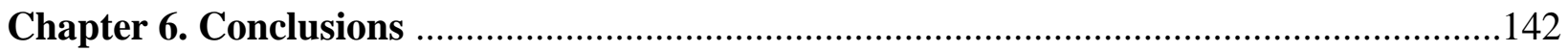




\section{List of Tables}

Chapter 2 - Table 1. Seed viability status for current and historic seed sources of Ailanthus....38

Chapter 3 - Table 1. Long term soil vials containing 33 isolates of $V$. nonalfalfae isolated from Ailanthus created in 2012, and 2013, 2014 and their viability or contamination status after plating on PDA in 2018. .66

Chapter 3 - Table 2. Long term soil vials containing 19 isolates of $V$. dahliae isolated from Ailanthus created in 2010, 2012, and 2013 and their viability or contamination status after plating on PDA in 2018.

Chapter 3 - Table 3. Field Site and Plot details which were inoculated with either $V$. nonalfalfae, both V. dahliae and V. nonalfalfae (Mix), or Water Control in the Spring of 2017..68

Chapter 3 - Table 4. Treatment details and mortality rates for plots which were treated with preliminary approach methods of $V$. nonalfalfae formulation techniques to control Ailanthus regeneration in a timber harvested forest.

Chapter 3 - Table 5. Abnormalities observed in vessels of Ailanthus seedling stems infected with water, $V$. nonalfalfae, $V$. dahliae, and both fungi in a root dip inoculation experiment visualized in a microtome analysis. (-) denotes nothing abnormal noticed in any vessels of entire cross section.

Chapter 4 - Table 1. Disease ratings of tolerant and susceptible Ailanthus trees from the WILDS, a wildlife conservation center built on a reclaimed surface mine site in Southeastern Ohio. Details of Ailanthus tree cores: include age, years with vascular discoloration indicating previous Verticillium infections and years of abnormal compressed annual growth rings. Rating scale is taken from O'Neal and Davis 2015 and follows a 0-8 scale: 0-healthy foliage, 1-chlorosis and/or necrotic margins on leaves, 2 -slight wilt ( $<15 \%$ wilting foliage) with no or slight defoliation $(<15 \%)$, 3-moderate wilt ( 15 to $<50 \%$ wilting foliage with no or slight defoliation 
(<15\%), 4-severe wilt (50 to 100\% wilting foliage with no or slight defoliation $(<15 \%)$, 5moderate defoliation (15 to $<50 \%$ ), 6-severe defoliation (50 to $90 \%$ ), 7-very severe defoliation (90 to $100 \%$ ) with epicormic sprouting, 8-dead.

Chapter 4 - Table 2. Morphological and conidial production differences in $V$. nonalfalfae colonies grown on potato dextrose agar plates containing varying levels of Sequestrene 138, a chelated iron product used to prevent Verticillium species infections in agricultural systems ...100

Chapter 4 - Table 3. Disease progression through biweekly percent wilt ratings of Ailanthus seedlings grown in soil augmented with different concentrations of Sequestrene 138, a chelated iron product used to prevent Verticillium species infections in agricultural systems, and inoculated with $V$. nonalfalfae via root dip into a $1 \times 10^{7}$ conidia $\mathrm{ml}^{-1}$ suspension.

Chapter 5 - Table 1. Verticillium isolates and their original host species used in pathogenicity testing of Ailanthus to create area under the disease curve and MALDI-TOF-MS analysis. PCR column refers to what the isolate showed bands in the PCR analysis. $\mathrm{Vn}=V$. nonalfalfae, Valf $=$ $V$. alfalfae, $\mathrm{Vd}=V$. dahliae, $\mathrm{Valb}=V$. albo-atrum, $-=$ no bands were illuminated in gel results. A slash between names indicates that two distinct bands were produced for that isolate in the respective species' PCR.

Chapter 5 - Table 2 Comparisons of the AUDCP and Qin ratings for isolates in previous studies and this study. 


\section{List of Figures}

Chapter 2 - Figure 1. Ailanthus seed embryo challenged with blue tetrazolium chloride. A positive blue tetrazolium chloride (TZ) test resulted in (A) complete staining of radical and hypocotyl or (B) staining of radical only, whereas a negative TZ test resulted

Chapter 2 - Figure 2 Ailanthus seed production versus diameter at breast height (DBH, cm) using the combined dataset.

Chapter 2 - Figure 3. Distribution of (A) seed counts, (B) diameter at breast height (DBH, cm), and (C) age for seed producing Ailanthus from historic data sets and the current study

Chapter 2 - Figure 4. Relationship between age and diameter at breast height (DBH, $\mathrm{cm}$ ) of open-grown Ailanthus. Equation for combined data is given above. Equation for Wickert et al. (this study) and Kasson et al. 2013, respectively, are as follows: $\mathrm{Y}=0.8517 \times \sqrt{\mathrm{DBH}}+1.027$, $R^{2}=0.76, p<0.0001 ;$ and $\mathrm{Y}=1.1266 \times \sqrt{ } \mathrm{DBH}-1.964, R^{2}=0.83, p<0.0001$

Chapter 2 - Figure 5. Relationship between number of seeds produced by Ailanthus and diameter at breast height $(\mathrm{DBH}, \mathrm{cm})$. Cumulative seed production for an individual Ailanthus over its lifetime, as it grew from $1-49 \mathrm{~cm}$ in diameter, was estimated to be ca.10 million seeds.41

Chapter 3 - Figure 1. Ten-ml scintillation vials containing a 1:1:1 sterile mix of potting soil/sand/ perlite were flooded with conidia harvested from 4-week-old cultures of either Verticillium dahliae or $V$. nonalfalfae and stored at $4{ }^{\circ} \mathrm{C}$ for 3-8 years .71

Chapter 3 - Figure 2. Inoculated rye grain and inoculated soil used for formulation experiments. (A) Inoculation of rye grain with sections of $V$. nonalfalfae colonized agar, (B) Sterile potting soil inoculated with $V$. nonalfalfae conidial suspension, (C) After two weeks, rye grain was fully colonized by $V$. nonalfalfae (D) $V$. nonalfalfae colonized soil showing hyphae on top of soil aggregates.

Chapter 3 - Figure 3. Inoculation selection in permanent 10th acre plots with a 37.2-foot diameter. Each circle represents an Ailanthus stem with its unique identification 
Number. Size of circles represents diameter ranges. Red circles are the trees which represent $10 \%$ of the entire basal area while being closest to plot center and inoculated. A) Plot 1: Mixture Inoculation. Entire basal area for this site was 10.34 square feet and the inoculated trees were closest to $10 \%$ of the entire basal area (1.03 sq. ft.) at $1.32 \mathrm{sq}$. ft. B) Plot 2: V. nonalfalfae Inoculation. Entire basal area for this site was 13.11 square feet and the inoculated trees were closest to $10 \%$ of the entire basal area (1.31 sq. ft.) at 0.86 sq. ft. C) Plot 4: Control. Entire basal area for this site was 2.67 square feet and the inoculated trees were closest to $10 \%$ of the entire basal area ( 0.26 sq. ft.) at 0.35 sq. ft.

Chapter 3 - Figure 4. Mortality of Ailanthus trees in three plant hardiness zone groups and three treatments ( $V$. nonalfalfae, mixture of $V$. nonalfalfae and $V$. dahliae and Water Control). Treatments were found to be statistically significant when analyzed with a Cochran-MantelHaenszel Test ( $p$ value - 0.000). However, with the same test and the removal of the Water Control, there was no statistically significant difference between the $V$. nonalfalfae and the Mixture treatments ( $\mathrm{p}$ value 0.3090)

Chapter 3 - Figure 5. Examples from microtome sections of Ailanthus seedlings infected with different Verticillium species. (A) An example of most of the microtome samples being free of any abnormalities in the vessels. (B) seedling treated with Verticillium nonalfalfae showing abnormal segments in vessels resembling fungal hyphae (seedling N17), (C) A completely gummed vessel in a seedling treated with both fungi (seedling B4), (D) Abnormal grouping of live cells clogging vessels in a control seedling (seedling C1).

Chapter 4 - Figure 1. (A) Example Ailanthus tree core from the West Virginia University organic farm (which served as a control) displaying normal growth patterns with average spacing between individual growth rings. (B) An Ailanthus tree core displaying a ring of yellow vascular discoloration and continued growth that overcame infection by a Verticillium species. (C) Close up of vascular discoloration in photo B. (D) An Ailanthus tree core displaying an occurrence only noticed at the WILDS of compressed rings. (E) Close up of ring compression with seemingly lacking evidence of annual late wood hypothesized to be due to heavy metal accumulation and subsequent toxicity. 
Chapter 4 - Figure 2. Qualitative iron peaks for Ailanthus tree cores from the WILDS and from the West Virginia University Organic Farm

Chapter 4 - Figure 3. Qualitative iron peaks for Ailanthus tree cores from the WILDS and from the West Virginia University Organic Farm colored according to tolerance and susceptibly ratings

Chapter 4 - Figure 4. (A) Qualitative iron peaks for Ailanthus tree cores from the WILDS colored by susceptible and tolerant ratings. (B) Iron peaks for the most tolerant trees at the WILDS with ratings of 0 , meaning they displayed no external symptoms after being inoculated with the vascular wilt pathogen Verticillium nonalfalfae two times. (C) Iron peaks for the most susceptible trees at the WILDS with ratings of 8 , meaning they displayed no external symptoms after being inoculated with the vascular wilt pathogen $V$. nonalfalfae once in 2015. .105

Chapter 4 - Figure 5. Seven treatments of gradually increasing iron concentrations in the form of Sequestrene 138 added to potato dextrose agar plates with pure cultures of $V$. nonalfalfae placed in the center of the plate after being excised with a sterile $4 \mathrm{~mm}$ cork borer. Measurements of growth, conidial production and viability occurred after 3 weeks of growth at ambient room temperature.

Chapter 4 - Figure 6. A comparison showing the reduction of aerial hyphae of $V$. nonalfalfae produced with increasing intensity of iron concentrations in PDA plates. From left to right are treatments of control PDA + A with no added iron, $0.001 \mathrm{~g}$ Sequestrene/500 mL $\mathrm{H}_{2} \mathrm{O} / 19 \mathrm{~g}$ PDA and $0.1 \mathrm{~g}$ Sequestrene $/ 500 \mathrm{~mL} \mathrm{H}_{2} \mathrm{O} / 19 \mathrm{~g}$ PDA.

Chapter 4 - Figure 7. (A) An Ailanthus seedling grown in soil containing no iron additions showing severe symptomatic wilting after being root dip inoculated with $V$. nonalfalfae (B) An Ailanthus seedling grown in soil containing $0.1 \mathrm{~g} / \mathrm{gallon}$ of Sequestrene 138 showing milt symptomatic wilting and chlorosis after being root dip inoculated with $V$. nonalfalfae (C) An asymptomatic Ailanthus seedling grown in soil containing $0.4 \mathrm{~g} / \mathrm{gallon}$ of Sequestrene 138 amended soil after being root dip inoculated with $V$. nonalfalfae (D) Survival curve for Ailanthus seedlings after being grown in Sequestrene 138 augmented soil low $(n=6)$ and high $(n=6)$ concentrations and a control $(n=5)$ containing no iron and being root dip inoculated with $V$. 
nonalfalfae conidial suspension. WPI = weeks post inoculation $(\mathrm{E}-\mathrm{F}) \mathrm{V}$. nonalfalfae was successfully isolated from both symptomatic tissues and soil of all three treatments.

Chapter 5 - Figure 1. (A) Asymptomatic Ailanthus seedlings inoculated with V. nonalfalfae originating from spinach (B) Severely wilted Ailanthus seedlings inoculated with $V$. nonalfalfae originating from Ailanthus.

Chapter 5 - Figure 2. Mean disease rating of Ailanthus seedlings inoculated with nine Verticillium strains originally isolated from different plant hosts. An ANOVA and Student's ttest indicate mean disease ratings are statistically significantly different (p-value: 0.01 )

Chapter 5 - Figure 3. Principal component analysis (PCA) plot showing average peaks for all reads of the fungal smear replicates for the 32 isolates. Each line represents a fungal smear of the isolate type grouped in colors representing isolate groups.

Chapter 5 - Figure 4. A principle component analysis shows isolates of $V$. nonalfalfae from Ailanthus cluster with $V$. nonalfalfae isolates from Acer pennsylvanicum and Actinidia chinensis but separately from and hops and Solanaceous hosts isolates. An ANOVA and Tukey's Test with 95\% confidence interval delineated clusters (see circles) that are statistically significant from each other ( $\mathrm{p}$-value $\leq 0.05)$.

Chapter 5 - Figure 5. Heat map confirms the trends in the PCA plot, showing the separation of the eight groupings of species and host associations into separate clusters. .136

Chapter 5 - Figure 6. Nearly complete sequence coverage of the proteome illustrated in representative mass spectra containing distinct averaged protein peaks for four species of Verticillium fungi included in the analysis. (A) V. albo-atrum from potato (B) V. nonalfalfae from Ailanthus (C) V. dahliae from Ailanthus (D) V. alfalfae from alfalfa. Similarities between the four Verticillium species are highlighted with a black arrow and unique features highlighted with a yellow arrow. 


\section{Chapter 1}

\section{Literature review}

\section{Tree-of-heaven (Ailanthus altissima)}

Tree-of-heaven (Ailanthus altissima (Mill.) Swingle) is a highly invasive exotic tree species in North America. It was introduced to America from China in 1784 into Philadelphia, PA as an ornamental garden tree. Due to its ability to thrive in poor sites, grow rapidly, and produce beautiful leaves and seed inflorescences it quickly became a desirable lawn and city tree (Kasson et al. 2013). Ironically, all of these desirable traits translate to why this tree has become one of the most aggressive invasive species in North America today. The ability to grow in poor sites such as compacted urban soils means that it has the capacity to grow in a range of habitats including sidewalk cracks, abandoned lots, and in ecologically sensitive areas. The ability to grow up to three meters in its second year of growth enables it to out compete native vegetation. The seed clusters, which collectively on one tree, can contain thousands of seeds give tree-ofheaven the ability to reproduce at alarming rates. Since its introduction, tree-of-heaven has been confirmed in 44 of 50 states and if left unmanaged it will undoubtedly spread to the remaining states.

Ailanthus escaped the cities and proliferated in the forests of much of the Northeast over the last 235 years where it was able to go unnoticed for decades. This range expansion is tied heavily to railroad transportation in the 1800's and the establishment of the interstate highway system in the 1950's. These transportation corridors allowed for miles of disturbed edge habitat which tree-of-heaven thrives in. Its invasive potential became very apparent quickly after the attack of the gypsy moth (Lymantria dispar L.) on oak species in the Mid-Atlantic area in the 1980's. With large portions of the native forest canopy killed due to the defoliation by the gypsy moth, tree-of-heaven was able to take over the niche of the oaks as they were removed from the 
landscape in timber salvage efforts. Large areas of open salvaged forest land quickly were covered by millions of tree-of-heaven seedlings which rapidly closed the canopy and created monoculture forests of tree-of- heaven. This monoculture tree-of-heaven forest type promotes the growth of other coevolved invasive Asiatic species of an equally competitive nature, such as mile-a-minute (Persicaria perfoliata (L.) H. Gros), Japanese knot weed (Fallopia japonica Houtt.), Japanese stiltgrass (Microstegium vimineum (Trin.) A. Camus), Japanese barberry (Berberis thunbergii DC.) and Japanese angelica tree (Aralia elata (Miq.) Seem). Commonly, the only native species that reestablish in Mid-Atlantic forests plagued with tree-of-heaven are undesirable low ecological value species such as hay-scented fern (Dennstaedtia punctilobula (Michx.) T. Moore) or Pennsylvania smartweed (Polygonum pennsylvanicum (L.) M. Gómez). With the continued globalization of our world and introduction of more invasive species into our forests, such as hemlock woolly adelgid (Adelges tsugae Annand) which is killing native eastern hemlock (Tsuga canadensis (L.) Carrière) and emerald ash borer (Agrilus planipennis Fairmaire) that is quickly eradicating native ash (Fraxinus L.) species, we can expect to see more Ailanthus on the landscape as they conquer the fallen species niche and continued loss of native forest diversity.

Not only is tree-of-heaven a nuisance tree that overtakes and outcompetes native species that are valuable for wildlife habitat or timber management, it provides a bridge for additional invasive species to establish in new landscapes. Shot hole borer (Euwallacea validus Eichhoff) is a small ambrosia beetle in the family Curculionidae originally from Asia, the same region that tree-of-heaven is native to. Euwallacea validus has an affinity for tree-of-heaven likely due to its co-evolutionary past together in Asia. The beetle can commonly be found interacting with stressed Ailanthus trees since the stressed trees are releasing ethanol, which attracts the beetle. 
Like all ambrosia beetles, this beetle has a fungal symbiont that is carried in mycangia on its body to infect trees with its symbiont which the beetle utilizes as a food source (Cognato et al. 2015). The fungal species in symbiosis with Euwallacea validus is a plant pathogenic and saprophytic Fusarium Link. This fungal symbiont was tested on several important tree species in North America and it was found through stem inoculation experiments that avocado (Persea americana Mill.) has confirmed susceptibility to the Fusarium symbiont of Euwallacea validus (Kasson et al. 2013). Symptoms were noticed in avocado two weeks after inoculation with one of the fungal isolate strains from E. validus (Kasson et al. 2013). Avocados are grown primarily in warm temperature zones, such as Florida which boasts an annual income of $\$ 18$ million annually due to the avocado industry (Crane at al. 2007). With the infamous spread of tree-of-heaven associated with how Ailanthus can produce over 10 million seeds during a 40-year life time, there lies a threat of Ailanthus increasing in numbers in Florida (Wickert et al. 2017). This almost-guaranteed increase in the range and population of Ailanthus creates a bridge across the landscape for E. validus beetles carrying the lethal Fusarium strains to travel to avocado orchards.

Euwallacea validus is not the only exotic and invasive insect with an affinity for tree-ofheaven. Pennsylvanian entomologists have found the recently (2015) introduced exotic and highly invasive spotted lanternfly (Lycorma delicatula White) will congregate in masses of thousands of individuals on Ailanthus trees (Barringer et al. 2015). Research is ongoing as to why the insect prefers to congregate on Ailanthus, but it's thought to be related to cytotoxin accumulation to ward of predation (Dara et al. 2015). A cyclic behavior in the life style of the insect was noticed with adults frequenting Ailanthus trees while young nymphs aggregate and feed on several different tree species, particularly fruit trees and grape vines (Kim et al. 2011). 
This varying host preference leads to concerns over the abundant presence of Ailanthus on the landscape that act as some obligate life cycle stage which allows for Lycorma delicatula to succeed in our North American forests, orchards, and vineyards. Lycorma delicatula has the potential to cause harm to the orchard and vineyard industry due to its piercing and sucking feeding habit which steals valuable sap from the plant host, especially when thousands of insects can cover a single plant (Barringer et al. 2015).

In 2017, a new wood boring insect, Agrilus smaragdifrons Ganglbauer, was discovered for the first time in North America (Hoebeke et al. 2017). It's suspected that this insect is an obligate feeder of tree-of-heaven but it is unknown if this insect can damage any of our native trees that are closely related to Ailanthus, such as our native paradise-tree (Simarouba glauca DC.) which is also in the Simaroubacea family. The prospect that an obligate insect can infest plants within the same family is a possibility, much like how fringe tree (Chionanthus virginicus L.) is in a distinct genus from Fraxinus species but is in the same family of Oleaceae. Emerald ash borer is killing Fraxinus species at an alarming rate and until recently was thought to only infest the Fraxinus genus, but $C$. virginucus was found to be a novel host of the emerald ash borer in the eastern United States (Cipollini 2015).

The longer the invasive Ailanthus is permitted to take over the North American landscape and forest, the higher its potential for allowing more introduced and detrimental insects establish in our forests and continuing to destroy our native forest diversity and composition. Pesticides have proven to not be enough to eradicate this noxious pest tree and the need for integrated pest management tactics is dire. 


\section{Verticillium nonalfalfae}

Members of this genus cause a vascular wilt to more than 350 species of both herbaceous and woody plants (Markell et al. 2015). The genus is cosmopolitan and very frequent in agricultural systems. The most current organization of the genus Verticillium Nees sensu stricto contains ten species, with the most famous of the genus being V. dahliae Kleb., V. albo-atrum Reinke \& Berthold, and V. alfalfae Inderbitzin (Inderbitzen and Subbarao 2014).

While the genus Verticillium is known to infect over 350 species of agricultural crops, $V$. nonalfalfae Inderbitzin has a relatively small host range. $V$. nonalfalfae is known to infect varied hosts in many genera, but as the name suggests, not alfalfa (Medicago saliva L.). Common hosts include common hop (Humulus lupulus), eggplant (Solanum melongena L.), potato (Solanum tuberosum L.), petunia (Petunia spp. Juss.) and spinach (Spinacia oleraceae L.) (Kasson et al. 2014).

$V$. nonalfalfae causes disease by proliferating in the xylem tissues of the woody host. Conidia clog the xylem vessels of the tree which are responsible for transporting nutrients and water to the canopy, thus causing wilted and nonfunctioning foliage (Schall 2008). The fungus fills the tissues of the plant and is able to be isolated from the leaves, rachises, and woody tissues. As the tree dies and decomposes the fungus remains viable in the plant tissues and surrounding soil as dark melanized hyphae allowing the soil to serve as an infectious reservoir. Melanized hyphae allow the fungus to persist in the soil up to 14 years without a host present (Wilhelm 1955). 


\section{Taxonomy and Phylogenetics of the genus Verticillium}

Initially, the genus Verticillium contained many different fungi that shared similar morphological growth patterns of specialized hyphae which created distinct whorls around each conidiophore. Fungi in the previous classification of Verticillium included parasites or saprotrophs of plants, nematodes, insects and even other fungi. This large genus was eventually separated, and it no longer contains the entomogenous and fungicolous Verticillium-like anamorphs. The insect and fungal parasite specialist species were placed in a new genus named Lecanicillium which resides in the class: Sordariomycetes, Order: Hypocreales, and family: Cordycipitaceae (Gams and Zare 2001). As the genus Verticillium stands today, it is proven to be heterogenus; both by molecular confirmation through analyses of sequences of the small and large ribosomal DNA subunits, 5.8S and the ITS regions as well as traditional morphological culture observations. No sexual state is known for any Verticillium species (Grams and Zare 2001).

The genus Verticillium resides in the class Sordariomycetes and in the family Plectosphaerellaceae. The genus has been recently broken into two clades. Verticillium nonalfalfae has been placed in the clade Flavnonexudans due to its absence of yellow hyphal pigments. The same study that clarified these different clades also renamed species due to this pigment difference (Inderbitzin et al. 2011). Verticillium nonalfalfae was formally known as $V$. albo-atrum, however it has been recently deciphered that the true V. albo-atrum is distantly related to $V$. nonalfalfae. Even though they are distantly related, both $V$. albo-atrum and $V$. nonalfalfae are known to occur in the same host.

Verticillium nonalfalfae is morphologically the same as V. alfalfae, however the two fungi differ in pathogenicity. The species do not hybridize and have mating type incompatibility. 
DNA characters also differ between these distinct species, allowing them to be molecularly confirmed with classic specific primer PCR techniques. Phylogenic analysis suggests that the fungus is native to the U.S. through suspected geographic restricted clades (Kasson et al. 2015). Currently, V. nonalfalfae is confirmed in Canada, Cuba, Japan, Slovenia, the United Kingdom and most recently Austria (Maschek and Halmschlager 2016).

In 2019, the genome for the $V$. nonalfalfae strain specifically from Ailanthus was sequenced with the use of Illumina HiSeq 2000 sequencing. The sequence generated $29.3 \mathrm{M}$ paired sequence reads or $3.4 \mathrm{~Gb}(100 \times$ coverage $)$, and 454 sequencing produced $1.3 \mathrm{M}$ singleton reads totaling $523 \mathrm{Mb}$ (16x coverage) (Kasson et al. 2019). The genome was compared to the already sequenced species $V$. dahliae and $V$. alfalfa for confirmation. Additionally, the annotation was compared to a $V$. nonalfalfae strain from hops which proved to be lethal to hops. The final genome annotation of the Ailanthus isolate included a total of 9,627 protein-coding genes and 196 tRNAs. AntiSMASH (v4.1.0) predicted 22 putative secondary metabolite clusters (Blin et al. 2017). The lethal hop strain held 9,269 proteincoding genes and a total assembly size of $34.2 \mathrm{Mb}$ (Jakše et al. 2018). With this knowledge, we can begin to make comparisons on what select gene clusters and individual genes translate to in the proteome and how function of the diverse strains of Verticillium nonalfalfae differ. Specific protein complexes in Kingdom Fungi are conserved, such as the ones that exist in yeast fungi, and they carry out distinct functions in fungi (Gavin et al. 2002). A protein complex that is being well studied in many systems is the pathogenicity or virulence gene cluster in fungi and the avirulence gene clusters in the plants associated with disease (Han et al. 2001). Even minute differences in these gene clusters can change the severity of pathogenicity of an organism and even create a non-pathogenetic organism. 


\section{History of Verticillium wilt caused by $V$. nonalfalfae and $V$. dahliae}

In 2002 a vascular wilt was found naturally occurring in in Pennsylvania where it was causing sever mortality in Ailanthus stands (Schall 2008). Seven years later the wilt was found in Virginia and in 2012 symptoms of wilt were observed in Ohio (Schneider et al. 2013, Rebbeck et al. 2013). Symptomatic tissues from the wilted trees were plated on nutrient agar to isolate the causal agent, which in all three cases was discovered to be $V$. nonalfalfae. Since 2002, there have been several projects answering the main research questions of the possibility of utilizing this fungus as a biocontrol in the field such as: incidence of natural occurrence, spread from disease epicenter and pathogen host range and transmission of disease.

In 2005 Schall and Davis performed host testing of seven common co-occurring native forest tree species. Testing occurred in the greenhouse with seedlings as well as inoculating hosts in the forest. $V$. nonalfalfae was not pathogenic on any of the artificially inoculated hosts except for striped maple (Acer pennsylvanicum L.). All striped maple greenhouse seedlings and saplings in the field died when directly inoculated. However, striped maple in naturally infected stands experienced $<1 \%$ mortality, reducing the threat of a native tree species succumbing to Verticillium wilt in managed tree-of-heaven stands in the future (Schall and Davis 2009).

In a later study Kasson expanded Schall's previous host range work and subjected 71 additional species of ornamental trees and closely related species to tree-of-heaven in the family Simaroubaceae to inoculation with $V$. nonalfalfae strain VnAa140. Only three native tree hosts showed signs of wilt due to natural infection in inoculated Ailanthus stands: devil's walking stick (Aralia spinose L.), striped maple and staghorn sumac (Rhus thyphina L.) at 17\%, 13\% and 16\% incidence respectively (Kasson et al. 2015). However, the causal agent was unable to be reisolated from the staghorn sumac and therefore Koch's postulates was never confirmed. These 
trees also recovered the next season, while Ailanthus suffered from $100 \%$ mortality and no recovery. These low infection rates on low-value species supported the usage of $V$. nonalfalfae in further studies as a biocontrol for Ailanthus in the forest.

In order to study the spread of the pathogen in a forested setting, 100 Ailanthus trees were inoculated with $V$. nonalfalfae in the forest during 2006 which caused disease in 40,000 confirmed Ailanthus stems one-year post inoculation (Kasson et al. 2015). Throughout the years of Kasson's PhD dissertation work, inoculative augmentation of Ailanthus with the endemic $V$. nonalfalfae decreased Ailanthus stem densities from 1,500 canopy stems/ha to almost zero from 2008 to 2011 (Kasson 2013).

O’Neal et al. 2015 elucidated the impressive spread of the wilt pathogen by studying intraspecific root grafts and clonal growth within Ailanthus stands in 2011. He found that on average one tree-of-heaven has 2.3 trees connected to it through functional root grafts ranging from 0 - 8 trees connected to one stem (O'Neal and Davis 2015). Verticillium nonalfalfae is able to spread through these root grafts and infect multiple trees through one inoculation point.

Extensive research was completed on pathogenicity of $V$. nonalfalfae strains from varying hosts against tree-of-heaven seedlings. Only tree-of-heaven derived isolates caused disease in tree-of-heaven. Results of these studies concluded there are different strains within the species $V$. nonalfalfae that are nonpathogenic to hosts other than the host species from which the isolate was recovered from (Kasson et al. 2014). Whole genome sequencing of an V. nonalfalfae isolate derived from Ailanthus molecularly confirmed results from the pathogenicity testing which highlights the genetic differences that allow for the dissimilarities in host pathogenicity (Kasson et al. 2019). 
Another fungus in the genus Verticillium causes an observably lesser aggressive disease on Ailanthus (personal observation). Verticillium dahliae will also cause a vascular wilt disease on Ailanthus, however the tree seems to be able to live with these natural infections for many years. The pathogenicity of the two species is markedly different. $V$. nonalfalfae is aggressive and able to kill a tree-of-heaven in as little as three months to one year (depending on time of year of inoculation) while it may take anywhere between 1-15 years for $V$. dahliae to kill the tree (Schall and Davis 2009, O’neal and Davis 2015). This mortality is likely caused by secondary infections by Armillaria mellae (Vahl) P. Kumm., the honey mushroom producing root rot fungus. In fact, a tree infected with $V$. dahliae may even be able to overcome the infection. In plant pathology is it common for two organisms to have synergistic effects on disease progression such as nematodes increasing the severity of disease and in some cases one species is able to predispose the host and enables the secondary host to aid in the destruction of the plant, much like the previously mentioned example of the Armillaria fungus (Powell 1971). However, there are also cases where one organism fills the niche that the biocontrol agent is meant to fill and prevents the desired infection from happening, much like the previously mentioned Dutch Trig ${ }^{\circledR}$ (Garbaye 1991). The interaction between the two Verticillium species has not been studied. It is possible that the weaker $V$. dahliae could inhibit the infiltration of $V$. nonalfalfae and reduce the efficacy of utilizing this highly successful fungus as a biocontrol for tree-ofheaven.

This study addresses questions remaining unanswered in the potential biocontrol of Ailanthus with the vascular wilt pathogen $V$. nonalfalfae. 


\section{Examples of Successful Biocontrol efforts}

Chemical pesticides are often used for unusually challenging non-native and native forest insect and plant pests. It's been estimated that approximately 50,000 exotic species exist and are established in the United States, with around 4,300 being considered invasive (Pimentel et al. 2004, Corn et. Al. 1999). In a study considering only seventy-nine of those invasive species researchers found they caused $\$ 97$ billion in damages during the last century (OTA 1993). In the state of Florida, management of one species of exotic invasive aquatic plant, Hydrilla veticilliata (L.f.) Royle, costs $\$ 14.5$ million annually to manage though the use of chemical pesticides like Pond Logic ${ }^{\circledR}$ and WipeOut ${ }^{\circledR}$ along with mechanical removal with rakes (Pimentel et al. 2005, Haller et al. 1980). Additionally, the state is losing $\$ 10$ million annually due to loss of habitat for fishing and hunting of only two very popular recreational lakes that are entirely colonized by Hyrdilla (Pimentel et al. 2005). Managing for invasive species, especially with the use of chemical pesticides, is an expensive and often reoccurring task with many layers of cascading economic and environmental impacts.

Due to the deleterious effects of utilizing chemical-based pesticides over long periods of time, such as negatively impacting non-target species, disrupting food chain hierarchies, and being harmful to human health, there is a need to lesser our reliance on chemically-based pesticides (Metts et al. 2005, Margni et al. 2002, Eichelberger and Lichtenberg 1971, PeirisJohn and Wickremasinghe 2008). Although there are these negative impacts of chemical pesticides, we cannot simply ignore invasive species in order to stop the use of harmful chemicals, since there is an even larger environmental cost to allowing invasive species to become established on a landscape. Invasive species impact biodiversity, forest composition, 
establishment of native flora, and therefore remove key components of an ecosystem's primary food web for wildlife.

We can lessen the use of herbicides through the relatively new concept of integrated pest management. Integrated pest management is potentially one of the biggest advances in entomology and plant pathology in the last century of agriculture (Kogan 1998). It focuses on lessening the demand and reliance on chemical pesticides by incorporating other aspects to pest management such as; setting thresholds for action, crop rotations, cultural changes such as quarantines, genetic engineering, regional planting of resistant varieties and lastly, the use of biocontrol agents. Biocontrol agents are defined as living antagonistic organisms, or their products, that are used to reduce or eliminate a pest species (Tranier et al. 2014). Introducing an effective biocontrol agent can reduce usages of and dependence on pesticides. A positive aspect of biocontrol organisms is that a living organism can become established on the landscape and successfully reproduce, therefore not being required to be reintroduced/applied every year. In some cases, a one-time application of the biocontrol is all that is needed to control a population. However, biocontrol methods can have a higher initial cost since many years of research and care are required to maintain a population of living organisms that will eventually be released into the environment to control the pest species. Biocontrol methods require experts to maintain them, unlike pesticides which are easily applied and require minimal training and certifications. However, these biocontrol agents require years of vetted scientific research to confirm they are suited for the invasive organism's suppression while not impacting any other native species or being able to survive their introduced climates. Many biocontrol methods focus on introducing an herbivorous or predatory insect from the exotic plant or insect's native home range that is a restricted specialist on the host. 
This classic biocontrol method shows much success since the specialist is adapted to only persist on one species in its native range. The tamarisk leaf beetle (Diorhabda elongate Brullé) feeds exclusively on the exotic and invasive salt cedar (Tamarix pentandra Lour.), although it did not become established in the wild due to cold winters (Kauffman 2005, Knutson et al. 2012). Conversely, there are classical biocontrol species that have a generalist approach and can utilize more than one species for their host. The generalist broad-nosed weevil, (Plectrophoroides lutra Schoenherr) was deemed not suitable for biological control due to its broad host range defoliating many species of native plants instead of only defoliating the invasive Brazilian pepper tree (Schinus terebinthifolius Raddi) (Wheeler 2011). Regardless of these environmental and scientific holds up, classic biocontrol methods utilizing insects can be a very effective biocontrol method.

The use of fungi as a biocontrol is a relatively new concept. The use of "mycoherbicides" started in the 1970s and has led to a few major discoveries to control invasive insects, noxious aquatic weeds, herbaceous plants and woody shrubs and trees (Barreto et al. 2000, Mathur and Gehlot 2018). The fungus Entomophaga maimaiga was augmentively released into Northeastern forests in the late 1980 's to reduce populations of the devastating destructive and invasive gypsy moth (Lymantria dispar) (Hajek et al. 1996). Today, the fungal pathogen, plays a main role in maintaining gypsy moth population below the action threshold due to its ability to overwinter and continually infect gypsy moth larva each spring (Fettig et al. 2005, Hajek and Roberts 1991). There are some odd years when populations of gypsy moth rise over the action threshold and land managing agencies can deploy other options, such as: mating disruption tactics, introductions of the 
nucleopolyhedrosis virus (NPV) virus and releasing Bacillus thuringiensis (Bt) Berliner as suppression measures (Podgwaite et al. 1979, McManus et al. 1980).

The invasive water chestnut or water caltrop (Trapa natans L.) is inhibited by members of three genera of Ascomycotan fungi. Cercospora piaropi Fresen. and Cercospora rodmanii Fresen. both afflict water hyacinth (Eichhornia crassipes (Mart.) Solms) with dark brown lesions causing a leaf spot disease. This fungus was introduced on the Chinese plant in 1917 in Texas. The pathogen was used as a biocontrol of water hyacinth in the late 80's in Africa and is now an established disease of the water hyacinth (Van Driesche et al. 2002). Multiple applications of this fungus could kill the plant however it mostly controls established populations from expanding instead of completely eradicating the pest. Additionally, Sclerotium rolfsii Sacc. and Botrytis cinereal Pers. feed on the entirety of the caltrop plant (Van Driesche et al. 2002). However, all three of these fungi have broad host ranges, ruling them out to be effective and selective fungal pathogens.

Uromyces heliotropii Sred. is a species specific fungal biocontrol used against the invasive Eurasian common heliotrope (Heliotropium europaeum L.) in Australia (Hasan et al. 1992). The common heliotrope is extremely competitive and takes over grazing fields and abandoned disturbed areas. This is a problem as the foliage is toxic to sheep and managing for its removal is necessary from grazing lands. Australian researchers released the autoecious macrocyclic rust in green house experiments and in fields overrun with common heliotrope. In both experiments $100 \%$ mortality was recorded after seven weeks (Hasan and Aracil 1991). Due to the large seed bank of the common heliotrope, populations still remain in Australia but the population is maintained making Uromyces heliotropii an established biocontrol agent. 
Perhaps the most successful example of fungal biocontrol against invasive plants is the control of the golden wreath wattle tree (Acacia saligna (Labill.) H. L. Wendl.) with the Basidiomycota rust fungus Uromycladium tepperianum (Sacc.) McAlpine. Acacia saligna is a woody shrub that originates from Australia and was introduced to the South African coast in the 1800's to be used as a reforestation species after excessive harvest of native tree species for firewood. The same traits that made A. saligna desirable for the rapid establishment of the African bush country also allowed for exceptional colonization in many other types of disturbed sites which allowed it to become an invasive pest rather quickly. This rust fungus forms large galls on the plant causing the branches to swell and break while also restricting flow of water and mineral resources to the canopy which will eventually cause the canopy to thin and decline. Without a canopy, the plant is no longer able to photosynthesize and the plant dies in as little as three years (Martin 1999). Seed production of the invasive plant is also reduced allowing for less establishment in disturbed landscapes (Wood and Morris 2007). Uromycladium tepperianum originates from Australia as well and was introduced to control the pest tree in Africa. Since the rust's introduction in 1987, the spread of Acacia saligna has halted and indigenous vegetation is returning to the landscape once consumed by the noxious weed (Morris 1997). Acacia saligna density has declined between $87 \%$ - $98 \%$ between 1991-2005 from of approximately 50,000 acacia stems/ha to 2,400 stems/ha after an inoculation of just 50 trees per site at five sites (Wood and Morris 2007). Uromycladium tepperianum releases spores that easily enable it to spread across the landscape via wind dispersal and through human distribution. With such success in natural spread there is no need to formulate a commercialized form of the biocontrol although that is a tactic seen in other systems. 
Some biocontrols have been commercialized, such as the Dutch elm disease resistance product - DutchTrig®. DutchTrig® is a formulated fungal biocontrol for the exotic and aggressive plant pathogen Ophiostoma ulmi (Buisman) Melin \& Nannf. and O. novoulmi (Buisman) Melin \& Nannf. Ophiostoma ulmi and O. novo-ulmi cause the devastating vascular wilt disease: Dutch elm disease (DED). DED kills American elm (Ulmus americana L.) as the tree vessels are clogged by the pathogen and tree defense of rapid occlusion increases mortality. DutchTrig® can prevent the colonization of Ophiostoma fungal species by activating the elm trees natural defense mechanisms. By introducing a non-pathogenic specific strain of a Verticillium albo-atrum named WCS850 and isolated from potato plants in the Netherlands, the elm tree reacts to the presence of the Verticillium fungi as a foreign body within the elm tree's vascular tissues and prevents the infection of the Ophiostoma fungi (Scheffer et al. 2008). In 1998, researchers treated 8,500 American elm trees with Verticillium albo-atrum strain WCS850 and reported that the rate of new DED infections declined in 4 years from $0.53 \%$ to $0.22,0.10$, and $0.05 \%$ (Scheffer et al. 2008).

Such success in both reducing invasive species population and preventing their establishment gives hope to finding more successful biocontrol methods. The hunt continues for integrated pest management tactics for many invasive species, especially woody species which are historically more challenging to manage for on a landscape, such as: Robinia psuedoacacia L., Elaeagnus umbellata Thunb, Paulownia tomentosa (Thunb.) Steud. and Ailanthus. 


\section{References}

Barreto, R., Charudattan, R., Pomella, A., \& Hanada, R. (2000). Biological control of neotropical aquatic weeds with fungi. Crop Protection, 19(8-10), 697-703.

Barringer, L. E., Donovall, L. R., Spichiger, S. E., Lynch, D., \& Henry, D. (2015). The first new world record of Lycorma delicatula (Insecta: Hemiptera: Fulgoridae). Entomological news, 125(1), 20-24.

Bhat, R. G., \& Subbarao, K. V. (1999). Host range specificity in Verticillium dahliae. Phytopathology, 89(12), 1218-1225.

Blin, K., Wolf, T., Chevrette, M. G., Lu, X., Schwalen, C. J., Kautsar, S. A., Suarez Duran, H. G., de Los Santos, E. L. C., Kim, H. U., Nave, M., Dickschat, J. S., Mitchell, D.A., Shelest, E., Breitling, R., Takano, E., Lee, S. Y., Weber, T., \& Medema, M.H. (2017). antiSMASH 4.0improvements in chemistry prediction and gene cluster boundary identification. Nucleic Acids Research, 45(W1), W36-W41.

Brown, C. A. (2014). Biomass production, composition, and ethanol potential of switchgrass grown on reclaimed surface mines in West Virginia. (Master's thesis, West Virginia University). Retrieved from ProQuest. (1573301).

Cognato, A. I., Hoebeke, E. R., Kajimura, H., \& Smith, S. M. (2015). History of the exotic ambrosia beetles Euwallacea interjectus and Euwallacea validus (Coleoptera: Curculionidae: Xyleborini) in the United States. Journal of Economic Entomology, 108(3), 1129-1135.

Corn, L. C., Buck, E. H., Rawson, J., \& Fischer, E. 1999. Harmful Non-Native Species: Issues for Congress. Congressional Research Service Issue Brief, RL30123.

Coventry, E., Noble, R., Mead, A., Marin, F. R., Perez, J. A., \& Whipps, J. M. (2006). Allium white rot suppression with composts and Trichoderma viride in relation to sclerotia viability. Phytopathology, 96(9), 1009-1020.

Crane, J., Evans, E., \& Balerdi, C. (2007). A review of the Florida avocado industry. Proceedings VI World Avocado Congress. ISBN No 978-956-17-0413-8.

Dara, S. K., Barringer, L., \& Arthurs, S. P. (2015). Lycorma delicatula (Hemiptera: Fulgoridae): a new invasive pest in the United States. Journal of Integrated Pest Management, 6(1), 20.

Ding, J., Reardon, R., Wu, Y., Zheng, H., \& Fu, W. (2006). Biological control of invasive plants through collaboration between China and the United States of America: a perspective. Biological Invasions, 8(7), 1439.

Ding, J., Wu, Y., Zheng, H., Fu, W., Reardon, R., \& Liu, M. (2006). Assessing potential biological control of the invasive plant, tree-of-heaven, Ailanthus altissima. Biocontrol Science and Technology, 16(6), 547-566.

Eichelberger, J. W., \& Lichtenberg, J. J. (1971). Persistence of pesticides in river water. Environmental Science \& Technology, 5(6), 541-544. 
Fettig, C. J., Fidgen, J. G., \& Salom, S. M. (2005). A review of sampling procedures available for IPM decision-making of forest and shade tree insects in North America. J. Arboriculture, 31, $38-47$.

Gams, W., \& Zare, R. (2001). A revision of Verticillium sect. Prostrata. III. Generic Classification. Nova Hedwigia, 329-337.

Garbaye, J. (1991). Biological interactions in the mycorrhizosphere. Experientia, 47(4), 370-375.

Gavin, A. C., Bösche, M., Krause, R., Grandi, P., Marzioch, M., Bauer, A., Schultz, J., Rick, J. M., Michon, A. M., Cruciat, C.M., Remor, M., Höfert, C., Schelder, M., Brajenovic, M., Ruffner, H., Merino, A., Klein, K., Hudak, M., Dickson, D., Rudi, T., Gnau, V., Bauch, A., Bastuck, S., Huhse, B., Leutwein, C., Heurtier, M. A., Copley, R. R., Edelmann, A., Querfurth, E., Rybin, V., Drewes, G., Raida, M., Bouwmeester, T., Bork, P., Seraphin, B., Kuster, B., Neubauer, G., \& Superti-Furga, G. (2002). Functional organization of the yeast proteome by systematic analysis of protein complexes. Nature, 415(6868), 141.

Hajek, A. E., \& Roberts, D. W. (1991). Pathogen reservoirs as a biological control resource: introduction of Entomophaga maimaiga to North American gypsy moth, Lymantria dispar, populations. Biological Control, 1(1), 29-34.

Hajek, A. E., Elkinton, J. S., \& Witcosky, J. J. (1996). Introduction and spread of the fungal pathogen Entomophaga maimaiga (Zygomycetes: Entomophthorales) along the leading edge of gypsy moth (Lepidoptera: Lymantriidae) spread. Environmental Entomology, 25(5), 1235-1247.

Haller, W. T., Shireman, J. V., \& Durant, D. F. (1980). Fish harvest resulting from mechanical control of hydrilla. Transactions of the American Fisheries Society, 109(5), 517-520.

Han, Y., Liu, X., Benny, U., Kistler, H. C., \& VanEtten, H. D. (2001). Genes determining pathogenicity to pea are clustered on a supernumerary chromosome in the fungal plant pathogen Nectria haematococca. The Plant Journal, 25(3), 305-314.

Hasan, S., \& Aracil, E. (1991). Biology and effectiveness of Uromyces heliotropii Sred., a potential biological control agent of Heliotropium europaeum L. New Phytologist, 118(4), 559563.

Hasan, S., Delfosse, E. S., Aracil, E., \& Lewis, R. C. (1992). Host-specificity of Uromyces heliotropii, a fungal agent for the biological control of common heliotrope (Heliotropium europaeum) in Australia. Annals of Applied Biology, 121(3), 697-705.

Hoebeke, E. R., Jendek, E., Zablotny, J. E., Rieder, R., Yoo, R., Grebennikov, V. V., \& Ren, L. (2017). First North American Records of the Eastasian Metallic Wood-Boring Beetle Agrilus smaragdifrons Ganglbauer (Coleoptera: Buprestidae: Agrilinae), a Specialist on tree-of-heaven (Ailanthus altissima, Simaroubaceae). Proceedings of the Entomological Society of Washington, 119(3), 408-423.

Inderbitzin, P., \& Subbarao, K. V. (2014). Verticillium systematics and evolution: how confusion impedes Verticillium wilt management and how to resolve it. Phytopathology, 104(6), 564-574. 
Inderbitzin, P., Bostock, R. M., Davis, R. M., Usami, T., Platt, H. W., \& Subbarao, K. V. (2011). Phylogenetics and taxonomy of the fungal vascular wilt pathogen Verticillium, with the descriptions of five new species. PloS One, 6(12), e28341.

Inderbitzin, P., Davis, R. M., Bostock, R. M., \& Subbarao, K. V. (2013). Identification and differentiation of Verticillium species and $V$. longisporum lineages by simplex and multiplex PCR assays. PLoS One, 8(6), e65990.

Jakše, J., Jelen, V., Radišek, S., de Jonge, R., Mandelc, S., Majer, A., Curk, T., Zupan, B., Thomma, B. P. H. J., \& Javornik, B. (2018). Genome Sequence of a Lethal Strain of XylemInvading Verticillium nonalfalfae. Genome Announcements, 6(2), e01458-17.

Kasson, M. T. (2012). Verticillium nonalfalfae: A potential biological control of the invasive Ailanthus in Pennsylvania.

Kasson, M. T., Kasson, L. R., Wickert, K. L., Davis, D. D., \& Stajich, J. E. (2019). Genome Sequence of a Lethal Vascular Wilt Fungus, Verticillium nonalfalfae, a Biological Control Used Against the Invasive Ailanthus altissima. Microbiol Resource Announcement, 8(4), e01619-18.

Kasson, M. T., O’Donnell, K., Rooney, A. P., Sink, S., Ploetz, R. C., Ploetz, J. N., Konkol, J. L., Carrillo, D., Freeman, S., Mendel, Z., Smith, J. A., Black, A.W., Hulcr, J., Bateman, C., Stefkova, K., Campbell, P. R., Geering, A. D., Dann, E. K., Eskalen, A., Mohotti, K., Short, D. P., Aoki, T., Fenstermacher, K. A., Davis, D. D., \& Geiser, D. M. (2013). An inordinate fondness for Fusarium: phylogenetic diversity of fusaria cultivated by ambrosia beetles in the genus Euwallacea on avocado and other plant hosts. Fungal Genetics and Biology, 56, 147-157.

Kasson, M. T., O’Neal, E. S., \& Davis, D. D. (2015). Expanded host range testing for Verticillium nonalfalfae: potential biocontrol agent against the invasive Ailanthus altissima. Plant Disease, 99(6), 823-835.

Kasson, M. T., Short, D. P. G., O'Neal, E. S., Subbarao, K. V., \& Davis, D. D. (2014). Comparative pathogenicity, biocontrol efficacy, and multilocus sequence typing of Verticillium nonalfalfae from the invasive Ailanthus altissima and other hosts. Phytopathology, 104(3), 282292.

Kauffman, William. (2005). Program for Biological Control of Saltcedar (Tamarix spp.) in Thirteen States. United States Department of Agriculture.

Khan, M. Z., \& Law, F. C. (2005). Adverse effects of pesticides and related chemicals on enzyme and hormone systems of fish, amphibians and reptiles: a review. Proceedings of the Pakistan Academy of Sciences, 42(4), 315-323.

Kim, J. G., Lee, E. H., Seo, Y. M., \& Kim, N. Y. (2011). Cyclic behavior of Lycorma delicatula (Insecta: Hemiptera: Fulgoridae) on host plants. Journal of Insect Behavior, 24(6), 423.

Knutson, A. E., DeLoach, C. J., Tracy, J. L., \& Randal, C. W. (2012). Field Evaluation of Diorhabda elongate and D. carinata (Coleoptera: Chrysomelidae) for Biological Control of Saltcedars (Tamarix spp.) in Northwest Texas. Southwestern Entomologist, 37(2), 91-103. 
Kogan, M. (1998). Integrated pest management: historical perspectives and contemporary developments. Annual Review of Entomology, 43(1), 243-270.

Malcolm, G. M., Kuldau, G. A., Gugino, B. K., \& Jiménez-Gasco, M. D. M. (2013). Hidden host plant associations of soilborne fungal pathogens: an ecological perspective. Phytopathology, 103(6), 538-544.Margni, M., Rossier, D., Crettaz, P., \& Jolliet, O. (2002). Life cycle impact assessment of pesticides on human health and ecosystems. Agriculture, Ecosystems \& Environment, 93(1-3), 379-392.

Markell, S. G., Harveson, R. M., Block, C. C., \& Gulya, T. J. (2015). Sunflower diseases. In Sunflower (pp. 93-128). AOCS Press.

Maschek, O., \& Halmschlager, E. (2016). First report of Verticillium wilt on Ailanthus in Europe caused by Verticillium nonalfalfae. Plant Disease, 100(2), 529-529.

Mathur, M., \& Gehlot, P. (2018). Recruit the Plant Pathogen for Weed Management: Bioherbicide-A Sustainable Strategy. In Fungi and their Role in Sustainable Development: Current Perspectives (pp. 159-181). Springer, Singapore.

McManus, M. L., Schneeberger, N., Reardon, R., \& Mason, G. (1980). The gypsy moth. US Department of Agriculture, Forest Service.

McNabb, H. S. Jr., Heybroek, H. M., \& MacDonald, W. L. (1970). Anatomical factors in resistance to Dutch elm disease. Netherlands Journal of Plant Pathology, (76)3, 196-205.

Metts, B. S., Hopkins, W. A., \& Nestor, J. P. (2005). Interaction of an insecticide with larval density in pond-breeding salamanders (Ambystoma). Freshwater Biology, 50(4), 685-696.

Morris, M. J. (1997). Impact of the Gall-Forming Rust Fungus Uromycladium tepperianumon the Invasive Tree Acacia salignain South Africa. Biological Control, 10(2), 75-82.

Morris, M. J. (1999). The contribution of the gall-forming rust fungus Uromycladium tepperianum (Sacc.) McAlp. to the biological control of Acacia saligna (Labill.) Wendl. (Fabaceae) in South Africa. 125-128.

O’Neal, E. S., \& Davis, D. D. (2015). Intraspecific root grafts and clonal growth within Ailanthus altissima stands influence Verticillium nonalfalfae transmission. Plant Disease, (99)8, 1070-1077.

O'Neal, E. S., \& Davis, D. D. (2015). Biocontrol of Ailanthus altissima: inoculation protocol and risk assessment for Verticillium nonalfalfae (Plectosphaerellaceae: Phyllachorales). Biocontrol Science and Technology, (25)8, 950-969.

Peiris-John, R. J., \& Wickremasinghe, R. (2008). Impact of low-level exposure to organophosphates on human reproduction and survival. Transactions of the Royal Society of Tropical Medicine and Hygiene, 102(3), 239-245. 
Pimentel, D., R. Zuniga, and D. Morrison. 2005. Update on the environmental and economic costs associated with alien-invasive species in the United States. Ecological Economics Volume 52, Issue 3, 15 February 2005, Pages 273-288

Pimentel, D., Zuniga, R., \& Morrison, D. (2005). Update on the environmental and economic costs associated with alien-invasive species in the United States. Ecological Economics, 52(3), 273-288.

Podgwaite, J. D., Shields, K. S., Zerillo, R. T., \& Bruen, R. B. (1979). Environmental persistence of the nucleopolyhedrosis virus of the gypsy moth, Lymantria dispar. Environmental Entomology, 8(3), 528-536.

Powell, N. T. (1971). Interaction of plant parasitic nematodes with other disease-causing agents. In B. M. Zuckerman, W. F. Mai, \& R. A. Rohde, (Eds.), Plant Parasitic Nematodes (119-136).

Rebbeck, J., Malone, M. A., Short, D. P. G., Kasson, M. T., O'Neal, E. S., \& Davis, D. D. (2013). First report of Verticillium wilt caused by Verticillium nonalfalfae on tree-of-heaven (Ailanthus altissima) in Ohio. Plant Disease, 97(7): 999-999.

Schall, M. J. (2008). Verticillium wilt of Ailanthus altissima (Doctoral dissertation). Retrieved from ProQuest. (3346370).

Schall, M. J., \& Davis, D. D. (2009). Ailanthus altissima wilt and mortality: etiology. Plant Disease, 93(7), 747-751.

Scheffer, R. J., Voeten, J. G. W. F., \& Guries, R. P. (2008). Biological control of Dutch elm disease. Plant Disease, 92(2), 192-200.

Snyder, A. L., Kasson, M. T., Salom, S. M., Davis, D. D., Griffin, G. J., \& Kok, L. T. (2013). First report of Verticillium wilt of Ailanthus altissima in Virginia caused by Verticillium nonalfalfae. Plant Disease, 97(6), 837-837.

Tranier, M. S., Pognant-Gros, J., Quiroz, R. D. L. C., González, C. N. A., Mateille, T., \& Roussos, S. (2014). Commercial biological control agents targeted against plant-parasitic rootknot nematodes. Brazilian Archives of Biology and Technology, 57(6), 831-841.

United States. Congress. Office of Technology Assessment. (1993). Harmful Non-indigenous Species in the United States. Congress.

Van Driesche, R., Blossey, B., Hoddle, M., Lyon, S., \& Reardon, R. (2002). Biological control of invasive plants in the Eastern United States. USDA Forest Service Publication FHTET-200204).

Webster, C. R., Jenkins, M. A., \& Jose, S. (2006). Woody invaders and the challenges they pose to forest ecosystems in the eastern United States. Journal of Forestry, 104(7), 366-374.

Wheeler, G. S., Geiger, J., Mc Kay, F., Rendon, J., Chawner, M., \& Pratt, P. D. (2011).

Defoliating broad-nosed weevil, Plectrophoroides lutra; not suitable for biological control of Brazilian pepper (Schinus terebinthifolius). Biocontrol Science and Technology, 21(1), 89-91. 
Wickert, K. L., O’Neal, E. S., Davis, D. D., \& Kasson, M. T. (2017). Seed production, viability, and reproductive limits of the invasive Ailanthus altissima (tree-of-heaven) within invaded environments. Forests, 8(7), 226.

Wilhelm, S. (1955). Longevity of the Verticillium wilt fungus in the laboratory and field. Phytopathology, 45, 180-181.

Wood, A. R., \& Morris, M. J. (2007). Impact of the gall-forming rust fungus Uromycladium tepperianum on the invasive tree Acacia saligna in South Africa: 15 years of monitoring. Biological Control, 41(1), 68-77. 


\title{
Chapter 2
}

\section{Seed Production, Viability, and Reproductive Limits of the Invasive Ailanthus altissima (tree-of-heaven) within Invaded Environments}

\section{Kristen L. Wickert}

\begin{abstract}
The success of some invasive tree species is attributed, in part, to high fecundity in the form of sexual propagules. If invasive trees produce more seed annually than co-occurring native trees, they will have a greater ability to disperse and establish across the landscape. In this study, seed production of female Ailanthus trees was investigated to determine (1) reproductive age limits; (2) annual and cumulative seed output; and (3) seed viability. Existing data on Ailanthus seed production were combined with a novel dataset to compare variability in seed production and explore relationships with tree diameter and age. Results from this study showed the reproductive window of Ailanthus is exceptional, spanning more than a century, with seed viability exceeding $65 \%$ from a 104 -year-old individual. Germination studies and complementary tetrazolium assays also confirmed high propagule viability from a 7-year-old Ailanthus and supports tetrazolium assays as a proxy for germination studies. Not only can individual Ailanthus produce $>1$ million seeds annually, but a significant relationship exists between seed production and tree diameter. Using this relationship, cumulative seed production in individual Ailanthus can reach ca. 10 and 52 million seeds over a 40-year and 100-year period, respectively. This study provides a comprehensive investigation of various facets of the reproductive potential of Ailanthus.
\end{abstract}




\section{Introduction}

The invasive Ailanthus altissima (Mill.) Swingle (tree-of-heaven), a member of the mostly tropical Quassia family (Simaroubaceae), hereafter referred to as Ailanthus, was first introduced into the United States from England into Philadelphia, Pennsylvania in 1784. Early propagation by botanists and nurserymen was exclusively vegetative, which limited both the spread and widespread adoption of Ailanthus until ca. 1820, when seed-bearing (gynoecious) Ailanthus became established in the eastern United States (Kasson et al. 2013). By the late 1800s, Ailanthus' ability to spread naturally from seed was widely acknowledged (Gray 1868). At that time, seed-producing females were strongly promoted in ornamental plantings (Barry and Smith 1885) and their seed spread naturally along well-traveled railway corridors (Kasson et al. 2013). Since that time, sexual reproduction and subsequent movement of seed across the United States along transportation corridors has played an important role in shaping Ailanthus' current population structure (Aldrich et al. 2010). Ailanthus now occurs in more than 40 states, mostly as an urban and roadside weed, and is especially in the Mid-Atlantic where it has resided for ca. 200 years (Kasson et al. 2013, Aldrich et al. 2010, McAvoy et al. 2012). Despite its long residency, widespread invasion of Ailanthus into eastern forests is relatively recent, with most invasions in Pennsylvania following salvage logging from widespread gypsy moth defoliations in the late twentieth century (Kasson et al. 2013). In Ohio, prescribed burning to enhance oak regeneration has also facilitated spread of Ailanthus in several areas of the state (Rebbeck et al. 2015). The impact of such large-scale invasions in forests and their adverse effects on native species richness and incidence have only been recently elucidated (Gaertner et al. 2009, Harris et al. 2013, Kota et al. 2007, Motard et al. 2011). Invasions of Ailanthus along transportation corridors have long been recognized, but only recently have studies assessed the mechanisms of 
spread in these environments (Planchuelo et al. 2016, Planchuelo et al. 2017, Von de Lippe et al. 2013). Researchers are now beginning to appreciate the role that roads play in facilitating forest invasions (Von de Lippe et al. 2013, Mortensen, et al. 2009). Previous studies on Ailanthus seed production have reported reproductive outputs from several hundred thousand (Bory et al. 1980, Cabra-Rivas and Castro- Díez 2016) to several million seeds in a single year, with large interannual variation and tree size-dependent effects (Illick and Brouse 1926, Martin and Canham 2010). Martin and Canham (2010) reported Ailanthus out-produced other exotic invasive counterparts (e.g., Acer platanoides L.) and co-occurring native tree species by several orders of magnitude, but without the periodic seed crop failures common among many native species. Similarly, Cabra-Rivas and Castro-Diez (2016) reported that Ailanthus showed greater seed viability than the invasive Robinia pseudoacacia L. and native Fraxinus angustifolia Vahl in Spain. Moreover, Ailanthus is unexpectedly fecund even in environments presumably less favorable for invasion such as closed canopy forests (Kota et al. 2007, Martin and Canham 2010) or as germinants following submergence in water (Kaproth and McGraw 2008, Kowarik 2008). Recent studies have shown certain morphological characteristics (e.g., samara width) affect water dispersal positively, but affect wind dispersal negatively (Planchuelo et al. 2016) The recent discovery that Ailanthus can produce seed beyond 100 years of age (Kasson et al. 2013), coupled with the fact that almost no data exists regarding the species' mean reproductive capacity and age-related seed production limitations, has raised questions about Ailanthus' actual reproductive outputs. In this study, the minimum and maximum age at which female Ailanthus trees produce seed and to what extent tree and seed age influences seed viability was evaluated. Secondly, the maximum and mean annual seed outputs for Ailanthus were quantified. Finally, the cumulative number of seeds produced during Ailanthus' reproductive lifetime was modeled, 
and relationships between tree DBH (diameter at breast height, $1.4 \mathrm{~m}$ above soil line) and seed production were explored.

\section{Materials and methods}

\section{Seed production}

To study age- and size-dependent effects on seed reproduction as well as intra-specific variation within reproduction, 55 seed-bearing Ailanthus trees were sampled at various locations along transportation corridors throughout south-central Pennsylvania in August 2011 and 2012 (Table S1). Of the 55 sampled trees, 54 were destructively sampled (felled) for seed quantification and age determination. The location of the largest tree precluded removal and was instead cored with an increment borer to determine age (Kasson et al. 2013). Ten average-sized seed clusters were removed from this tree and six other additional destructively sampled forest trees for quantification. Total clusters were counted for total seed estimations, since it was impractical to collect all the seeds from these seven large trees. Small diameter seed-producing Ailanthus trees were targeted when present since there was insufficient/conflicting data on the minimum reproductive age of Ailanthus (Feret 1973, Hegi 1906, Kowarik and Säumel 2007) In addition, small diameter seed-producing trees were generally abundant along transportation corridors throughout the sampling area, thus providing a robust sampling population. Presumably some of these small diameter trees were sprouts arising from pre-existing root systems but could not be differentiated from seed-origin plants since roots were not excavated. For each tree included in the study, one cross-section disk was removed at either DBH or ground level (for trees $<1.4 \mathrm{~m}$ in height $\mathrm{t}$ ) or was sampled at DBH with an increment borer (Haglof Inc., Madison, MS, USA) to determine age. For felled trees, all available seed from the current year was collected into pre-labeled plastic bags. If seed was inadvertently released during felling, 
estimates of unrecovered seed were made in 5\% intervals and recorded. For multi-stemmed trees (trees whose trunk forked below DBH), a cross-section was taken from each stem to compare ages and diameters of the conjoined stems. Diameters $(\mathrm{cm})$ for the multi-stemmed trees were individually converted into basal area $(\mathrm{BA}=\mathrm{DBH} 2 \times 0.00007854$ (constant)), summed, and converted to a single $\mathrm{DBH}$ value $(\mathrm{DBH}=$ Square root of $(\mathrm{BA} / 0.00007854))$. Basal area is defined as the cross-sectional area $\left(\mathrm{m}^{2}\right)$ of a tree stem at DBH. Basal area is defined as the crosssectional area $\left(\mathrm{m}^{2}\right)$ of a tree stem at DBH. In the lab, Ailanthus seed from each tree was air-dried for up to three weeks, after which seeds were placed into paper bags and maintained at room temperature. Mean seed weight (mg) including the samara was determined for 25 randomly selected seeds from each tree. Seed with damaged samaras were excluded from weight measurements. Total dried seed was weighed and number of seeds per tree estimated by dividing total seed weight by mean seed weight for each tree. For trees where only 10 seed clusters were sampled $(n=7)$, mean seed count was determined and multiplied by the number of seed clusters estimated per tree. In addition to trees sampled specifically for this study, data from 21 seedbearing trees from France (Bory and Clair-Maczulajtys 1980) and two historic seed-bearing trees from Pennsylvania (Illick and Brouse 1926), whose diameters and seed production were previously reported, were included in the master dataset to permit comparisons and analyses. Since ages of sampled Ailanthus were not reported for these two studies, only relationships between DBH and seed production were explored.

\section{Germination Studies to Assess Seed Viability Based on Tree and Seed Age}

For tree-age seed viability studies, 64 seeds with samaras per seed source were placed in a $15.2 \times 25.4 \mathrm{~cm}$ plastic bag containing ca. $900 \mathrm{~mL}$ of potting soil mix (Sun Gro Horticulture Canada Ltd., Vancouver, BC, Canada) and $50 \mathrm{~mL}$ tap water. Seed was collected in late summer 
2016 from two locations from Pennsylvania and five locations from West Virginia (Table 2-1, Table S1). Trees included in the study ranged from 7 to 104 years old (Table 2-1). Concurrently, 64 seeds with samaras per seed source for each of two seed-producing trees and 43 and 40 seeds per seed source for two additional seed-producing trees previously collected in Pennsylvania from 2008-2010 from female Ailanthus trees (Kasson et al. 2013, Kasson et al. 2015) were treated similarly (Table 2-1). For both germination studies, the seed/soil mix was maintained at $1.7^{\circ} \mathrm{C}$ for 28 days, as previously reported (Kasson et al. 2015), after which seeds were placed into seed flats containing additional potting mix, transferred to a greenhouse, and misted daily until initial germination was observed. Upon germination, individual seedling wells were labeled with date of germination. As new seedlings emerged, additional wells were labeled for up to 4weeks, after which no additional seeds germinated. Total germinants were counted and divided by the number of total seeds evaluated.

\section{Tetrazolium Assay to Evaluate Seed Viability}

As a complementary experiment to the germination study, a blue tetrazolium chloride (TZ) test (Cottrell 1947) was performed on three of the same 2016 seed collections used in the germination studies. Tree ages were 7, 20, and 104 years. Tetrazolium chloride is a redox indicator commonly used to confirm cellular respiration and has been used frequently as a proxy for germination studies (Cottrell 1947). One hundred seeds from each of three seed collections sampled in 2016 were randomly selected. The experiment was replicated twice. Seeds encased in their samaras were soaked for $14 \mathrm{~h}$ in distilled sterile water, after which seeds were cut in half, longitudinally bisecting the seed radical (embryo). If a seed was determined to be deteriorated or damaged during bisectioning, it was excluded from the TZ test but included in the overall count. For seeds that appeared to be sound, half of the seed was placed into a 96-well microtiter plate 
containing $1 \%$ tetrazolium chloride solution (Alfa Aesar Haverhill, MA, USA). Individual wells were capped and wrapped in foil due to the light sensitivity of the assay. Each plate was incubated in a water bath at $40{ }^{\circ} \mathrm{C}$ for $3 \mathrm{~h}$, after which seeds were removed and scored based on the intensity of staining to the seed radicals. Following the TZ test, seeds were classified as positive (staining of radical only or complete staining of radical and hypocotyl) or negative (no staining) (Figure 2-1).

\section{Statistical Analyses}

To examine age-DBH relationships and seed production-DBH relationships, two regression analyses were performed. For the age-diameter linear regression, datasets were analyzed individually and combined. External validation methods $\left(\mathrm{R}^{2}\right)$ were used to assess model validity. Assumptions of linearity and homoscedasticity (equal variances) were tested and data were square-root transformed to meet required assumptions. To analyze DBH-seed production relationships, data were Ln transformed, after which a goodness of fit test (Shapiro-Wilk W test) was used to test for normality. Statistical analyses were conducted using Minitab 17.1.0 (Minitab Inc., State College, PA, USA).

\section{Results}

\section{Seed Production}

Seed production ranged from 40-996,000 seeds per tree with a mean of ca. 70,000 seeds for all trees sampled from across the three studies (Figures 2-2 and 2-3A). Mean seed production per tree was ca. 32,000 seeds (range: 40-686,000) for the 55 Pennsylvania trees included in the current study, ca. 86,000 seeds (range: 240-325,000) for 21 trees reported by Bory and Clair- 
Maczulajtys (1980), and ca. 940,000 seeds (range: 880,000-996,000) for the two large Ailanthus trees reported by Illick and Brouse (1926) (Figure 2-3A, Table S1).

Mean seed production per seed cluster for Ailanthus ranged from 32-1452 seeds, with a mean of 543 seeds per cluster for all 29 trees included in this study and two previous studies. Mean seed production per cluster was 567 seeds (range: $91-1452, \mathrm{n}=70$ ) for the seven sampled Pennsylvania trees included in the current study, 388 seeds (range: 32-500) for 21 trees reported by Bory and Clair-Maczulajtys (1980), and 959 seeds (range: 703-1364, $\mathrm{n}=4$ clusters) for one tree reported by Illick and Brouse (1926).

The greatest seed-producing trees in the combined dataset were from Pennsylvania. These include two trees reported by Illick and Brouse (1926), which produced ca. 880,000 and 996,000 seeds per tree, respectively, and tree PA-62, located on the campus of the Pennsylvania State University, which produced ca. 685,000 seeds in 2012 (Figure 2-2 and Figure 2-3A, Table S1).

Mean diameter of Ailanthus trees sampled in Pennsylvania from 2011-2012 (11.3 cm) was similar to Ailanthus sampled from France in ca. $1980(13.1 \mathrm{~cm})$. However, significantly larger diameter trees were included in the Pennsylvania study $(\max \mathrm{DBH}=115 \mathrm{~cm})$ compared to trees sampled across France $(\max \mathrm{DBH}=30 \mathrm{~cm})($ Figure 2-3B, Table S1). Trees reported by Illick and Brouse (1926) had diameters of 20.3 and $30.5 \mathrm{~cm}$ (Figure 2-3B). The results of this current study support an upward trending relationship between seed production and tree DBH (Figure 2-2). Indeed, the top 10 highest seed-producing Ailanthus trees from the combined dataset averaged $30.0 \mathrm{~cm}$ DBH (range 13-115 cm) and produced ca. 4 million seeds compared to the 10 lowest seed-producing Ailanthus, which accounted for ca. 2300 seeds, with a mean DBH of $3.8 \mathrm{~cm}$ (range 2.4-7.6 cm) (Figure 2-2, Table S1). 
The mean age of the seed producing Ailanthus trees sampled across south-central Pennsylvania was 17 years, with a range from 4-104 years (Figure 2-3C, Table S1). The oldest tree reported here, PA-62, was exceptional in both seed production and age, with an estimated 685,000 seeds produced in 2012 at 99 years of age. Seed collected in both 2008 and 2016 from PA-62 were used in the germination assays.

Regression analysis revealed a significant positive linear relationship between Ailanthus age and DBH, with $\mathrm{DBH}$ being a strong single predictor of age for both individual and combined datasets (Figure 2-4). DBH accounted for $76 \%$ and $83 \%$ of the observed variability in ages for trees sampled for this study and a previous study by Kasson et al. 2013, respectively, and 87\% of variability in the combined analysis (Figure 2-4). Using these results, the ages of the Pennsylvania trees reported by Illick and Brouse (1926) were estimated to be 21 years old (20.3 $\mathrm{cm} \mathrm{DBH})$ and 29 years old $(30.5 \mathrm{~cm} \mathrm{DBH})$ (Table S1). Estimated ages for French trees reported by Bory and Clair-Maczulajtys (1980) averaged 15 years with a range of 4-29 years, the latter of which was the predicted age for the Ailanthus tree that produced their commonly cited 325,000 seeds (Table S1).

Regression analysis of the combined Ailanthus dataset revealed a significant relationship $(\mathrm{R} 2=0.66)$ between $\mathrm{Ln}$ number of seeds and $\mathrm{Ln} \mathrm{DBH}(\mathrm{cm})$, indicating that $\mathrm{DBH}$ alone accounted for ca. $66 \%$ of the variability in seed production (Figure 2-5). Although the model was developed to estimate Ailanthus seed production for trees with a specific DBH, the model can also provide estimates of cumulative seed production for the lifetime of an individual Ailanthus. For example, the lifetime seed production of a $50 \mathrm{~cm} \mathrm{DBH}$ Ailanthus is estimated to be ca. 10 million seeds. Because age-DBH relationships were also explored, it is assumed this estimate of 10 million seeds encompasses a reproductive window of ages $4-43$ years (Figure $2-4$ ). Since the 
average growth of these trees per year was not determined, cumulative seed production was estimated per year and summed. The lifetime seed production of a $115 \mathrm{~cm}$ Ailanthus, such as tree PA-62, is estimated to be around 52 million seeds.

\section{Germination Studies to Assess Seed Viability Based on Seed and Tree Age}

Germination rates for seed collected in 2016 ranged from 1.6-78.1\% (Table 2-1). No agerelated trends were apparent, as both the oldest and youngest seed-producing trees had similarly high germination rates of $65.6 \%$ and $78.1 \%$, respectively. For historic seed sources collected from 2008-2012, germination rates ranged from 0-26.5\% (Table 2-1). More recently collected seed appeared to have higher germination success compared to seed collected in 2009 and 2008, although only three seed sources were compared. Nevertheless, seed collected 7-9 years prior to this study and stored under ideal lab conditions (dry and cool) did germinate.

\section{Tetrazolium Assay to Evaluate Seed Viability}

Results of the TZ test for the seed collected in 2016 supported the results of the germination study, with $22 \%, 70 \%$, and $62 \%$ viability as compared to $16 \%, 78 \%$, and $66 \%$ germination for seed sources WV-02, PA-61, and PA-62, respectively (Table 2-1). Viability among replicates for individual seed sources were similar, with a range of $17-26 \%$ viability for WV-02, 67-72\% viability for PA-61, and 55-69\% viability for PA-62 (Table 2-1). These results indicate the $\mathrm{TZ}$ test provides a robust evaluation of seed viability and may serve as a suitable substitute for germination studies of Ailanthus. 


\section{Discussion}

Although annual seed production for Ailanthus trees sampled in this study and from the two historic reports varied considerably, seed production was generally positively related to tree diameter, which validates previous studies (Figure 2-2; (Bory and Clair-Maczulajtys 1980, Kowarik and Säumel 2007). Martin and Canham (2010) estimated mean seed production of a 30cm DBH Ailanthus tree in a forested stand at ca. 2 million seeds (range: 564,000-3,793,000). However, these estimates (that resulted from inverse modeling) did not address the issue of which individual tree was contributing seeds and, therefore, cannot be directly compared with mean seed production reported herein. Nevertheless, their data generally support the current study's results; large Ailanthus trees can produce $>1$ million seeds per year. This quantity far exceeds the 325,000 seeds per tree per year reported by Bory and Clair-Maczulajtys (1980).

In addition to their analysis of seed production in Ailanthus, Martin and Canham (2010) reported that the invasive Acer platanoides L. can produce ca. 27,000 seeds annually, but with a dramatic decline in seed production over time, suggesting that seed inundation likely contributes less to the invasiveness of this species compared to Ailanthus. Not surprisingly, few other invasive perennial woody species in the United States have annual seed production that surpasses Ailanthus. One exception, velvet tree (Miconia calvescens DC.) in Hawaii, can produce 5-8 million seeds per tree annually and is listed in the top 100 world's worst invasive alien species (http://www.issg.org/worst100_species.html) (Mason et al. 2008, Meyer 1998). The broadleaved paperbark tree (Melaleuca quinquenervia (Cav.) S.T. Blake), which has invaded the Florida Everglades, also can produce ca. 1 million seeds annually and store up to 20 million seeds produced over successive years in small woody seed pods until conditions favor germination (Swearingen 2018). Saltcedar (Tamarix spp. L.), which has devastated freshwater 
riparian ecosystems throughout the southwestern United States, can produce up to ca. 500,000 seeds per tree per year (Di Tomaso 1998). However, unlike paperbark tree seeds, saltcedar seeds are exceptionally short-lived (ca. $<5$ weeks) and must come in contact with suitable moisture shortly after dispersal to ensure germination (Di Tomaso 1998). This suggests, as with $A$. platanoides, saltcedar deploys other strategies to facilitate invasion (Di Tomaso 1998).

Seed data from Ailanthus sampled in Pennsylvania indicate these populations had $>30 \%$ more seeds per cluster compared to trees reported from southern France despite having less total seeds/tree, which may be in part explained by strong positive height-seed production relationships in southern France's Mediterranean climate (Kowarick and Säumel 2007). The greater seed production among larger trees may reflect greater crown volume to capture sunlight and a correspondingly larger root biomass to absorb soil moisture and nutrients (Snook et al. 2005). In addition, previous studies by Kowarik and Säumel (2007) showed strong positive height-seed production relationships, which were not explored in this study. Regardless of the factors driving seed production, the results emphasize the significant numbers of seeds and resulting seedlings that a few dozen large trees could produce in a landscape, especially following a major site disturbance downwind/downstream of large seed-producing Ailanthus trees.

Some of the young roadside seed-bearing Ailanthus trees sampled in this study were likely vegetative sprouts arising from pre-existing root systems, probably due to wounding during roadside mowing or trimming. However, the growth form and isolated nature of other young Ailanthus saplings suggests that such trees were likely of seed-origin, supporting the fact that Ailanthus saplings as young as four years of age can produce seed. 
In this study, it was determined DBH was a strong predictor of seed production from Ailanthus trees sampled throughout Pennsylvania. Tree DBH-seed/fruit production relationships for other tree species have been reported (Snook et al. 2005, Ares and Brauer 2004, Healy et al. 1999, Kainer et al. 2007). Studies on big-leaf mahogany (Swietenia macrophylla King) in the neotropical forests of southern Mexico (Snook et al. 2005) and Brazil nut (Bertholletia excels Humb. \& Bonpl.) in northwestern Brazil (Kainer et al. 2007) not only showed that nut production increased with stem diameter, but large trees were more consistent nut producers with limited seed crop failures. Furthermore, Kainer et al. (2007) reported that DBH alone explained $>50 \%$ of the variability in seed production among individuals. In North America, Ares and Brauer (2004) and Healy et al. (1999) reported nut yield for black walnut (Juglans nigra L.) in south-central United States $\left(\mathrm{R}^{2}=0.55\right)$ and northern red oak (Quercus rubra L.) in Massachusetts $\left(\mathrm{R}^{2}=0.54\right)$, respectively, was significantly and positively related to tree $\mathrm{DBH}$. These estimates may be conservative in that large Ailanthus trees seem to have fewer seed crop failures (Martin and Canham 2010).

Although seed viability was not assessed for the 4-5-year-old Ailanthus included in this study, viability of such seed has been previously reported for small diameter sprouts (Kowarick and Säumel 2008). Nevertheless, seed viability was confirmed from at least one 7-year old tree included in this study with a $78.1 \%$ germination rate and $70 \%$ seed viability based on a tetrazolium test. Two slightly older trees also included in this study, ages 12 and 16, had much lower germination rates $(<20 \%)$ despite being part of the same 2016 collections from the same geographic region. These observations support there being other factors (i.e., genetics, microenvironment) that influence seed viability (Motard et al. 2011, Constán-Nava and Bonet 2012, Delgado et al. 2009). The oldest tree assessed in this study (PA-62), a 104-year-old female 
located on the campus of Penn State University, had a high germination rate of 65.6\% and 62\% seed viability based on the $\mathrm{TZ}$ test. Overall, the tetrazolium test appears to be a reliable proxy for germination based on the reported sampling sizes and replications.

Previous seed germination studies from PA-62 reported similarly high germination rates Kasson et al. 2013. Coupled with the ca. 700,000 seeds produced annually by this tree, almost half a million viable offspring are produced each year. This is in sharp contrast to a 114-year-old Ailanthus (HSAa29) in Philadelphia observed with seed production 3-4 orders of magnitude lower than the PA-62 in 2011 (Kasson et al. 2013). Observations in 2017 of this same tree in Philadelphia indicate that this tree may have stopped producing seed altogether. Although viability of seed from the Philadelphia Ailanthus was not determined, low seed production may suggest fecundity is more variable in advanced age and influenced by other mitigating factors (Moore and Lacey 2009). For example, pollarding (pruning of upper branches to promote dense foliage and branches) was observed in HSAa29, which has been associated with losses in seed production and diameter growth in both strychnine tree (Strychnos nux-vomica L.) and Eucalyptus spp. L'Heritier in India (Nicholson 1937, Varghese et al. 2009). Furthermore, the inherent costs associated with maintenance of sexual reproduction may eventually give way to exclusively asexual reproduction in older trees, which was evidenced by the numerous vegetative sprouts found growing under tree HSAa29.

\section{Conclusions}

The remarkable success of Ailanthus invasion into the United States is due in part to prolific seed production and prolonged fecundity. In this study, it was established that Ailanthus seed production can begin as early as $4-5$ years and can extend $>100$ years, at which time seed viability can exceed $65 \%$. Total lifetime seed production is dependent upon the individual 
lifespan of the tree, but females that live 40 years will easily produce 10 million seeds during their lifetime, whereas exceptionally fecund long-lived trees may produce in excess of $>50$ million seeds. Seed viability varied somewhat among individuals, but seed from both the youngest and oldest individuals assayed in this study (ages 7 and 104 years) had viability $>65 \%$. The prolonged reproductive window, as noted in at least two aging Ailanthus trees in Pennsylvania (104 and 114 years as of 2017), ensures the continued reproductive success of this species, since old female trees can produce tens of millions of seeds over their lifetime. Thus, Ailanthus not only has an advantage over competitors by having an early reproductive start at 45 years of age, but the consistent, prolific annual seed production ensures that adequate Ailanthus seed will be present during any year that a site is disturbed, and that such sites can be readily colonized by Ailanthus seedlings.

\section{Acknowledgments}

Special thanks to Annie Ye, Toby Grapner, and Jim Savage who assisted with seed collection, sorting, and counting. Thanks to Christa Quint and Ida Holaskova for advice on statistics. Additional thanks to Pennsylvania Department of Transportation, Pennsylvania Game Commission, and Army Corps of Engineers, who provided sampling locations. Funding for

K.L.W. was provided by USDA APHIS (Agreement No. 16-8254-2074-CA) and USDA Forest Service, Northeastern Area, State and Private Forestry, Forest Health Technology Enterprise Team (FHTET), Morgantown, West Virginia (Cooperative Agreement 16-CA-11420004-296). 


\section{Tables}

Table 2-1. Seed viability status for current and historic seed sources of Ailanthus.

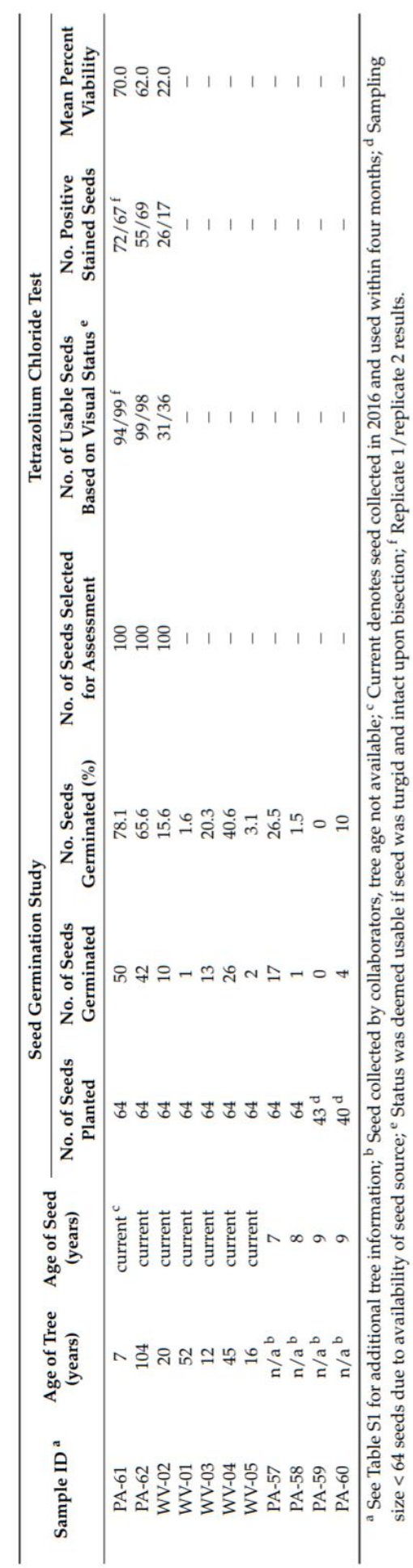




\section{Figures}
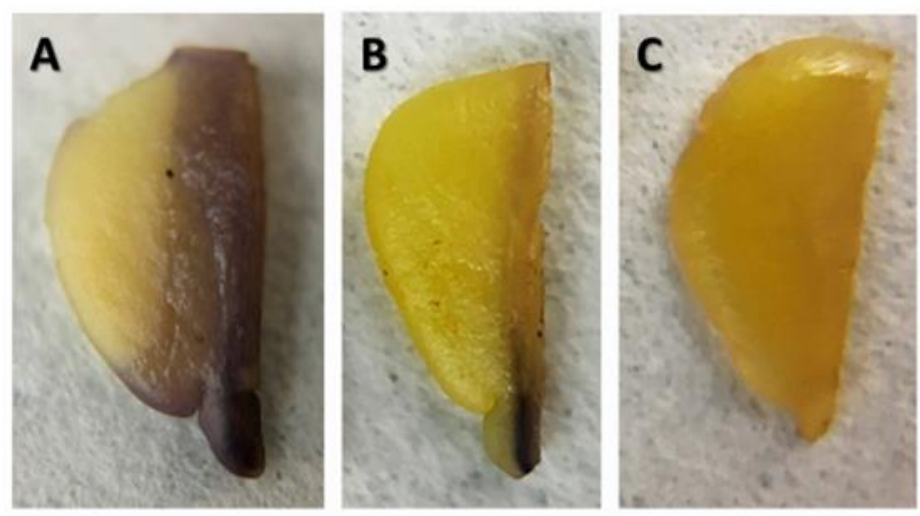

Figure 2-1. Ailanthus seed embryo challenged with blue tetrazolium chloride. A positive blue tetrazolium chloride (TZ) test resulted in (A) complete staining of radical and hypocotyl or (B) staining of radical only, whereas a negative TZ test resulted

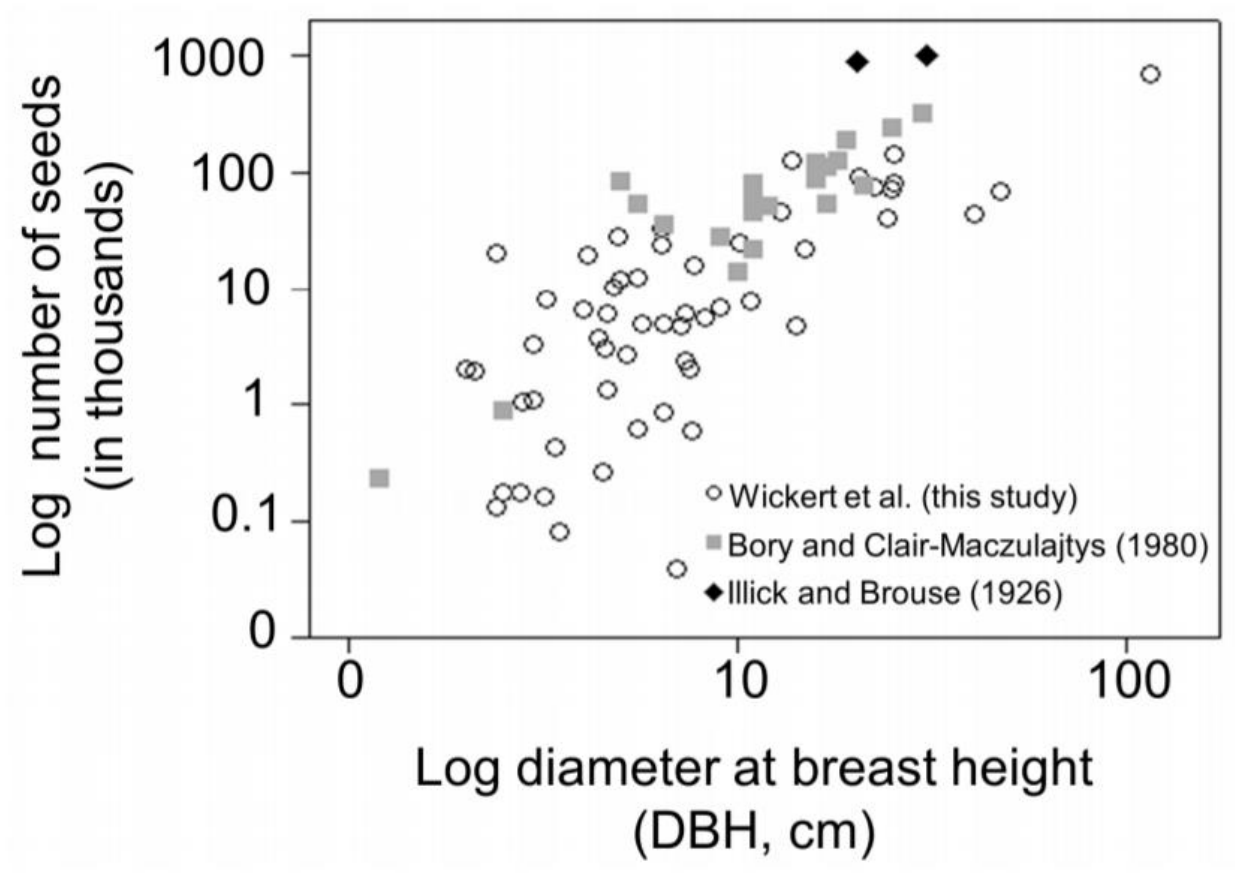

Figure 2-2. Ailanthus seed production versus diameter at breast height $(\mathrm{DBH}, \mathrm{cm})$ using the combined dataset 

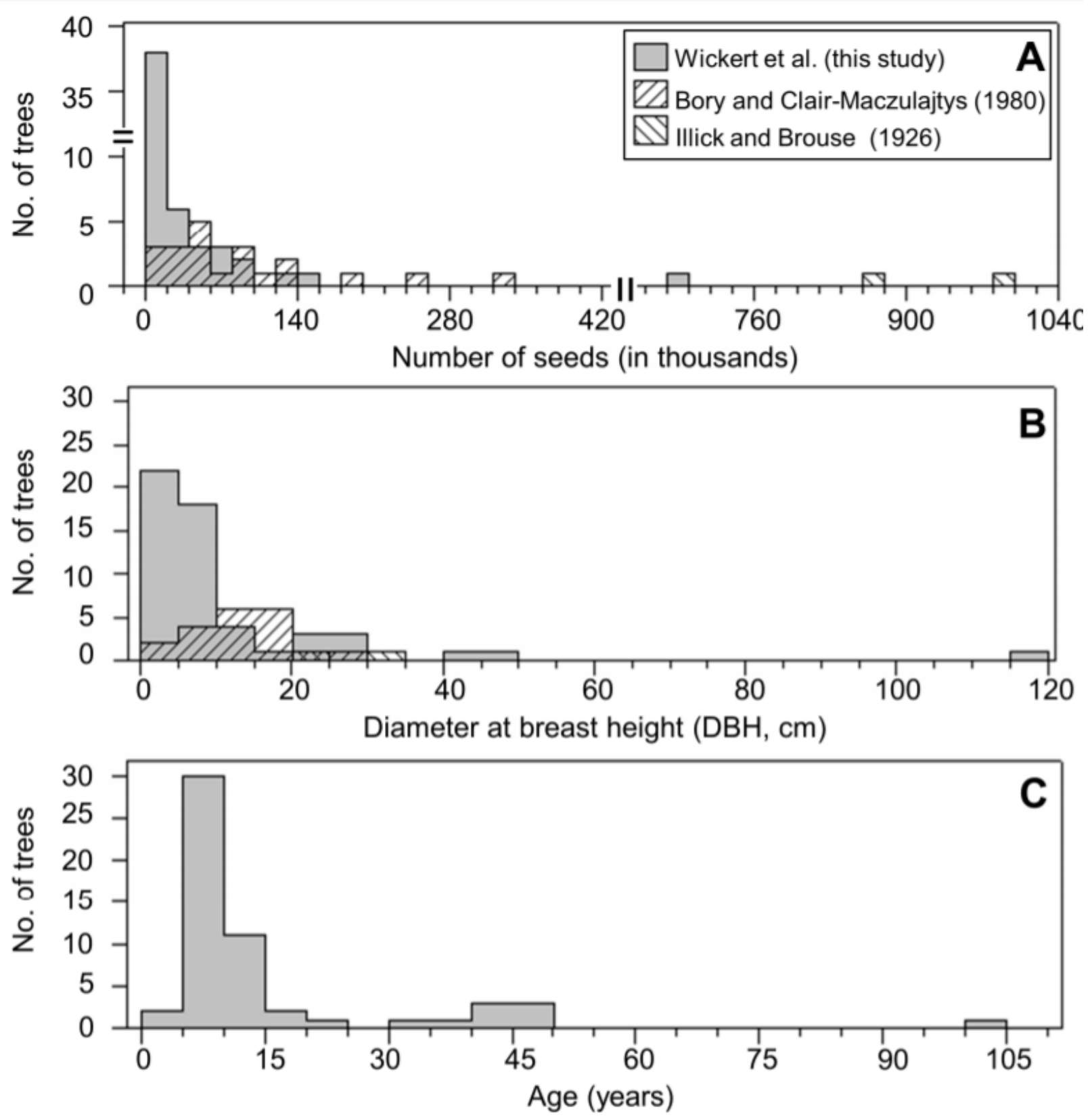

Figure 2-3. Distribution of (A) seed counts, (B) diameter at breast height (DBH, cm), and (C) age for seed producing Ailanthus from historic data sets and the current study 


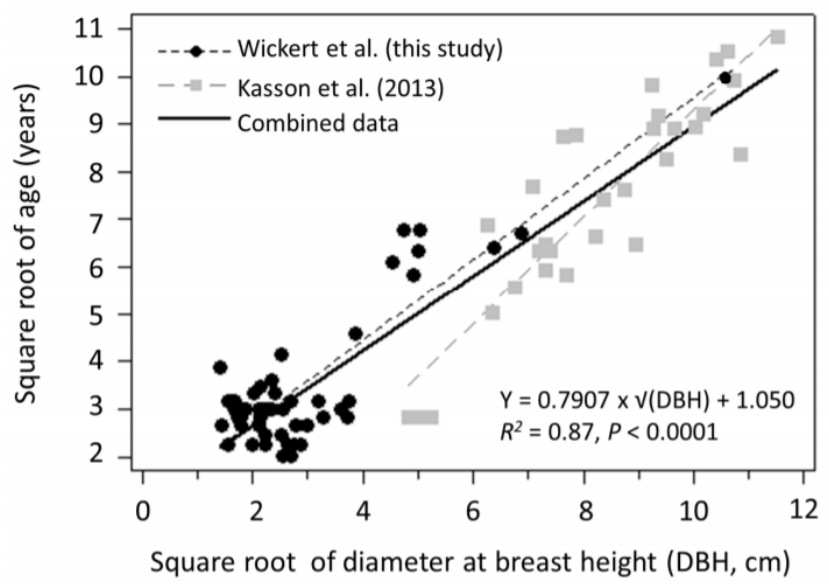

Figure 2-4. Relationship between age and diameter at breast height (DBH, cm) of open-grown Ailanthus. Equation for combined data is given above. Equation for Wickert et al. 2018 (this study) and Kasson et al. 2013, respectively, are as follows: $\mathrm{Y}=0.8517 \times \sqrt{\mathrm{DBH}}+1.027, R^{2}=$ $0.76, p<0.0001 ;$ and $\mathrm{Y}=1.1266 \times \sqrt{ } \mathrm{DBH}-1.964, R^{2}=0.83, p<0.0001$

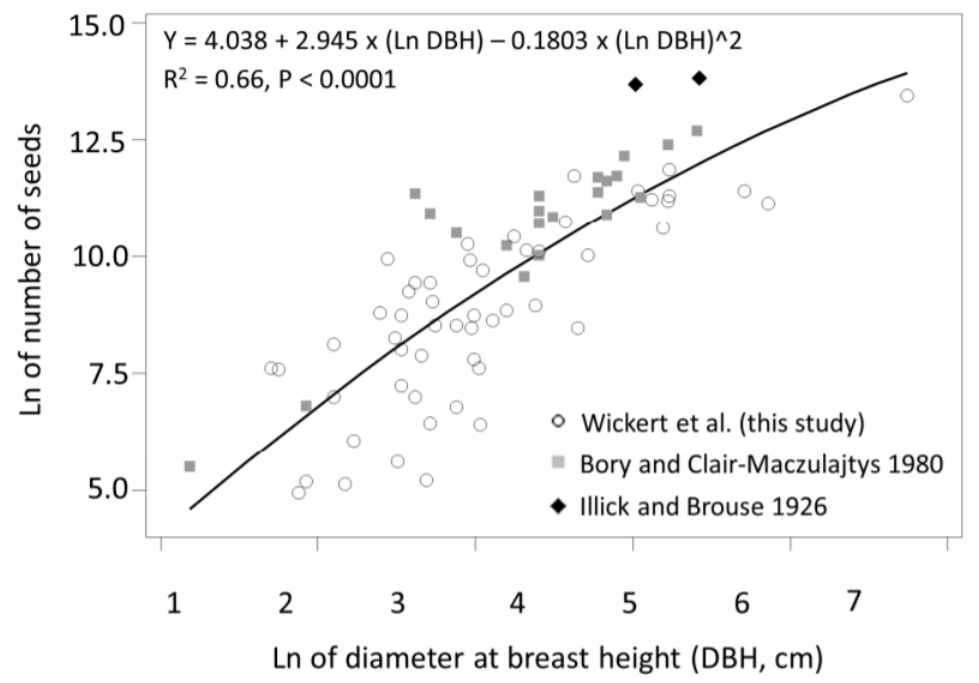

Figure 2-5. Relationship between number of seeds produced by Ailanthus and diameter at breast height (DBH, cm). Cumulative seed production for an individual Ailanthus over its lifetime, as it grew from 1-49 $\mathrm{cm}$ in diameter, was estimated to be ca. 10 million seeds 


\section{References}

Aldrich, P. R., Briguglio, J. S., Kapadia, S. N., Morker, M. U., Rawal, A., Kalra, P., Huebner, C.D. \& Greer, G. K. (2010). Genetic structure of the invasive tree Ailanthus in eastern United States cities. Journal of Botany.

Ares, A., \& Brauer, D. (2004). Growth and nut production of black walnut in relation to site, tree type and stand conditions in south-central United States. Agroforestry systems, 63(1), 83-90.

Barry, P. \& Smith, J.J.E. (1885) Arboriculture Notes-No. II: Bartram's Garden, Philadelphia. Hortic. J. Rural Art Rural Taste, 5, 371-375.

Bory, G., \& Clair-Maczulajtys, D. (1980). Production, dissemination and polymorphism of seeds in Ailanthus altissima. Revue génerale de botanique, 88(1049/1051), 297-311.

Cabra-Rivas, I., \& Castro-Díez, P. (2016). Comparing the sexual reproductive success of two exotic trees invading Spanish riparian forests vs. a native reference. PloS One, 11(8), e0160831.

Constán-Nava, S., \& Bonet, A. (2012). Genetic variability modulates the effect of habitat type and environmental conditions on early invasion success of Ailanthus in Mediterranean ecosystems. Biological Invasions, 14(11), 2379-2392.

Cottrell, H. J. (1947). Tetrazolium salt as a seed germination indicator. Nature, 159(4048), 748.

Delgado, J. A., Jimenez, M. D., \& Gomez, A. (2009). Samara size versus dispersal and seedling establishment in Ailanthus altissima (Miller) Swingle. Journal of Environmental Biology, 30(2), 183-186.

Di Tomaso, J. M. (1998). Impact, biology, and ecology of saltcedar (Tamarix spp.) in the southwestern United States. Weed Technology, 326-336.

Feret, P. P. (1973). Early flowering in Ailanthus. Forest Science, 237-239.

Gaertner, M., Den Breeyen, A., Hui, C., \& Richardson, D. M. (2009). Impacts of alien plant invasions on species richness in Mediterranean-type ecosystems: a meta-analysis. Progress in Physical Geography, 33(3), 319-338.

Gray, A. (1868). Manual of the Botany of the Northern United States. Ivison, Phinney, Blackman \& Co. New York.

Harris, P. T., Cannon, G. H., Smith, N. E., \& Muth, N. Z. (2013). Assessment of plant community restoration following tree-of-heaven (Ailanthus altissima) control by Verticillium albo-atrum. Biological invasions, 15(9), 1887-1893.

Healy, W. M., Lewis, A. M., \& Boose, E. F. (1999). Variation of red oak acorn production. Forest Ecology and Management, 116(1-3), 1-11.

Hegi, G. (1906). Illustrierte Flora von Mitteleuropa. München : J. F. Lehmann Verlag. 
Illick, J. S., \& Brouse, E. F. (1926). The Ailanthus tree in Pennsylvania (No. 38). Pennsylvania Department of Forests and Waters.

Kainer, K. A., Wadt, L. H., \& Staudhammer, C. L. (2007). Explaining variation in Brazil nut fruit production. Forest Ecology and Management, 250(3), 244-255.

Kaproth, M. A., \& McGraw, J. B. (2008). Seed viability and dispersal of the wind-dispersed invasive Ailanthus in aqueous environments. Forest Science, 54(5), 490-496.

Kasson, M. T., Davis, M. D., \& Davis, D. D. (2013). The invasive Ailanthus in Pennsylvania: a case study elucidating species introduction, migration, invasion, and growth patterns in the northeastern US. Northeastern Naturalist, 20(10), 1-61.

Kasson, M. T., O’Neal, E. S., \& Davis, D. D. (2015). Expanded host range testing for Verticillium nonalfalfae: potential biocontrol agent against the invasive Ailanthus altissima. Plant Disease, 99(6), 823-835.

Kota, N. L., Landenberger, R. E., \& McGraw, J. B. (2007). Germination and early growth of Ailanthus and tulip poplar in three levels of forest disturbance. Biological Invasions, 9(2), 197211.

Kowarik, I., \& Säumel, I. (2007). Biological flora of central Europe: Ailanthus altissima (Mill.) swingle. Perspectives in Plant Ecology, Evolution and Systematics, 8(4), 207-237.

Kowarik, I., \& Säumel, I. (2008). Water dispersal as an additional pathway to invasions by the primarily wind-dispersed tree Ailanthus altissima. Plant Ecology, 198(2), 241-252.

Martin, P. H., \& Canham, C. D. (2010). Dispersal and recruitment limitation in native versus exotic tree species: life-history strategies and Janzen-Connell effects. Oikos, 119(5), 807-824.

Mason, R. A., Cooke, J., Moles, A. T., \& Leishman, M. R. (2008). Reproductive output of invasive versus native plants. Global Ecology and Biogeography, 17(5), 633-640.

McAvoy, T. J., Snyder, A. L., Johnson, N., Salom, S. M., \& Kok, L. T. (2012). Road survey of the invasive tree-of-heaven (Ailanthus altissima) in Virginia. Invasive Plant Science and Management, 5(4), 506-512.

Meyer, J. Y. (1998). Observations on the reproductive biology of Miconia calvescens DC (Melastomataceae), an alien invasive tree on the Island of Tahiti (South Pacific Ocean) 1. Biotropica, 30(4), 609-624.

Moore, J. E., \& Lacey, E. P. (2009). A comparison of germination and early growth of four early successional tree species of the southeastern United States in different soil and water regimes. The American Midland Naturalist, 162(2), 388-395.

Mortensen, D. A., Rauschert, E. S., Nord, A. N., \& Jones, B. P. (2009). Forest roads facilitate the spread of invasive plants. Invasive Plant Science and Management, 2(3), 191-199. 
Motard, E., Muratet, A., Clair-Maczulajtys, D., \& Machon, N. (2011). Does the invasive species Ailanthus threaten floristic diversity of temperate peri-urban forests? Comptes Rendus Biologies, 334(12), 872-879.

Nicholson, J. W. (1937). Results of coppicing, pollarding and pruning experiments to stimulate Strychnos nux-vomica fruit production. Indian Forester, 63(9), 588-597.

Planchuelo, G., Catalán, P., \& Delgado, J. A. (2016). Gone with the wind and the stream: Dispersal in the invasive species Ailanthus altissima. Acta Oecologica, 73, 31-37.

Planchuelo, G., Catalán, P., Delgado, J. A., \& Murciano, A. (2017). Estimating wind dispersal potential in Ailanthus altissima: The need to consider the three-dimensional structure of samaras. Plant Biosystems-An International Journal Dealing with all Aspects of Plant Biology, 151(2), 316-322.

Rebbeck, J., Kloss, A., Bowden, M., Coon, C., Hutchinson, T. F., Iverson, L., \& Guess, G. (2015). Aerial detection of seed-bearing female Ailanthus altissima: A cost-effective method to map an invasive tree in forested landscapes. Forest Science, 61(6), 1068-1078.

Snook, L. K., Cámara-Cabrales, L., \& Kelty, M. J. (2005). Six years of fruit production by mahogany trees (Swietenia macrophylla King): patterns of variation and implications for sustainability. Forest Ecology and Management, 206(1-3), 221-235.

Swearingen, J.M. Plant Conservation Alliance, Alien Plant Working Group: Melaleuca quinquenervia (Cav.) Blake. Available online: https://www.nps.gov/plants/alien/fact/mequ1.htm (accessed on 15 May 2017).

Varghese, M., Ravi, N., Kamalakannan, R., \& Harwood, C. E. (2009). Effect of silvicultural treatments on growth, fertility and capsule traits in seedling seed orchards of Eucalyptus camaldulensis and E. tereticornis. New Forests, 37(1), 99-107.

Von der Lippe, M., Bullock, J. M., Kowarik, I., Knopp, T., \& Wichmann, M. (2013). Humanmediated dispersal of seeds by the airflow of vehicles. PloS One, 8(1), e52733. 


\title{
Chapter 3
}

\section{Disease progression of Verticillium nonalfalfae and $V$. dahliae, causal agents of Verticillium wilt of Ailanthus, in different hardiness zones of Pennsylvania, USA}

\author{
Kristen L. Wickert
}

\begin{abstract}
Ailanthus altissima is a prolifically entrenched exotic invasive species in North America. The biocontrol of Ailanthus has been a topic of extreme interest since the discovery of an aggressive Verticillium wilt disease of Ailanthus in 2002. After nearly 15 years of research, an augmentative release of the causal agent Verticillium nonalfalfae as a biocontrol could be in the near future. However, a few questions remain: i) can the interaction of two Verticillium species that are both pathogens of Ailanthus could inhibit the effectiveness of the biocontrol, and ii) do hardiness zones affect biocontrol efficacy? In a two-year study including 927 Ailanthus trees across 23 sites in 3 hardiness zone groups of Pennsylvania, Ailanthus trees died at a similar rate when they were co-inoculated with $V$. nonalfalfae and $V$. dahliae as when inoculated with $V$. nonalfalfae alone. There was no statistically significant effect of hardiness zone on the treatments. These results support the use of $V$. nonalfalfae in Ailanthus stands that are already infected with the less virulent pathogen, $V$. dahliae. Greenhouse inoculations produced similar results. Microtome assays proved there were no difference in host response via the production of tyloses or vessel clogging with organic gums in Ailanthus seedlings treated with only $V$. nonalfalfae, only $V$. dahliae, and both fungi together against water controls. Additionally, experiments tested whether a more viable method of formulation could be used to disseminate the biocontrol method by foresters and land mangers than standard inoculation processes which require aseptic technique and timely application. Out of eight treatments in a forest overcome with Ailanthus regeneration, three treatments proved to be viable means of infecting the seedlings established in the timber management area: direct inoculation, introduction of $V$. nonalfalfae in inoculated rye grain and introduction of $V$. nonalfalfae via inoculated soil. In a complementary greenhouse study, Ailanthus seedlings were planted in a soil augmented with $V$. nonalfalfae inoculated rye grain and soil inoculated with $V$. nonalfalfae. In both treatments, significant mortality occurred with the inoculated rye grain treatment causing $60 \%$ mortality and the soil causing $40 \%$ mortality in four weeks. Additionally, soil which was inoculated in 2010-2014 still contained viable Verticillium colonies when plated on potato dextrose agar in 2018. These findings lead to the increasing awareness of the potential to utilize $V$. nonalfalfae as a viable and competitive biocontrol method that has a long-lasting shelf life.
\end{abstract}




\section{Introduction}

Invasive species impose a huge ecological burden on our native forested ecosystems and cultivated landscapes. Approximately 50,000 exotic species have become established in the United States, with around 4,300 of those species being considered invasive (Corn et al. 1999, Pimentel et al. 2005). Although invasive trees account for a small percentage of weeds impacting US lands and agriculture, some notable examples such as melaleuca tree (Melaleuca quinquenervia (Cav.) S. T. Blake) in Florida are costing taxpayers between $\$ 3$ to $\$ 6$ million per year in efforts to control this ecosystem-altering invasive species (Pimentel et al. 2005). Tree-ofheaven (Ailanthus altissima (Mill.) Swingle), which arrived as an ornamental garden tree some 235 years ago in Philadelphia, PA, is another highly invasive tree species with a wide distribution throughout North America. As is the case with many entrenched invasive plants, pesticides have proven either inappropriate given the plant's distribution among co-occurring native plants or inadequate. The need for integrated pest management tactics, especially following the introduction of a newly established invasive insect, Lycorma delicatula White, a planthopper that preferentially feeds on Ailanthus but can cause substantial damage to commercial orchard trees and grape vines in vineyards, cannot be overstated.

Integrated pest management relies on several tactics, including cultural changes to control a population such as quarantines, habitat manipulation, incorporation of resistant varieties, and biological control methods, all which allow for a lesser reliance on chemical pesticide use (Kogan 1998). The potential for invasive species suppression via biological control is high and has been proven by the success of approximately 200 species of invasive insects which have been suppressed through biological control methods alone (Van Driesche et al. 2008). Biological control methods are also successful in managing invasive plant species, such as the rust fungi 
Uromyces heliotropii Sred. against the invasive Eurasian common heliotrope (Heliotropium europaeum L.) in Australia and Uromycladium tepperianum Sacc. against the invasive shrub Acacia saligna Lindley in South Africa (Morris 1997, Hasan et al. 1992). The biocontrol weevil mile-a-minute weevil (Rhinoncomimus latipes Korotyaev) also has shown potential in its suppression of mile-a-minute weed, Persicaria perfoliata (L.) H. Gross in the U.S. (Lake et al. 2011).

In the early 2000s, a vascular wilt disease caused by ascomycete fungus Verticillium nonalfalfae Inderbitzin, was found naturally occurring in Pennsylvania where it was causing severe mortality in Ailanthus stands (Schall and Davis 2009). Seven years later the wilt was found in several locations in Virginia, a second location in Pennsylvania, and in Ohio (Snyder et al. 2013, Rebbeck et al. 2013, Kasson et al. 2014). Since its discovery, there have been various studies to help elucidate phylogenetic relationships, biocontrol efficacy, host range and transmission in an attempt to answer whether this fungus could be used regionally as a biocontrol (Kasson et al. 2014, Kasson et al. 2015, O’Neal and Davis 2015).

Verticillium dahliae Kleb. also causes a vascular wilt disease on Ailanthus, however infected trees seem to be able to persist with these natural infections for many years (Schall and Davis 2009, Kasson et al. 2013). The pathogenicity of the two Verticillium species is markedly different: $V$. nonalfalfae is aggressive and able to kill a tree-of-heaven in as little as three months to one year (depending on time of year of inoculation) while $V$. dahliae may take several years to kill a tree (Schall and Davis 2009, O'Neal and Davis 2015). A tree infected with V. dahliae may even be able to overcome the infection (Kasson et al. 2013).

Despite their co-occurrence across the invaded range of Ailanthus little is known how these tworelated species of Verticillium interact in forested stands and in situations where they co-colonize 
the vascular system of a single plant (Schall and Davis 2009, Snyder et al. 2014). The confirmed hybridization between $V$. dahliae and a species related to $V$. albo-atrum Reinke \& Berthold, resulting in the emergence of the diploid V. longisporum (C. Stark) Karapapa, Bainbr. \& Heale with an increased virulence on Brassica plants, raises concerns about potential for new recombination events among $V$. dahliae and $V$. nonalfalfae (Inderbitzen et al. 2011).

Even without the possibility of hybridization, two organisms of different species can have synergistic effects on disease progression as they form a disease complex, such as nematodes acting as a primary pathogen that predisposes the host and enables the fungal secondary pathogen to infiltrate or digest the plant in a faster way (Powell 1971). Not all multiple pathogen disease complex interactions are always synergistic or complementary. There are also cases where one organism fills the niche that the other would infiltrate and utilize as an entry point to infect the host. The occurrence of a vascular wilt species may impose negatively on the occurrence of another. One such example is the utilization of a non-pathogenic strain of Verticillium albo-atrum from potato that is a formulated fungal biocontrol (marketed as DutchTrig®) against the Dutch elm disease (DED) vascular wilt pathogens Ophiostoma ulmi (Buisman) Melin \& Nannf. and O. novoulmi (Buisman) Melin \& Nannf. (Garbaye 1991). DutchTrig® can prevent the colonization of Ophiostoma fungal species by activating the elm trees' natural defense mechanisms (Scheffer et al. 2008). In 1998, researchers treated 8,500 American elm trees with DutchTrig® and reported that the rate of new DED infections declined in 4 years from $0.53 \%$ to $0.22,0.10$, and $0.05 \%$ (Scheffer et al. 2008). Another fungus used to prevent the infection of plant pathogenic fungi is Trichoderma harzianum Rifai (Elad et al. 1980). Trichoderma harzianum actively destroys the mycelium of Rhizoctonia solani J.G. Kühn and Athelia 
rolfsii (Curzi) C.C. Tu \& Kimbr. the causal agent of southern blight in agricultural systems by producing metabolites that lyse the cells of the plant pathogens in the soil (Elad et al. 1980). Considering that both Verticillium species can reside in the same host and ecosystem, it is vital to understand their interactions. It is possible that the weaker $V$. dahliae could inhibit or accelerate the infection of $V$. nonalfalfae and alter the efficacy of utilizing this highly successful fungus as a biocontrol for tree-of-heaven.

Another important aspect of biocontrol is the restrictions that temperatures may impose on the biocontrol agent's efficacy across the invaded range of the host. Hardiness zone temperature limitations could exist for either fungi or plants. Relatively high temperatures have been reported to reduce " $V$. albo-atrum" growth to a yeast-like budding stage, whereas $V$. dahliae maintains moderate growth at relatively high temperatures (Pegg and Brady 2002). As such, V. dahliae could be a more viable biocontrol agent in southern regions where warmer temperatures limit $V$. nonalfalfae from growing optimally.

Finally, successful biocontrols require the ability to be mass produced with an extended shelf life and applied by non-experts, such as the Dutch elm disease resistance product - DutchTrig ${ }^{\circledR}$. Currently, the standard application method for $V$. nonalfalfae is through specialized techniques that require aseptic preparation of asexual spore suspensions applied through hack and squirt methods. However, other less specialized techniques have been explored and varied success has been observed (O'Neal and Davis 2015). One major issue that remains is that formulations deployed against mature Ailanthus stems are not an effective mode of application for young regeneration. A biocontrol method should be successful on all stages of plant development, especially in preventing establishment. 
Currently, there is no tested and efficient application method that would prevent establishment of Ailanthus seedlings.

This study aims to understand the interaction of $V$. nonalfalfae and $V$. dahliae and the subsequent potential impact to efficacy of Verticillium wilt against Ailanthus. The objectives were to: i) evaluate the rate of mortality when the two Verticillium species were coinoculated into Ailanthus trees compared to mortality from V. nonalfalfae and V. dahliae alone; ii) determine the role, if any, of environmental influences from different hardiness zones on disease progression; and iii) determine if a viable formulation method could be employed to make the inoculation process easier for land management agencies.

\section{Materials and Methods}

\section{Inoculum preparation}

Verticillium nonalfalfae isolate VnAa140 cultures were actively maintained on Difco potato dextrose agar (PDA; BD and Co., Franklin Lakes, NJ, USA) amended with streptomycin $(0.01 \mathrm{mg} / \mathrm{mL}$; (Sigma-Aldrich, St. Louis, MO, USA) and tetracycline $(0.1 \mathrm{mg} / \mathrm{mL}$; Fisher Scientific, Pittsburgh, PA, USA), and grown at ambient temperature following a 16-h light/8-h dark cycle. Inoculum was prepared as previously described by Kasson et al. (2014). Briefly, 2week-old cultures of $V$. nonalfalfae were flooded with $5 \mathrm{ml}$ of sterile water and the surface scraped with a sterile disposable cell spreader. The resulting spore suspension was vortexed to dislodge conidia from associated mycelia and homogenize the suspension prior to passage through a sterile milk filter (KenAg, Ashland, $\mathrm{OH}$ ). Conidial concentrations were determined

using a hemocytometer and adjusted to $1 \times 10^{7}$ conidia $\mathrm{ml}^{-1}$. Viability of conidia was evaluated by counting CFU from 10-fold dilutions of suspensions on PDA+A plates. Only inoculum with $>80 \%$ viability after three days of growth on PDA+A were utilized. 


\section{Viability of $V$. nonalfalfae and V. dahliae in Long Term Storage}

Between 2010 and 2014, 10-ml scintillation vials containing a 1:1:1 sterile mix of potting soil/ sand/ perlite were flooded with conidia harvested from 4-week-old cultures, incubated at ambient temperatures for 2 weeks, and stored at $4^{\circ} \mathrm{C}$ (Figure 3-1). In total, these vials were kept in cold storage at $4^{\circ} \mathrm{C}$ between $4-8$ years. In 2018 , soil vials were removed from cold storage and after mixing, 5 grams of soil was distributed onto PDA + A plates and allowed to grow at ambient temperature following a 16-h light/8-h dark cycle until fungal mycelium was present. When present, fungal mycelium was subcultured and identified based on both colony morphology and PCR methods. Plates with soil did not produce any Verticillium colonies after 2 weeks were discarded and recorded as sterile. For bacteria or fungal colonies other than Verticillium, vials were recorded as contaminated and also discarded. Percent of total viable and Verticillium-positive vials for each species was calculated. In total, 82 vials of soil originally containing $V$. nonalfalfae and 58 vials originally containing $V$. dahliae were assessed. Thirty-two isolates V. nonalfalfae from Ailanthus trees in Pennsylvania, Ohio and one isolate from Chile were included in the $V$. nonalfalfae vials (Table 3-1). Nineteen isolates from Ailanthus trees from Pennsylvania, Maryland, and Ohio were included in the $58 \mathrm{~V}$. dahliae vials (Table 3-2).

\section{Efficacy of $V$. nonalfalfae-inoculated soil and rye grain on Ailanthus seedlings in a controlled environment}

Given the encouraging results regarding previous soil inoculations (O’Neal and Davis 2015) coupled with the prolonged viability of $V$. nonalfalfae in storage (Kasson et al. 2014, this study), an efficacy test was conducted to compare two topical applications of $V$. nonalfalfae: infested soil and colonized rye grain. Additionally, another treatment of rye grain was prepared by adding $1000 \mathrm{ml}$ of rye grain and $40 \mathrm{ml}$ of calcium carbonate to $880 \mathrm{ml}$ of tap water and 
autoclaving for 25 minutes. After cooling flasks for $24 \mathrm{~h}$, rye grain mixture was hand shaken to homogenize distribution of calcium carbonate. Flasks were inoculated individually with 2 fully colonized 2-week-old PDA plates of $V$. nonalfalfae isolate VnAa140. Periodically, $100 \mathrm{ml}$ of sterile water was adding to colonized flasks to maintain moisture while rye grain was colonized. Rye grain was allowed to be colonized for 4 weeks (Figure 3-2).

To permit comparisons, ten 3-week-old Ailanthus seedlings (susceptible seed source HPA-62; Wickert et al. 2017) per treatment were planted in sterile potting soil mixed with $V$. nonalfalfae pre-inoculated rye grain or soil in individual plots. Seedlings were allowed to grow for four weeks. Seedlings were rated on a $0-4$ scale 0 - healthy, 1 - necrotic margins, 2 - mild wilt and chlorosis, 3- severe wilt, 4 - dead. After 4 weeks, stems were harvested and plated for re-isolation.

\section{Comparisons among direct and indirect $V$. nonalfalfae inoculations in a newly regenerated forest stand in Pennsylvania}

Following the outcome of the topical applications of $V$. nonalfalfae under artificial growth conditions, an expanded comparative pathogenicity test was implemented under field conditions in a newly regenerated stand of Ailanthus in Pennsylvania on a previous mixed oak hardwood forest. The 8-hectare parcel was shelter cut in 2015, after which widespread invasion by Ailanthus occurred. Eight treatments were randomly assigned to individual $1 \mathrm{~m}^{2}$ plots: four $V$. nonalfalfae treatments included two indirect application methods including inoculated rye grain and inoculated soil applied evenly across the plot and two direct application methods including direct inoculation of stems with a sterile scalpel and $V$. nonalfalfae conidial solution $\left[1 \times 10^{7}\right]$ and foliar and stem spray application of $V$. nonalfalfae conidial solution $\left[\begin{array}{ll}1 \times 10^{7}\end{array}\right]$. All four direct 
and indirect treatments were replicated with sterile water and served as negative controls (Table 3-3).

Plots were marked with pin flags and boundaries demarcated at each of the four corners with colored flagging corresponding to a specific treatment. Average density of Ailanthus seedlings/saplings was 9 seedlings / plot with a minimum of 5 / plot and a maximum of 26 / plot. There were five blocks hosting the eight treatments for a total of 40 plots.

Colonized rye grain and infected soil inoculum were prepared as previously described above. Field inoculations occurred in May of 2018. A volume of $1000 \mathrm{ml}$ in a standard flask of rye grain and soil treatments applied to each plot. Spray treatments received roughly $200 \mathrm{ml}$ of inoculum at a concentration of $1 \times 10^{7} / \mathrm{ml}$ sprayed evenly across Ailanthus present within individual plots. Prior to application of individual treatments, the soil organic layer was scarified with a trowel to expose soil which was meant to mimic the disturbed landscape of a fresh timber harvest and allowing for contact between topical treatments and bare soil. After three months, the plots were revisited and the Ailanthus saplings showing symptoms of Verticillium wilt were recorded. Symptomatic tissues were collected to fulfill Koch's postulates.

\section{The influence of $V$. dahliae on the efficacy of $V$. nonalfalfae inoculations in three hardiness zone groups of Pennsylvania}

Concurrent to controlled environment studies assessing various direct and indirect inoculation methods, a regional direct inoculation study was implemented to assess efficacy of $V$. nonalfalfae alone and in mixed formulation with $V$. dahliae in three hardiness zone groups. The rationale behind such comparisons was threefold: 1) determine if the mixed inoculation would decrease the efficacy of $V$. nonalfalfae against Ailanthus; 2) determine if hardiness zone (and the associated temperatures) influenced disease progression; and 3) determine if co-colonization 
would permit hybridization between $V$. nonalfalfae and $V$. dahliae. Study sites were selected across two USDA plant hardiness zones (PHZ) within the state of Pennsylvania, PHZ 5 and 6 while focusing on two subgroups of PHZ 6: 6a and 6b. Hardiness zones were based on the average annual minimum winter temperature from 1976-2005: PHZ 5 experiences average annual extreme minimum temperatures of -28.9 to $-23.3 \mathrm{C}$, PHZ 6a -23.3 to $-20.6 \mathrm{C}$, and PHZ 6b -20.6 to -17.8 C. Eight sites were selected with a total of 23 plots on both private and public properties with two in PHZ 5, two in PHZ 6a and three in PHZ 6b (Table 3-4). Due to the limited distribution of Ailanthus in PHZ 5, only three total plots were established while seven total plots were established on PHZ 6a and 13 on PHZ 6b. Selection criteria for stands also required a minimum density of 10 tree-of-heaven stems $>2.54 \mathrm{~cm} \mathrm{DBH}$ (diameter at breast height $-1.4 \mathrm{~m}$ above soil line) within a 0.04 ha plot area $(11.3 \mathrm{~m}$ radius from plot center). All Ailanthus trees within the boundary of the plot were marked with an individual identification number and flagging. A total of 927 Ailanthus stems were included in this study, with a range of $11-90$ trees / plot and an average of 41 trees / plots across the study.

Sites were mapped using Microsoft Excel with azimuth and distance from plot center translated to $\mathrm{x}$ and $\mathrm{y}$ coordinates. This map was used to calculate plot density and basal area $\left(0.005454 * \mathrm{DBH}^{2}\right)$. Trees that equaled $10 \%$ of the basal area closest to plot center were chosen to be inoculated with the fungus (Figure 3-3).

Three treatment types were utilized in this study, $V$. nonalfalfae conidial suspension, an equal parts mixture of $V$. nonalfalfae and $V$. dahliae conidial suspension, and a sterile water negative control. Six plots received $V$. nonalfalfae alone, twelve plots were treated with the mixture, and five plots received the water control. Inoculum was prepared as previously described utilizing the $V$. nonalfalfae isolate VnAa140 and $V$. dahliae isolate PSUVd1 from 
Ailanthus in Pennsylvania. Inoculum concentration was $1 \times 10^{7}$ spores / $\mathrm{ml}$ Given the large distribution of sites across Pennsylvania, inoculations occurred over a two-day period. After plots were established and mapped, selected trees were inoculated based off of previous inoculation methods by Kasson et al. 2014.

Disease progression was monitored initially at a biweekly occurrence the first month post inoculation and then progressed to a once / month rating during the growing season for the first summer (June - August). A final rating was performed at the end of the second growing season, 64 weeks post inoculation. As trees showed symptoms they were marked with spray paint in the field with different colors pertaining to rating dates for easy visualization in future visits. Disease progression was initially rated on a $0-1$ dead or alive scale with an additional rating system of 15 (1- asymptomatic, 2-chlorotic, 3, wilting, 4 both, 5 defoliation) and a percent accompanied that rating of what was represented in the canopy of individual trees. Additionally, for statistical analysis, individual tree deaths were translated to an alive (0) or dead (1) final rating once canopies reached a "functionally dead" rating of $>80 \%$ wilted canopy. Functionally dead implies that that at $>80 \%$ wilt and defoliation the canopy will not be able to recover, indicating inevitable death of the tree.

A one-time sampling of rachises, leaves and stem tissues occurred near the end of the experiment to re-isolate fungi and fulfill Koch's postulates. Fungi were identified using classic fungal morphology and PCR techniques with Verticillium primer sets from Inderbitzin et al. 2013 to detect both $V$. dahliae and V. nonalfalfae. 


\section{Comparisons among individual and mixed inoculations of $V$. nonalfalfae and $V$. dahliae on greenhouse Ailanthus}

To accompany results from the field study and remove potential outside variables, 120 three-month old Ailanthus seedlings (susceptible seed source HPA-62; Wickert et al. 2017) were planted in sterile potting soil and root dip inoculated with either a water control, $V$. nonalfalfae alone, $V$. dahliae alone or both of the Verticillium species. All conidial inoculum suspensions were at a concentration of $1 \times 10^{7}$ conidia $\mathrm{ml}^{-1}$. Thirty plants were inoculated in each treatment type. After inoculation plants were allowed to grow for three weeks and rated on a weekly basis with a 0-4 scale 0 - healthy, 1 - necrotic margins, 2 - chlorosis, - severe wilt, 4-dead. After 3 weeks, stems were harvested and plated for pathogen re-isolation.

Additionally, to analyze potential impacts to functional conductive vascular tissue, symptomatic Ailanthus seedlings from all four treatments were destructively harvested to be visualized with a microtome. Fifteen seedlings inoculated with both fungi, and 10 each from the water inoculated control, $V$. nonalfalfae alone, $V$. dahliae alone treatments. Slices were taken with a microtome at the West Virginia University Medical School. The most complete cross section of the Ailanthus seedling was selected on each microscope slide. If any abnormalities were found they were recorded such as number of vessels with gum blockage and number of vessels with mycelium present.

For both forest and greenhouse inoculations, symptomatic plant tissue was aseptically plated on potato dextrose agar augmented with antibiotics streptomycin sulfate and tetracycline $(\mathrm{PDA}+\mathrm{A})$ to allow for isolation of the Verticillium causal agents. Genomic DNA was extracted from fungal mycelial plugs harvested from Difco potato dextrose broth (PDB; BD and Co., Franklin Lakes, NJ, USA) following procedures described by Short et al. 2015. All PCR was 
performed on a MJ Research PTC-200 Peltier Thermal Cycler (GMI, Ramsey, MN) using primers (Integrated DNA Technologies, Coralville, IA, USA) ITS 4 and ITS5 (White et al. 1990) to amplify the nuclear internal transcribed spacer regions ITS1-5.8S-ITS2 (ITS) and BioLine PCR Kits (Bioline USA Inc, Taunton, MA) in $24.5 \mu \mathrm{L}$ reactions containing: $1 \mu \mathrm{L}$ of each of two primers, $1 \mu \mathrm{L}$ genomic DNA, $10 \mu \mathrm{L}$ nuclease free water, and 12.5 Bioline PCR Mastermix. For gel electrophoresis, $4 \mu \mathrm{L}$ of SYBR gold (Invitrogen, Grand Island, NY, USA) and $4 \mu \mathrm{L}$ of loading dye (5Prime, Gaithersburg, MD) were added to PCR products which were then loaded into a gel comprising $0.5 \%$ Tris-Borate-EDTA buffer (Amresco, Solon, OH, USA) and 1.5\% w/v agarose (Amresco, Solon, OH, USA). Electrophoresis was performed at $90 \mathrm{v}$ for $45 \mathrm{~min}$ and DNA bands were visualized on a UV transilluminator (Syngene, Frederick, MD, USA). A 100 bp molecular ladder (Omega Bio-tek, Norcross, GA, USA) was included for size comparison. PCR products were purified using ExoSap-IT (Affymetrix, Santa Clara, CA). Representative PCR amplicons were Sanger sequenced with the same primers used for PCR (Eurofins, Huntsville, AL, USA). BLASTn searches of the NCBI GenBank database found 99 to $100 \%$ maximum identity matches with the fungal identity sequences deposited.

For long-term storage, representative isolates were placed onto PDA slants and maintained at $4^{\circ} \mathrm{C}$. From each site, representative isolates were retained for DNA confirmation. Representative slants are maintained in cold storage in the Kasson Plant Pathology Lab at West Virginia University and are available upon request.

\section{Statistical Analysis}

All distributions were checked for normality except for forest field plot data since the percent ratings were translated to a binomial value, which was used to statistically compared 
effects of hardiness zone and treatment types in an analysis deviance table (Type II Wald Chi Squared Test). A one-way analysis of variance (ANOVA) and student t-test were used to determine if any statistically significant differences occurred between the treatment types in the greenhouse experiments (co-pathogenicity testing and formulation techniques). Statistical analysis of survivorship of the mixed inoculations of greenhouse Ailanthus was performed using the "Survival / Reliability" function in JMP 13.1.0 (SAS Institute Inc., Cary, NC). Post-hoc pairwise comparisons to the control treatment were performed for treatments that reached at least $80 \%$ mortality by the end of the trial. Survival data analysis overview using Kaplan-Meier estimates to understand survivorship through both log-rank and Wilcoxon tests were used. Logrank tests score mortality at all time points evenly, while Wilcoxon tests score early mortality more heavily. Statistical analysis was performed SAS JMP 13.1.0 (SAS Institute Inc., Cary, $\mathrm{NC})$.

\section{Results}

\section{Viability of $V$. nonalfalfae and $V$. dahliae in Long Term Storage}

Vials containing soil inoculated with $V$. dahliae and $V$. nonalfalfae from 2010, 2012, 2013, and 2014 maintained viable cultures of the fungus. Of 58 vials containing V. dahliae $36 \%$ were sterile, $28 \%$ were contaminated and 26 percent remained pure and viable cultures. Both of the two vials containing isolates from 2010 still contained viable pure cultures of $V$. dahliae proving that $V$. dahliae can remain viable for up to eight years in refrigerated soil in vials. Of 82 vials containing $V$. nonalfalfae, $37 \%$ were sterile, $16 \%$ were contaminated by other fungi that quickly overgrew the Verticillium colonies present and $48 \%$ remained pure and viable cultures. The oldest vials that produced viable $V$. nonalfalfae colonies were from 2012. 


\section{Efficacy of $V$. nonalfalfae-inoculated soil and rye grain on Ailanthus seedlings in a}

controlled environment

Ailanthus seedlings in a controlled environment suffered mortality from both the inoculated rye grain and inoculated soil plantings. First symptoms of chlorosis occurred in three weeks post inoculation in only the rye grain infected pots. In both treatments, considerable mortality occurred with the inoculated rye grain treatment causing $60 \%$ mortality and the soil causing $40 \%$ mortality in four weeks.

\section{Comparisons among direct and indirect $V$. nonalfalfae inoculations in a newly regenerated forest stand in Pennsylvania}

Animal herbivory and destruction of marked sites prevented statistical analyses of the field applications. However, an incidence of positive or negative wilt could be recorded on saplings in plots not destroyed by animals. Of the only two undisturbed blocks (Block 1 and Block 5), the plots treated with inoculated rye grain, direct inoculations and inoculated soil applications experienced mortality. In Block 1, 50\% of the saplings died in the inoculated rye grain plot, and $38 \%$ in the inoculated soil plot, with $100 \%$ of saplings in the direct inoculation plot experiencing mortality. In Block 5, 40\% of saplings died in the inoculated rye grain plot, and $45 \%$ in the inoculated soil plot, with $100 \%$ of saplings in the direct inoculation plot experiencing mortality. There was no mortality in the control plots in either block. Verticillium nonalfalfae was successfully re-isolated out of symptomatic tissues from Block 1 and Block 5 in two inoculated rye grain plots and two inoculated soil plots. 
The influence of $V$. dahliae on the efficacy of $V$. nonalfalfae inoculations in three hardiness zone groups of Pennsylvania

Plots treated with the water control experienced no mortality. Both of the remaining treatment types killed every tree in the plot and outside of the plot boundaries in some instances. In order to statistically compared the treatments and their interaction with hardiness zone, two separate analyses occurred, one without the water treatment and one with water. When water was included the treatments were statistically significantly different from each other. However, when water was removed from the analysis there was not significant difference between $V$. nonalfalfae alone and the Verticillium mixture when analyzed with a Cochran-Mantel-Haenszel Test (based on live and dead counts as a table of scores) and controlling for hardiness zones. The row means scores differ analysis produced a (Prob 0.3090) with a >95\% confidence.

\section{Comparisons among individual and mixed inoculations of $V$. nonalfalfae and $V$. dahliae on greenhouse Ailanthus}

The results from the greenhouse inoculation showed the $V$. dahliae trees suffered from chlorosis around three weeks post inoculation with no seedlings dying during the three-week duration of the experiment. Only one seedling out of $30 \mathrm{~V}$. dahliae infect seedlings showed symptoms deserving a rating of 3 indicating severe wilt at the end of the experiment. Thirteen of $30 \mathrm{~V}$. dahliae infected trees had symptoms of chlorosis. At the end of the three-week period all trees inoculated with $V$. nonalfalfae were symptomatic. They also showed more rapid onset of disease than compared to the controls and $V$. dahliae. At two weeks three saplings were dead and five more severely wilted. Eighteen additional seedlings died by the third week in the $V$.

nonalfalfae treatment. The remaining four seedlings expressed symptoms of wilt at the end of the experiment. Trees inoculated with both Verticillium species mimicked disease progression of the 
$V$. nonalfalfae inoculated trees. At two weeks post inoculation in the treatment receiving both fungi, six trees had died from severe wilt. At three weeks, an additional 13 had died leaving 11 symptomatic plants in the study. This observation supports the rate of the disease progression of noticed in the field plots. All but one of the controls survived the experiment without any symptoms. The one symptomatic tree likely showed wilt symptoms due to inadequate watering. Plants were harvested at four weeks with onset of serious symptoms so that they could be processed in microtome analysis.

Symptoms progressed at different rates across the three treatments, and the results from the statistical analysis using the Survival Curve Kaplan-Meier Estimates showed that the four treatments were statistically significantly different from each other, with tests between groups Log-rank $\mathrm{p}<0.0001$ and Wilcoxon $\mathrm{p}<0.0001$. The results of this pathogenicity assay indicate that the presence of Verticillium dahliae does not have a statistically significant impact on the efficacy of Verticillium nonalfalfae.

There were no obvious differences between anatomical features, such as tyloses formation, gumming of vessels or presence of fungal tissue in the microtome samples of the vascular tissue analysis. Out of all the 45 microtome samples, there were only ten that showed abnormal structures and their distribution across all treatments negated a specific response to an individual treatment. Of the 10 abnormalities seen on the slides, five consisted of less than two vessels with large masses in the vessel, two consisted of possible hyphae evident in vessels, and three showed a possible gum sealing as a response. The control treatment included five of the 10 abnormalities seen across the entire analysis and these five seedlings featured an example of each of the three described abnormalities (Table 3-5). 


\section{Discussion}

Soil which was inoculated in 2010-2014 still contained viable Verticillium colonies when plated on potato dextrose agar in 2018 . These findings lead to the increasing potential to utilize V. nonalfalfae as a viable and competitive biocontrol method that has a long-lasting shelf life. The longer shelf life of refrigerated inoculated soil might be a better method for maintaining the longer lasting formulation techniques.

Formulation techniques were successful in forested plots and in controlled greenhouse studies. This opens the possibility for more rigorous studies testing formulation techniques. However, the scarification of the soil with the hand trowel to mimic post-timber harvest soils may have induced injury to the already established saplings in the plots allowing for an easy entry point of infection for $V$. nonalfalfae. The question remains unclear if $V$. nonalfalfae inoculated rye grain or soil can inhibit regeneration when used as a preventative measure directly after forestry management tactics or timber harvests. Additionally, the root dip inoculation method also minutely damage roots and raise the same question in the green house experiments. Due to animal predation of the rye grain, it might not be an adequate application method even though it caused a higher incidence of disease than the inoculated soil treatments. In future experiments, treatments enclosed with fencing might enable this process to be adequately applied and monitored.

The interaction of two Verticillium pathogens of Ailanthus did not inhibit the effectiveness of the biocontrol utilizing $V$. nonalfalfae alone. This means a prior screening for $V$. dahliae does not need to occur prior to treatment with $V$. nonalfalfae. Throughout this two-year study, Ailanthus trees died at a similar rate when they were co-inoculated with $V$. nonalfalfae and $V$. dahliae as compared to inoculated with $V$. nonalfalfae alone. Since $V$. dahliae was not 
recovered from the plots treated with the mixture of the two fungi, the potential impact of $V$. dahliae on disease progression is limited and long-term impact to use of the biocontrol is negligible. This allows for sustained control of Ailanthus trees across the landscape regardless of the presence of $V$. dahliae. Considering the broad host range for $V$. dahliae, it's possible that incidence of $V$. dahliae on other crops near $V$. nonalfalfae infected Ailanthus stands drops due to the reduction of Ailanthus reservoir (Woolliams 1966).

Potential non-target effects of increasing the amount of dead and dying Ailanthus trees in the Mid-Atlantic region could impact invasive insect populations. Ailanthus acts as a bridge for in the establishment of invasive insects. The Asiatic shot hole borer (Euwallacea validus Eichhoff) thrives in weakened and dying Ailanthus trees where as it carries and disseminates plant pathogenic Fusarium species which is still poorly understood. The potential for E. validus to infect native trees in Ailanthus stands with this pathogenic symbiont increases as more Ailanthus increase across the landscape (Kasson et al. 2013). Fewer Ailanthus could decrease the population of the new invasive spotted lantern fly (Lycorma delicatula White) which has an affinity for healthy Ailanthus and may even require Ailanthus to complete a life stage as it develops to an adult (Barringer et al. 2015).

\section{Conclusions}

While the interaction of two or more pathogens in some disease complexes may increase or inhibit the virulence of another pathogen, that is not the case with the two pathogenic Verticillium species of Ailanthus. V. nonalfalfae is not inhibited by the presence of $V$. dahliae. This factor increases our confidence in the efficacy of utilizing $V$. nonalfalfae as a biocontrol agent for the invasive tree. Hardiness limitations did not impact $V$. nonalfalfae across the state of Pennsylvania and it's PHZs of 5, 6a, and 6b. 
While direct inoculation methods via hack and squirt have shown to be effective against Ailanthus mature stems, there has not been a successfully method to suppress small diameter Ailanthus regeneration in forested areas. Applying $V$. nonalfalfae inoculated rye grain or inoculated soil formulations could effectively control/kill Ailanthus regeneration from large post timber harvest landscapes. Inoculated soil presents an incredibly viable method for storage of the pathogen which can also be readily applied to suppress regeneration when timber management activities occur. 


\section{Acknowledgements}

I would like to thank the Pennsylvania Department of Conservation and Natural Resources for aiding in site selection, especially Russel Gibbs, Ben Gamble, and Andrew

Rohrbach. Anita Simmons, Ernie Jenkins, and Kirk Hanlon generously offered access and allowed research plots to be established on their properties and I am very thankful for their kindness. Dr. Scott Salom and Rachel Brooks mirrored this project in Virginia hardiness zones for compilation in a publication and the authors appreciate their collaborative efforts. The authors would like to thank the West Virginia University Medical School for providing microtome preparations of samples. Thank you to APHIS for funding this project. 


\section{Tables}

Table 3-1: Long term soil vials containing 33 isolates of $V$. nonalfalfae isolated from Ailanthus created in 2012, and 2013, 2014 and their viability or contamination status after plating on PDA in 2018.

\begin{tabular}{|c|c|c|c|c|c|}
\hline $\begin{array}{l}\text { Soil Vial } \\
\text { ID }\end{array}$ & Isolate Name & Original Location & Replicate Vials & Date Created & Status \\
\hline $\mathrm{N} 36$ & Pike $\mathrm{Co} . \mathrm{OH}$ & Ohio & 1 & 7.24 .2014 & Active \\
\hline N55 & Pike Co.. OH & Ohio & 2 & 7.24 .2014 & Active \\
\hline $\mathrm{N} 25$ & VnAal40 & Pennsyivania & 1 & 7.17 .2012 & Active \\
\hline $\mathrm{N} 73$ & VnAa140 & Pennsyivania & 1 & 7.24 .2014 & Active \\
\hline N59 & VnAa140 & Pennsylvania & 1 & 9.19 .2012 & Active \\
\hline $\mathrm{N} 31$ & VnAa140 & Pennsyivania & 2 & 7.17 .2012 & Sterile \\
\hline N78 & VnAa140 & Pennsylvania & 2 & 9.19 .2012 & Contaminated \\
\hline N69 & VnAa140 & Pennsylvania & 3 & 7.17 .2012 & Active \\
\hline N81 & VnAa140 & Pennsyivania & 3 & 9.19 .2012 & Active \\
\hline N82 & VnAa140 & Pennsylvania & 4 & 7.17 .2012 & Sterile \\
\hline $\mathrm{N} 45$ & VnAa141 & Pennsylvania & 1 & 12.7 .2012 & Active \\
\hline N18 & VnAa142 & Pennsylvania & 1 & 12.7 .2012 & Contaminated \\
\hline N10 & $\mathrm{VnAaOH}_{2}$ & Ohio & 1 & 11.29 .2012 & Contaminated \\
\hline $\mathrm{N} 35$ & $\mathrm{VnAaOH}_{2}$ & Ohio & 2 & 11.29 .2012 & Active \\
\hline $\mathrm{N} 43$ & $\mathrm{VnAAOH}_{1}$ & Ohio & 3 & 11.29 .2012 & Active \\
\hline $\mathrm{N} 64$ & $\mathrm{Vnna}_{2} \mathrm{OH} 2$ & Ohio & 1 & 7.17 .2012 & Contaminated \\
\hline N1 & $\mathrm{VnAAOH}_{3}$ & Ohio & 1 & 11.29 .2012 & Sterile \\
\hline $\mathrm{N} 52$ & $\mathrm{VnAAOH}_{3}$ & Ohio & 2 & 11.29 .2012 & Active \\
\hline N51 & $\mathrm{VnnAaOH}_{4}$ & Ohio & 1 & 11.29 .2012 & Sterile \\
\hline N54 & $\mathrm{Vn} \mathrm{A}_{2} \mathrm{OH} 5$ & Ohio & 1 & 7.17 .2012 & Active \\
\hline $\mathrm{N} 17$ & $\mathrm{VnAaOH} 6$ & Ohio & 1 & 11.29 .2012 & Active \\
\hline $\mathrm{N} 29$ & $\mathrm{VnA}_{4} \mathrm{OH} 6$ & Ohio & 2 & 11.29 .2012 & Sterile \\
\hline $\mathrm{N} 2$ & VnAaPA145 & Pennsylvania & 1 & 9.17 .2013 & Sterile \\
\hline $\mathrm{N} 32$ & VnAaPA145 & Pennsyivania & 2 & 9.17 .2013 & Sterile \\
\hline N57 & VnAaPA145 & Pennsylvania & 3 & 9.17 .2013 & Contaminated \\
\hline $\mathrm{N} 24$ & VnAaPA200 & Pennsyivania & 1 & 8.6 .2013 & Active \\
\hline $\mathrm{N} 28$ & VnAaPA200 & Pennsylvania & 2 & 8.6 .2013 & Active \\
\hline N66 & VnAaPA200 & Pennsylvania & 3 & 8.6 .2013 & Sterile \\
\hline $\mathrm{N} 6$ & VnAaPA201 & Pennsyivania & 1 & 8.6 .2013 & Active \\
\hline $\mathrm{N} 76$ & VnAaPA201 & Pennsylvania & 2 & 8.6 .2013 & Active \\
\hline $\mathrm{N} 49$ & VnAaPA201 & Pennsylvania & 3 & 8.6 .2013 & Active \\
\hline $\mathrm{N} 21$ & VnAaPa202 & Pennsylvania & 1 & 8.6 .2013 & Active \\
\hline $\mathrm{N} 72$ & VnAaPA202 & Pennsyivania & 2 & 8.6 .2013 & Active \\
\hline N62 & VnAaPA202 & Pennsylvania & 3 & 8.6 .2013 & Active \\
\hline N16 & VnAaPA203 & Pennsyivania & 1 & 8.6 .2013 & Active \\
\hline N33 & VnAaPA203 & Pennsyivania & 2 & 8.6 .2013 & Active \\
\hline N74 & VnAaPA203 & Pennsylvania & 3 & 8.6 .2013 & Active \\
\hline N7 & VnAaPA204 & Pennsylvania & 1 & 8.6 .2013 & Active \\
\hline $\mathrm{N} 48$ & VnAaPA204 & Pennsylvania & 2 & 8.6 .2013 & Active \\
\hline N68 & VnAaPA204 & Pennsylvania & 3 & 8.6 .2013 & Active \\
\hline $\mathrm{N} 4$ & VnAaPA205 & Pennsyivania & 1 & 8.6 .2013 & Sterile \\
\hline N37 & VnAaPA205 & Pennsyivania & 2 & 8.6 .2013 & Sterile \\
\hline N77 & VnAaPA205 & Pennsylvania & 3 & 8.6 .2013 & Active \\
\hline $\mathrm{N} 22$ & VnAaPA206 & Pennsylvania & 1 & 8.6 .2013 & Sterile \\
\hline N63 & VnAaPA206 & Pennsylvania & 2 & 8.6 .2013 & Contaminated \\
\hline $\mathrm{N} 23$ & VnAaPA207 & Pennsylvania & 1 & 8.6 .2013 & \begin{tabular}{|c} 
Sterile \\
\end{tabular} \\
\hline $\mathrm{N} 42$ & VnAaPA207 & Pennsylvania & 2 & 8.6 .2013 & Active \\
\hline N5 & VnAaPA208 & Pennsylvania & 1 & 8.23 .2013 & Sterile \\
\hline $\mathrm{N} 46$ & VnAaPA208 & Pennsylvania & 2 & 8.23 .2013 & Contaminated \\
\hline N8 & VnAaPA209 & Pennsylvania & 1 & 8.23 .2013 & Sterile \\
\hline N39 & VnAaPA209 & Pennsyivania & 2 & 8.23 .2013 & Contaminated \\
\hline $\mathrm{N} 47$ & VnAaPA209 & Pennsylvania & 3 & 8.23 .2013 & Sterile \\
\hline N19 & VnAaPA210 & Pennsylvania & 1 & 8.23 .2013 & Sterile \\
\hline N75 & VnAaPA210 & Pennsylvania & 2 & 8.23 .2013 & Contaminated \\
\hline N61 & VnAaPA210 & Pennsylvania & 3 & 8.23 .2013 & Sterile \\
\hline $\mathrm{N} 3$ & VnAaPA211 & Pennsyivania & 1 & 8.23 .2013 & Sterile \\
\hline N50 & VnAaPA211 & Pennsylvania & 2 & 8.23 .2013 & Sterile \\
\hline N65 & VnAaPA211 & Pennsylvania & 3 & 8.23 .2013 & Sterile \\
\hline $\mathrm{N} 26$ & VnAaPA212 & Pennsylvania & 1 & 8.23 .2013 & Sterile \\
\hline $\mathrm{N} 20$ & VnAaPA212 & Pennsylvania & 2 & 8.23 .2013 & Sterile \\
\hline $\mathrm{N} 56$ & VnAaPA212 & Pennsyivania & 3 & 8.23 .2013 & Sterile \\
\hline N15 & VnAaPA213 & Pennsylvania & 1 & 9.16 .2013 & Active \\
\hline N80 & VnAaPA213 & Pennsylvania & 2 & 9.16 .2013 & Active \\
\hline $\mathrm{N} 53$ & VnAaPA213 & Pennsylvania & 3 & 9.16 .2013 & Sterile \\
\hline N14 & VnAaPA214 & Pennsylvania & 1 & 9.16 .2013 & Active \\
\hline $\mathrm{N} 30$ & VnAaPA214 & Pennsyivania & 2 & 9.16 .2013 & Sterile \\
\hline $\mathrm{N} 34$ & VnAaPA214 & Pennsylvania & 3 & 9.16 .2013 & Contaminated \\
\hline $\mathrm{N} 44$ & VnAaPA214 & Pennsylvania & 4 & 9.16 .2013 & Active \\
\hline N11 & VnAaPA215 & Pennsylvania & 1 & 9.16 .2013 & Sterile \\
\hline $\mathrm{N} 27$ & VnAaPA215 & Pennsylvania & 2 & 9.16 .2013 & Sterile \\
\hline N13 & VnAaP,A216 & Pennsyivania & 1 & 9.16 .2013 & Sterile \\
\hline $\mathrm{N} 40$ & VnAaPA216 & Pennsylvania & 2 & 9.16 .2013 & Sterile \\
\hline N67 & VnAaPA216 & Pennsylvania & 3 & 9.16 .2013 & Active \\
\hline N12 & VnAaPA217 & Pennsylvania & 1 & 9.16 .2013 & Contaminated \\
\hline N38 & VnAaPA217 & Pennsylvania & 2 & 9.16 .2013 & \begin{tabular}{|l|} 
Contaminated \\
\end{tabular} \\
\hline $\mathrm{N} 41$ & VnAaPA217 & Pennsylvania & 3 & 9.16 .2013 & Active \\
\hline N9 & VnAaPA218 & Pennsylvania & 1 & 9.16 .2013 & Active \\
\hline N79 & VnAaPA218 & Pennsylvania & 2 & 9.16 .2013 & Contaminated \\
\hline N70 & VnAaPA221 & Pennsylvania & 1 & 9.30 .2013 & Active \\
\hline $\mathrm{N} 60$ & VnAaPA223 & Pennsylvania & 1 & 9.30 .2013 & Sterile \\
\hline N71 & VnAaP.A224 & Pennsylvania & 1 & 10.2 .2014 & Active \\
\hline N58 & Zup-MLD (P)-2 & Chile & 1 & 5.8 .2013 & Active \\
\hline
\end{tabular}


Table 3-2: Long term soil vials containing 19 isolates of $V$. dahliae isolated from Ailanthus created in 2010, 2012, and 2013 and their viability or contamination status after plating on PDA in 2018.

\begin{tabular}{|c|c|c|c|c|c|}
\hline Soil Vial ID & Isolate Name & $\begin{array}{c}\text { Original Location of } \\
\text { Isolation }\end{array}$ & Replicate Vials & Date Created & Status \\
\hline D33 & PSUVd1 & Pennsylvania & 1 & 2.15 .2010 & Active \\
\hline D35 & PSUVd1 & Pennsylvania & 2 & 2.15 .2010 & Active \\
\hline D5 & VdAaMD1 & Maryland & 1 & 5.8 .2013 & Contaminated \\
\hline D3 & VdAaMD1 & Maryland & 1 & 7.17 .2012 & Active \\
\hline D2 & VdAaMD1 & Maryland & 2 & 5.8 .2013 & Active \\
\hline D6 & VdAaMD1 & Maryland & 2 & 7.17 .2012 & Active \\
\hline D1 & VdAaMD1 & Maryland & 3 & 5.8 .2013 & Contaminated \\
\hline D4 & VdAaMD1 & Maryland & 3 & 7.17 .2012 & Active \\
\hline D53 & VdAaOH1 & Ohio & 1 & 9.3 .2013 & Sterile \\
\hline D54 & $\mathrm{VdAaOH1}$ & Ohio & 2 & 9.3 .2013 & Sterile \\
\hline D49 & VdAaOH1 & Ohio & 3 & 9.3 .2013 & Active \\
\hline D51 & $\mathrm{VdAaOH} 2$ & Ohio & 1 & 9.3 .2013 & Contaminated \\
\hline D52 & $\mathrm{VdAaOH} 2$ & Ohio & 2 & 9.3 .2013 & Contaminated \\
\hline D48 & $\mathrm{VdAaOH} 2$ & Ohio & 3 & 9.3 .2013 & Contaminated \\
\hline D38 & $\mathrm{VdAaOH} 3$ & Ohio & 1 & 9.3.2013 & Sterile \\
\hline D58 & $\mathrm{VdAaOH} 3$ & Ohio & 2 & 9.3 .2013 & Contaminated \\
\hline D36 & $\mathrm{VdAaOH} 3$ & Ohio & 3 & 9.3.2013 & Sterile \\
\hline D24 & VdAaOH4 & Ohio & 1 & 9.3.2013 & Active \\
\hline D50 & VdAaOH4 & Ohio & 2 & 9.3 .2013 & Sterile \\
\hline D47 & VdAaOH4 & Ohio & 3 & 9.3 .2013 & Sterile \\
\hline D39 & VdAaOH5 & Ohio & 1 & 9.3 .2013 & Active \\
\hline D56 & $\mathrm{VdAaOH5}$ & Ohio & 2 & 9.3 .2013 & Active \\
\hline D42 & VdAaOH5 & Ohio & 3 & 9.3 .2013 & Sterile \\
\hline D57 & VdAaOH6 & Ohio & 1 & 9.3 .2013 & Sterile \\
\hline D45 & $\mathrm{VdAaOH6}$ & Ohio & 2 & 9.3 .2013 & Contaminated \\
\hline D55 & VdAaOH6 & Ohio & 3 & 9.3.2013 & Sterile \\
\hline D37 & VdAaOH8 & Ohio & 1 & 9.16 .2013 & Active \\
\hline D44 & VdAaOH8 & Ohio & 2 & 9.16 .2013 & Contaminated \\
\hline D43 & VdAaOH8 & Ohio & 3 & 9.16 .2013 & Contaminated \\
\hline $\mathrm{D} 46$ & $\mathrm{VdAaOH} 9$ & Ohio & 1 & 9.3.2013 & Active \\
\hline D41 & VdAaOH9 & Ohio & 2 & 9.3.2013 & Active \\
\hline $\mathrm{D} 40$ & VdAaOH9 & Ohio & 3 & 9.3 .2013 & Active \\
\hline D16 & VdAaPA200 & Pennsylvania & 1 & 8.6.2013 & Sterile \\
\hline D30 & VdAaPA200 & Pennsylvania & 2 & 8.6.2013 & Contaminated \\
\hline D10 & VdAaPA200 & Pennsylvania & 3 & 8.6.2013 & Active \\
\hline D31 & VdAaPA201 & Pennsylvania & 1 & 8.6 .2013 & Active \\
\hline D13 & VdAaPA201 & Pennsylvania & 2 & 8.6.2013 & Active \\
\hline D29 & VdAaPA201 & Pennsylvania & 3 & 8.6 .2013 & Contaminated \\
\hline D28 & VdAaPA202 & Pennsylvania & 1 & 8.6 .2013 & Contaminated \\
\hline D19 & $\mathrm{VdAaPA} 202$ & Pennsylvania & 2 & 8.6 .2013 & Active \\
\hline D21 & VdAaPA202 & Pennsylvania & 3 & 8.6.2013 & Contaminated \\
\hline D12 & VdAaPA203 & Pennsylvania & 1 & 8.6.2013 & Sterile \\
\hline D18 & VdAaPA203 & Pennsylvania & 2 & 8.6 .2013 & Sterile \\
\hline D26 & VdAaPA203 & Pennsylvania & 3 & 8.6.2013 & Sterile \\
\hline D32 & VdAaPA204 & Pennsylvania & 1 & 8.6.2013 & Active \\
\hline D20 & VdAaPA204 & Pennsylvania & 2 & 8.6.2013 & Sterile \\
\hline D11 & VdAaPA205 & Pennsylvania & 1 & 8.6 .2013 & Contaminated \\
\hline D7 & $\mathrm{VdAaPa} 205$ & Pennsylvania & 2 & 8.6 .2013 & Active \\
\hline $\mathrm{D} 25$ & $\mathrm{VdAaPa} 205$ & Pennsylvania & 3 & 8.6.2013 & Sterile \\
\hline D17 & $\mathrm{VdAaPa} 206$ & Pennsylvania & 1 & 8.23 .2013 & Contaminated \\
\hline D34 & VdAaPa206 & Pennsylvania & 2 & 8.23 .2013 & Sterile \\
\hline $\mathrm{D} 23$ & VdAaPa206 & Pennsylvania & 3 & 8.23 .2013 & Sterile \\
\hline D14 & VdAaPA207 & Pennsylvania & 1 & 8.6 .2013 & Active \\
\hline D15 & VdAaPa207 & Pennsylvania & 2 & 8.6.2013 & Sterile \\
\hline D8 & VdAaPA207 & Pennsylvania & 3 & 8.6.2013 & Sterile \\
\hline D27 & VdAaPA208 & Pennsylvania & 1 & 8.6.2013 & Contaminated \\
\hline D22 & VdAaPa208 & Pennsylvania & 2 & 8.6 .2013 & Sterile \\
\hline D9 & VdAaPA208 & Pennsylvania & 3 & 8.6 .2013 & Sterile \\
\hline
\end{tabular}


Table 3-3: Field Site and Plot details which were inoculated with either $V$. nonalfalfae, both $V$. dahliae and V. nonalfalfae (Mix), or Water Control in the Spring of 2017

\begin{tabular}{|c|c|c|c|c|c|}
\hline Site Name & Plot ID & Hardiness Zone & Treatment Type & $\begin{array}{c}\text { Count of } \\
\text { Ailanthus } \\
\text { Stems in plot }\end{array}$ & Average dbh (in) \\
\hline Washington Park & 1 & 5 & V. nonalfalfae & 69 & 2.8 \\
\hline Washington Park & 2 & 5 & Mix & 17 & 2.7 \\
\hline Kennerdell & 1 & 5 & Mix & 40 & 4.3 \\
\hline Kirk Property & 1 & $6 a$ & V. nonalfalfae & 35 & 5 \\
\hline Kirk Property & 2 & $6 a$ & Mix & 32 & 4.3 \\
\hline Kirk Property & 3 & $6 a$ & Water Control & 11 & 4 \\
\hline Gallitzin State Forest & 1 & $6 \mathrm{a}$ & Water Control & 17 & 10.2 \\
\hline Gallitzin State Forest & 2 & $6 a$ & $V$. nonalfalfae & 56 & 4.1 \\
\hline Gallitzin State Forest & 3 & $6 \mathrm{a}$ & Mix & 34 & 5.7 \\
\hline Gallitzin State Forest & 4 & $6 a$ & Mix & 38 & 3.8 \\
\hline Ernie Property & 1 & $6 \mathrm{~b}$ & V. nonalfalfae & 48 & 5.2 \\
\hline Ernie Property & 2 & $6 \mathrm{~b}$ & Water Control & 15 & 5.9 \\
\hline Ernie Property & 3 & $6 \mathrm{~b}$ & Mix & 34 & 5.6 \\
\hline Tiadaghton State Forest & 1 & $6 b$ & Mix & 90 & 2.4 \\
\hline Tiadaghton State Forest & 2 & $6 b$ & V. nonalfalfae & 69 & 2.9 \\
\hline Tiadaghton State Forest & 3 & $6 \mathrm{~b}$ & Mix & 45 & 3.3 \\
\hline Tiadaghton State Forest & 4 & $6 \mathrm{~b}$ & Water Control & 88 & 1.4 \\
\hline Anita Property & 1 & $6 \mathrm{~b}$ & Mix & 25 & 3.6 \\
\hline Lebanon Valley College & 1 & $6 \mathrm{~b}$ & Mix & 29 & 6.2 \\
\hline Lebanon Valley College & 2 & $6 \mathrm{~b}$ & V. nonalfalfae & 43 & 6.1 \\
\hline Lebanon Valley College & 3 & $6 \mathrm{~b}$ & Mix & 39 & 4.5 \\
\hline Lebanon Valley College & 4 & $6 \mathrm{~b}$ & Water Control & 6 & 12 \\
\hline Lebanon Valley College & 5 & $6 \mathrm{~b}$ & Mix & 43 & 3.8 \\
\hline
\end{tabular}


Table 3-4: Treatment details and mortality rates for plots which were treated with preliminary approach methods of $V$. nonalfalfae formulation techniques to control Ailanthus regeneration in a timber harvested forest.

\begin{tabular}{|c|c|c|c|c|}
\hline Block & Plot & Treatment & $\begin{array}{c}\text { Total Healthy } \\
\text { Ailanthus } \\
\text { Saplings in plot } \\
\text { May 2018 }\end{array}$ & $\begin{array}{c}\text { Dead } \\
\text { Ailanthus } \\
\text { stems in plot } \\
\text { August 2018 }\end{array}$ \\
\hline 1 & 1 & Inoculated Rye Grain & 14 & 7 \\
\hline 1 & 2 & Sterile Rye Grain & 10 & - \\
\hline 1 & 3 & Inoculated Soil & 8 & 3 \\
\hline 1 & 4 & Sterile Soil & 21 & - \\
\hline 1 & 5 & Direct Stem inoculation & 8 & 8 \\
\hline 1 & 6 & Conidial Spray & 26 & 0 \\
\hline 1 & 7 & Sterie Water Spray & 7 & 0 \\
\hline 1 & 8 & Control - No Treatment & 9 & - \\
\hline 5 & 1 & Inoculated Rye Grain & 5 & 2 \\
\hline 5 & 2 & Sterile Rye Grain & 10 & 0 \\
\hline 5 & 3 & Inoculated Soil & 11 & 5 \\
\hline 5 & 4 & Sterile Soil & 16 & 0 \\
\hline 5 & 5 & Direct Stem inoculation & 11 & 11 \\
\hline 5 & 6 & Conidial Spray & 11 & 0 \\
\hline 5 & 7 & Sterie Water Spray & 12 & 0 \\
\hline 5 & 8 & Control - No Treatment & 8 & 0 \\
\hline
\end{tabular}


Table 3-5: Abnormalities observed in vessels of Ailanthus seedling stems infected with water, $V$. nonalfalfae, $V$. dahliae, and both fungi in a root dip inoculation experiment visualized in a microtome analysis. (-) denotes nothing abnormal noticed in any vessels of entire cross section.

\begin{tabular}{|c|c|c|}
\hline Treatment & Sapling ID & Abnormalities \\
\hline Control & $\mathrm{C} 1$ & 2 Vessels With Large Masses \\
\hline Control & $\mathrm{C} 10$ & 2 Vessels With Large Masses \\
\hline Control & $\mathrm{C} 11$ & - \\
\hline Control & $\mathrm{C} 14$ & 2 Vessels With Large Masses \\
\hline Control & $\mathrm{C} 21$ & - \\
\hline Control & $\mathrm{C} 26$ & - \\
\hline Control & $\mathrm{C} 28$ & Possible Hyphae \\
\hline Control & $\mathrm{C} 29$ & - \\
\hline Control & $\mathrm{C} 3$ & - \\
\hline Control & $\mathrm{C} 30$ & Completely Sealed Gum \\
\hline V. nonalfalfae & $\mathrm{N} 1$ & 1 Vessel With Large Mass \\
\hline V. nonalfalfae & N11 & - \\
\hline V. nonalfalfae & N17 & Possible Hyphae \\
\hline V. nonalfalfae & $\mathrm{N} 20$ & - \\
\hline V. nonalfalfae & $\mathrm{N} 21$ & - \\
\hline V. nonalfalfae & $\mathrm{N} 26$ & - \\
\hline V. nonalfalfae & $\mathrm{N} 29$ & - \\
\hline V. nonalfalfae & $\mathrm{N} 3$ & - \\
\hline V. nonalfalfae & $\mathrm{N} 30$ & - \\
\hline V. nonalfalfae & N9 & - \\
\hline V. dahliae & D1 & - \\
\hline V. dahliae & D13 & - \\
\hline V. dahliae & D16 & - \\
\hline V. dahliae & D17 & - \\
\hline V. dahliae & D18 & - \\
\hline V. dahliae & D25 & - \\
\hline V. dahliae & D26 & - \\
\hline V. dahliae & D27 & - \\
\hline V. dahliae & D30 & - \\
\hline V. dahliae & D5 & - \\
\hline Both Fungi & B1 & - \\
\hline Both Fungi & B11 & 2 Vessels With Large Masses \\
\hline Both Fungi & $\mathrm{B} 13$ & - \\
\hline Both Fungi & B15 & - \\
\hline Both Fungi & $\mathrm{B} 17$ & - \\
\hline Both Fungi & B18 & - \\
\hline Both Fungi & $\mathrm{B} 21$ & - \\
\hline Both Fungi & B25 & - \\
\hline Both Fungi & B26 & Completely Sealed Gum \\
\hline Both Fungi & B28 & - \\
\hline Both Fungi & B29 & - \\
\hline Both Fungi & B3 & - \\
\hline Both Fungi & B4 & Completely Sealed Gum \\
\hline Both Fungi & B5 & - \\
\hline Both Fungi & B6 & - \\
\hline
\end{tabular}




\section{Figures}

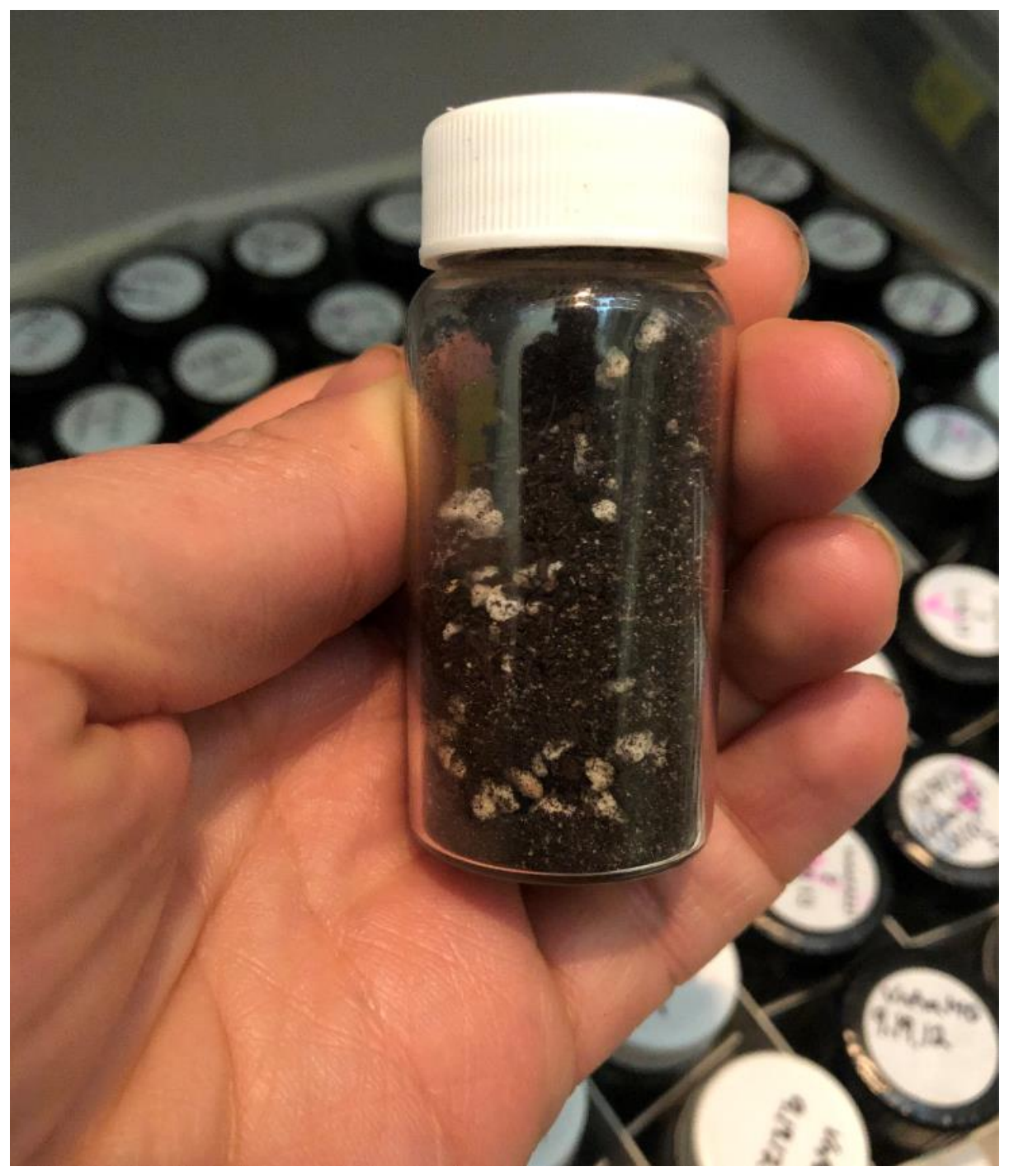

Figure 3-1: Ten-ml scintillation vials containing a 1:1:1 sterile mix of potting soil/sand/ perlite were flooded with conidia harvested from 4-week-old cultures of either Verticillium dahliae or $V$. nonalfalfae and stored at $4^{\circ} \mathrm{C}$ for 3-8 years. 

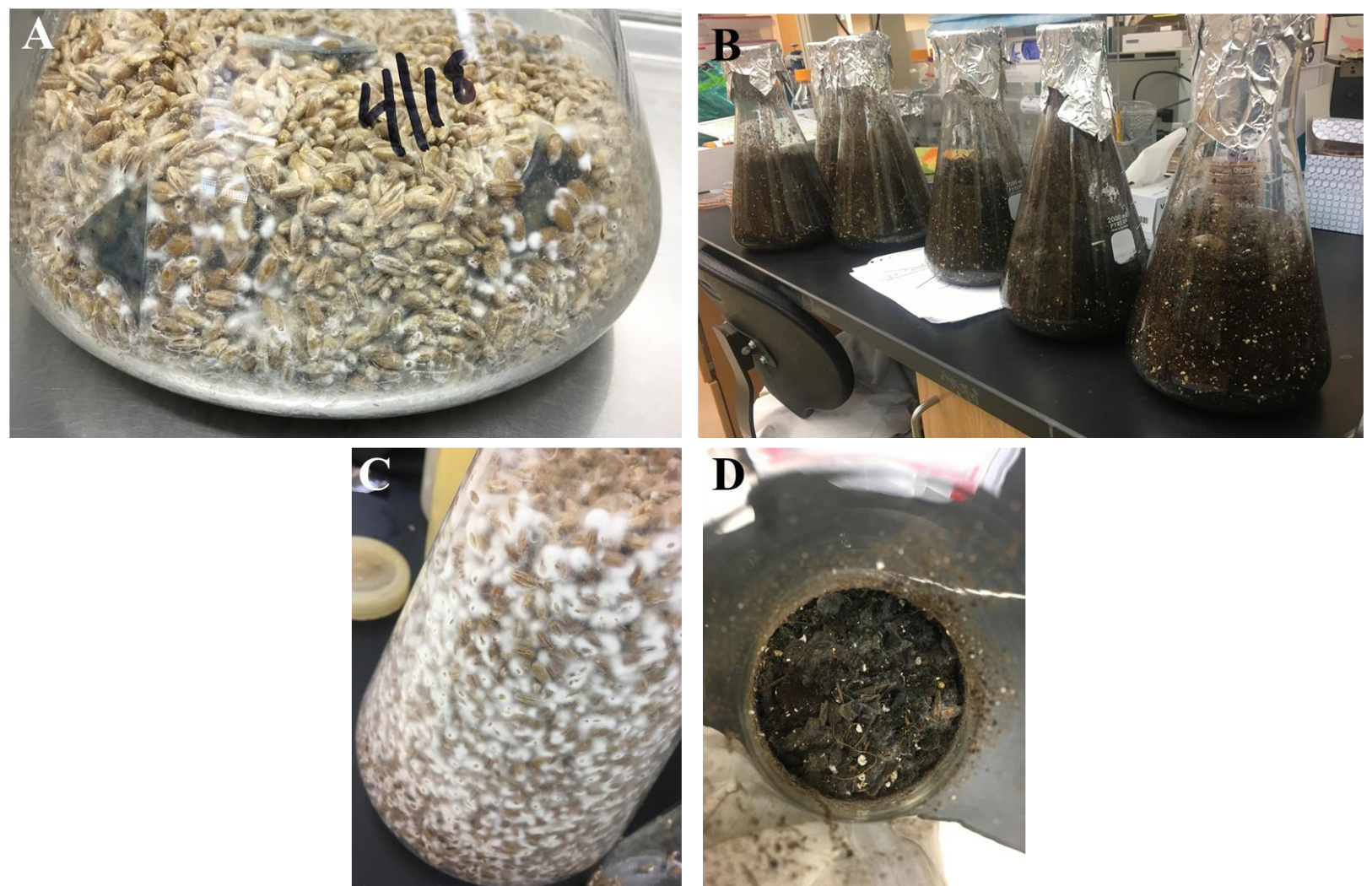

Figure 3-2: Inoculated rye grain and inoculated soil used for formulation experiments. (A) Inoculation of rye grain with sections of $V$. nonalfalfae colonized agar, (B) Sterile potting soil inoculated with $V$. nonalfalfae conidial suspension, (C) After two weeks, rye grain was fully colonized by $V$. nonalfalfae (D) $V$. nonalfalfae colonized soil showing hyphae on top of soil aggregates. 

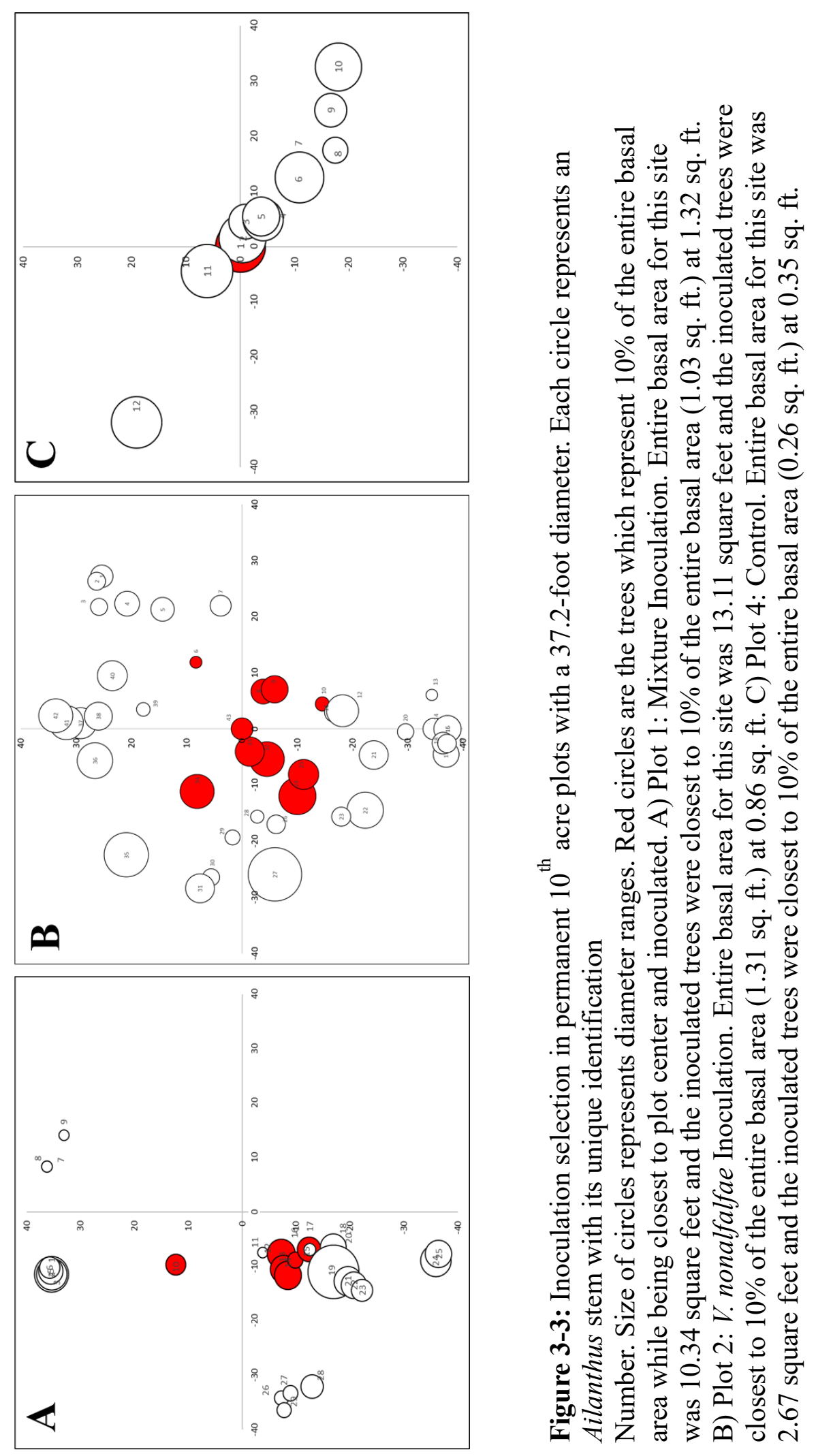


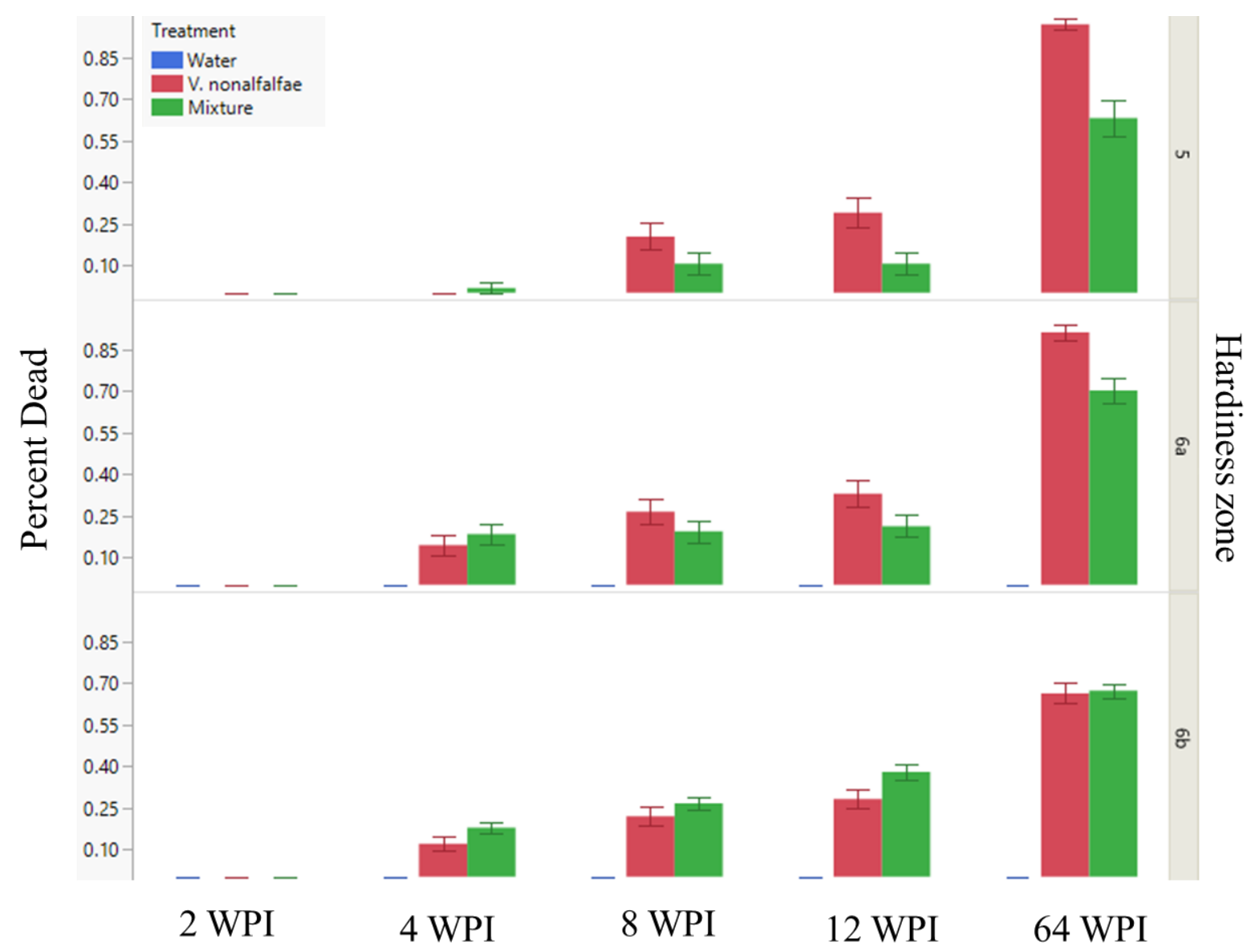

Figure 3-4: Mortality of Ailanthus trees in three plant hardiness zone groups and three treatments ( $V$. nonalfalfae, mixture of $V$. nonalfalfae and $V$. dahliae and Water Control). Treatments were found to be statistically significant when analyzed with a Cochran-MantelHaenszel Test ( $p$ value - 0.000). However, with the same test and the removal of the Water Control, there was no statistically significant difference between the $V$. nonalfalfae and the Mixture treatments ( $\mathrm{p}$ value 0.3090). 

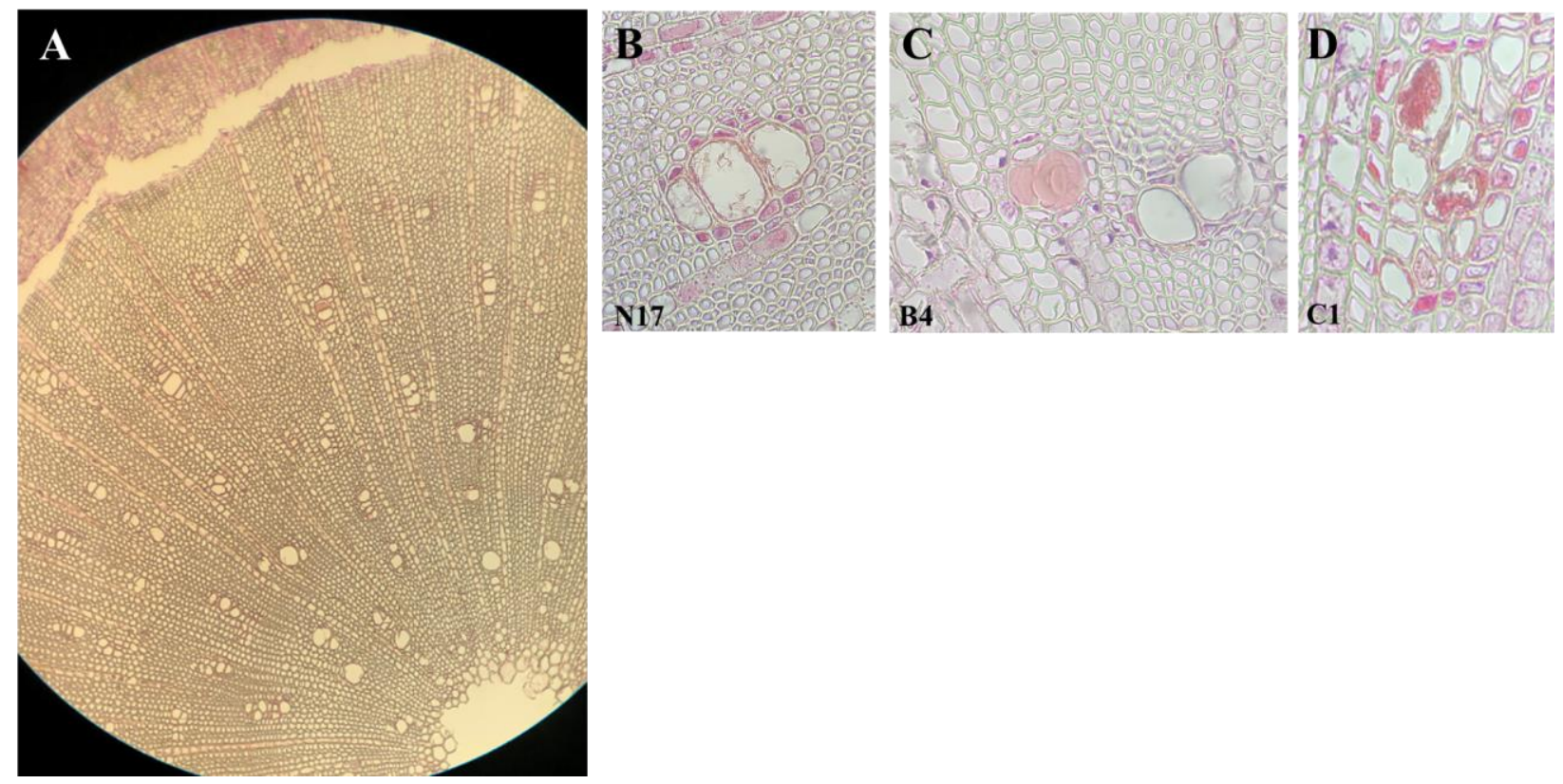

Figure 3-5: Examples from microtome sections of Ailanthus seedlings infected with different Verticillium species. (A) An example of most of the microtome samples being free of any abnormalities in the vessels. (B) seedling treated with Verticillium nonalfalfae showing abnormal segments in vessels resembling fungal hyphae (seedling N17), (C) A completely gummed vessel in a seedling treated with both fungi (seedling B4), (D) Abnormal grouping of live cells clogging vessels in a control seedling (seedling C1). 


\section{References}

Bhat, R. G., \& Subbarao, K. V. (1999). Host range specificity in Verticillium dahliae. Phytopathology, 89(12), 1218-1225.

Barringer, L. E., Donovall, L. R., Spichiger, S. E., Lynch, D., \& Henry, D. (2015). The first new world record of Lycorma delicatula (Insecta: Hemiptera: Fulgoridae). Entomological News, 125(1), 20-24.

Corn, M. L. (1999). Harmful non-native species. Congressional Research Service, Library of Congress.

Coventry, E., Noble, R., Mead, A., Marin, F. R., Perez, J. A., \& Whipps, J. M. (2006). Allium white rot suppression with composts and Trichoderma viride in relation to sclerotia viability. Phytopathology, 96(9), 1009-1020.

Elad, Y., Chet, I., \& Katan, J. (1980). Trichoderma harzianum: A biocontrol agent effective against Sclerotium rolfsii and Rhizoctonia solani. Phytopathology, 70(2), 119-121.

Garbaye, J. (1991). Biological interactions in the mycorrhizosphere. Experientia, 47(4), 370-375.

Hasan, S., Delfosse, E. S., Aracil, E., \& Lewis, R. C. (1992). Host-specificity of Uromyces heliotropii, a fungal agent for the biological control of common heliotrope (Heliotropium europaeum) in Australia. Annuals of Applied Biology, 121(3), 697-705.

Inderbitzin, P., Bostock, R. M., Davis, R. M., Usami, T., Platt, H. W., \& Subbarao, K. V. (2011). Phylogenetics and taxonomy of the fungal vascular wilt pathogen Verticillium, with the descriptions of five new species. PloS One, 6(12), e28341.

Inderbitzin, P., Davis, R. M., Bostock, R. M., \& Subbarao, K. V. (2011). The ascomycete Verticillium longisporum is a hybrid and a plant pathogen with an expanded host range. PloS One, 6(3), e18260.

Inderbitzin, P., Davis, R. M., Bostock, R. M., \& Subbarao, K. V. (2013). Identification and differentiation of Verticillium species and V. longisporum lineages by simplex and multiplex PCR assays. PLoS One, 8(6), e65990.

Kasson, M. T. (2012). Verticillium nonalfalfae: A potential biological control of the invasive Ailanthus in Pennsylvania. A dissertation in Plant Pathology, The Pennsylvania State University.

Kasson, M. T., O’Neal, E. S., \& Davis, D. D. (2015). Expanded host range testing for Verticillium nonalfalfae: potential biocontrol agent against the invasive Ailanthus altissima. Plant Disease, 99(6), 823-835.

Kasson, M. T., Short, D. P. G., O'Neal, E. S., Subbarao, K. V., \& Davis, D. D. (2014). Comparative pathogenicity, biocontrol efficacy, and multilocus sequence typing of Verticillium nonalfalfae from the invasive Ailanthus altissima and other hosts. Phytopathology, 104(3), 282292. 
Kogan, M. (1998). Integrated pest management: historical perspectives and contemporary developments. Annual Review of Entomology, 43(1), 243-270.

Lake, E. C., Hough-Goldstein, J., Shropshire, K. J., \& D’Amico, V. (2011). Establishment and dispersal of the biological control weevil Rhinoncomimus latipes on mile-a-minute weed, Persicaria perfoliata. Biological Control, 58(3), 294-301.

Malcolm, G. M., Kuldau, G. A., Gugino, B. K., \& Jiménez-Gasco, M. D. M. (2013). Hidden host plant associations of soilborne fungal pathogens: an ecological perspective. Phytopathology, 103(6), 538-544.

McNabb, H. S. Jr., Heybroek, H. M., \& MacDonald, W. L. (1970). Anatomical factors in resistance to Dutch elm disease. Netherlands Journal of Plant Pathology, (76)3, 196-205.

Morris, M. J. (1997). Impact of the Gall-Forming Rust Fungus Uromycladium tepperianumon the Invasive Tree Acacia saligna in South Africa. Biological Control, 10(2), 75-82.

O’Neal, E. S., \& Davis, D. D. (2015). Intraspecific root grafts and clonal growth within Ailanthus stands influence Verticillium nonalfalfae transmission. Plant Disease, (99)8, 10701077.

O'Neal, E. S., \& Davis, D. D. (2015). Biocontrol of Ailanthus altissima: inoculation protocol and risk assessment for Verticillium nonalfalfae (Plectosphaerellaceae: Phyllachorales). Biocontrol Science and Technology, (25)8, 950-969.

Pegg, G. F., \& Brady, B. L. (2002). Verticillium wilts. CABI.

Pimentel, D., Zuniga, R., \& Morrison, D. (2005). Update on the environmental and economic costs associated with alien-invasive species in the United States. Ecological Economics, 52(3), 273-288.

Powell, N. T. (1971). Interaction of plant parasitic nematodes with other disease-causing agents. In B. M. Zuckerman, W. F. Mai, \& R. A. Rohde, (Eds.), Plant Parasitic Nematodes (119-136).

Rebbeck, J., Malone, M. A., Short, D. P. G., Kasson, M. T., O'Neal, E. S., \& Davis, D. D. (2013). First report of Verticillium wilt caused by Verticillium nonalfalfae on tree-of-heaven (Ailanthus altissima) in Ohio. Plant Disease, 97(7): 999-999.

Schall, M. J. (2008). Verticillium wilt of Ailanthus altissima (Doctoral dissertation). Retrieved from ProQuest. (3346370).

Schall, M. J., \& Davis, D. D. (2009). Ailanthus altissima wilt and mortality: etiology. Plant Disease, 93(7), 747-751.

Scheffer, R. J., Voeten, J. G. W. F., \& Guries, R. P. (2008). Biological control of Dutch elm disease. Plant Disease, 92(2), 192-200.

Snyder, A. L., Kasson, M. T., Salom, S. M., Davis, D. D., Griffin, G. J., \& Kok, L. T. (2013).

First report of Verticillium wilt of Ailanthus altissima in Virginia caused by Verticillium nonalfalfae. Plant Disease, 97(6), 837-837. 
Van Driesche, R., \& Hoddle, M. (2009). Control of pests and weeds by natural enemies: an introduction to biological control. John Wiley \& Sons.

Woolliams, G. E. (1966). Host range and symptomatology of Verticillium dahliae in economic, weed, and native plants in interior British Columbia. Canadian Journal of Plant Science, 46(6), 661-669. 


\title{
Chapter 4
}

\section{Iron Hyperaccumulation in Ailanthus altissima Confers Tolerance to the Vascular Wilt}

\author{
Pathogen Verticillium nonalfalfae at a Reclaimed Surface Mine in Ohio
}

\begin{abstract}
Reclaimed surface mines are infamous for heavy metal accumulation in the soil; elevated metal concentrations can persist for decades after mining operations have ceased. Plants which grow in these mine areas can readily uptake toxic metals such as zinc, aluminum and iron. Many sensitive native species die from the toxicity on the landscape while some tolerant hardy invasive species that can withstand the toxic bioaccumulation increase in density. In 2015, the exotic and invasive species tree-of-heaven (Ailanthus altissima) was well established on a reclaimed strip mine in southeast Ohio. To eradicate the invasive tree, USFS representatives inoculated the trees with a pathogenic fungus, Verticillium nonalfalfae. After three years, many of the trees had not been killed by the normally very aggressive biocontrol candidate. This contrasted the normal average 2-5-month rate of mortality seen in Ailanthus trees inoculated with $V$. nonalfalfae in previous research studies. Tree cores were taken from Ailanthus trees at the reclaimed strip mine and a distinct abnormal tree growth pattern was noticed with tight compressed annual growth rings. Metal analysis using a Bruker Tracer XRF captured high fluorescence levels of iron in tree cores from the mine site when compared to cores taken from Ailanthus growing at the West Virginia University organic farm, which does not have a history of strip mining. Plating of $V$. nonalfalfae on chelated iron supplemented agar plates showed a reduction in conidia produced by the fungus but no impact to hyphal growth. Greenhouse experiments where Ailanthus seedlings were planted in highly iron-inundated soils exhibited a longer asymptomatic period prior to infection than seedlings grown in soil not supplemented with iron. This study suggests that there is acquired environmental tolerance of Ailanthus to $V$. nonalfalfae when trees are grown in soils with high levels of readily available iron like those at reclaimed strip mines.
\end{abstract}




\section{Introduction}

Tree-of-heaven (Ailanthus altissima (Mill.) Swingle) was introduced to the United States in 1784 in Philadelphia, PA and since then it has spread to most of the conterminous U.S. states (Aldrich et al. 2010, Kasson et al. 2013). Its ability to thrive in poor soils and quickly establish in disturbed areas contributes to its invasiveness, which have made it one of the most recognized and problematic non-native tree species in both the U.S. and Europe (Kowarik and Säumel 2007, Wickert et al. 2017). Given a nearly 235 -year residency in the eastern U.S., Ailanthus is firmly entrenched throughout the Mid-Atlantic region where it can be found in high numbers invading recently cut forest land (Kasson et al. 2013), abandoned urban and rural properties (Illick and Brouse 1926), along transportation corridors (McAvoy et al. 2012), and adjacent to disturbed forest edges or agricultural farms (Illick and Brouse 1926). Due to its ability to grow in nutrient poor soils, Ailanthus also has been observed colonizing and dominating highly degraded environments, such as brownfield sites (Brusa and Holzapfel 2018) and reclaimed mine lands (Miller 1990, Plass 1975, Peugh et al. 2013).

Ailanthus has long been known for its ability to readily establish on reclaimed mine sites, especially ones with acidic soils, which have low to moderate phosphorus (Plass 1975, Ranieri et al. 2016). Similar to its resilience in polluted urban environments, this presents significant management challenges in that Ailanthus thrives when no other plants will grow, yet despised when it outcompetes and/or hinders native plant succession. This, in turn, presents significant challenges for restoring native habitats without significant inputs such as herbicide treatments (Peugh et al. 2013).

In 2012, a vascular wilt disease caused by the native fungus $V$. nonalfalfae was found in Pike County, Ohio causing mortality to Ailanthus in a forest setting (Rebbeck et al. 2013). This 
followed similar discoveries of this same fungus killing Ailanthus across Virginia (Synder et al. 2013) and in two separate locations in Pennsylvania (Shall and Davis 2009, Kasson et al. 2014). Since then, $V$. nonalfalfae has been used effectively as a targeted biocontrol of Ailanthus in Pennsylvania, Virginia, and Ohio (Kasson et al. 2015, O'Neal and Davis 2015, Snyder et al. 2014) and more recently in Europe (Maschek and Halmschlager 2016, Maschek and Halmschlager 2017, Maschek and Halmschlager 2018).

In 2015, the USDA Forest Service established Verticillium wilt research plots at the WILDS wildlife conservation center, a former reclaimed mine site, near Cumberland, Ohio and inoculated Ailanthus trees with the pathogenic Ohio isolate of $V$. nonalfalfae. However, after three years, many of the Ailanthus trees had not been killed. Thirty percent of inoculated Ailanthus trees at the WILDS were susceptible and succumbed within the expected 2-5-month window seen in previous studies. Seventy percent of inoculated Ailanthus trees showed intolerance to infection through only expressing minor symptoms of wilt that either progressed slowly over the years until the tree experienced mortality or, recovered to pre-inoculation status with a full canopy free of wilt symptoms. Because most of the vetted Verticillium wilt of Ailanthus studies had been conducted on forested lands that had never been mined, questions were raised as to the role this site and possibly the heavy metals contained therein played in impacting the efficacy of $V$. nonalfalfae as a biocontrol fungus. The idea of genetic resistance was quickly discounted because some of the trees in direct proximity to susceptible trees did exhibit susceptibility.

In Ailanthus, adverse physiological and morphological effects that impact growth due to the heavy metal contamination/ accumulation such as chlorosis or growth stunting have been previously reported (Đunisijević-Bojović et al. 2012, Prasad 2013). The effects of metal 
contamination on fungi have been known for centuries, including the use of arsenic and copper sulfate to treat molded cereal grains and leaf mildews (Bååth 1989). In recent decades, iron, a heavy metal soil contaminant common in reclaimed mine sites in the region (Chibuike and Obiora 2014), has been used in spray/drench formulations to prevent infection from Verticillium species residing in the soil (Barash et al. 1988, Sahu et al. 1987, Goldweber 1975). It remains unclear if iron is simply increasing plant vigor or inhibiting function in the pathogen (Macur et al. 1991, Guerra and Anderson 1985). Conversely, other fungal diseases such as Cylindrocarpon destructans Zinssm. root rot in ginseng, iron enhances disease through enhanced pathogen growth, sporulation, and PPO enzyme activity (Rahman and Punja 2006). Iron deficiencies in the soil have been shown to increase plant defense responses and confers resistance to Dickeya dadantii Samson and Botrytis cinerea Pers. (Kieu et al. 2012).

This study elucidates the putative tolerance of Ailanthus to $V$. nonalfalfae in a reclaimed surface mine in Ohio. The objectives were: i) to evaluate the outward and radial growth response of putatively tolerant Ailanthus to a second field inoculation of V. nonalfalfae; ii) to determine the role, if any, of various heavy metals common in reclaimed mine sites in contributing to putative field tolerance; and iii) experimentally observe the interactions between candidate heavy metals and disease development in seedlings in a controlled environment setting.

\section{Materials and methods}

\section{Study Area}

The WILDS is a private, non-profit wildlife conservation center which stands on 4047 acres of reclaimed mine land. The property was initially surface mined for coal from the 1940's to the 1980's. Under the Surface Mining Control and Reclamation Act of 1977 (SMCRA) the property was contoured, topsoil was added, and erosion control plantings were implemented in 
the early 1980s. Since that time, various native habitat restoration projects have been conducted on the WILDS property (Hiremath et al. 2013, Peugh et al. 2013). However, hardy invasive plant species, such as autumn olive (Elaeagnus umbellata Thunb.) and tree-of-heaven, spontaneously invaded these sites and impeded efforts to restore native plant communities (Byrd et al. 2012, Cavender et al. 2014). The age of most of the overstory Ailanthus coincide with reclamation efforts dating back to the late 1980s.

The native tree species found at the WILDS are primarily white ash (Fraxinus americana L.), slippery elm (Ulmus rubra Muhl.), and red maple (Acer rubrum L.), with a varied understory ranging from open to dense cover of native spicebush (Lindera benzoin Thunb.) to invasive multiflora rose (Rosa multiflora Thunb.) and black raspberry (Rubus occidentalis L.) (Peugh et al. 2013). The most invasive plants at the WILDS include smooth brome (Bromus inermis Leyss.), Chinese bush clover (Lespedeza cuneate (Dum.Cours.) G. Don), Kentucky blue-grass (Poa pratensis L.), tall fescue (Festuca arundinacea Schreb.). Autumn olive and Ailanthus are among the top woody invaders on the property (Cavender et al. 2014).

\section{Two-year evaluation of outward symptoms and radial growth responses following artificial inoculation with $V$. nonalfalfae strain VnOH1}

To assess disease progression following a single spring inoculation, Ailanthus trees inoculated in 2015 with $V$. nonalfalfae strain $\mathrm{VnOH} 1$ were rated annually through the end of the 2017 growing season to assess health status. Susceptibility ratings were based off a previous 0-8 ordinal rating system developed by O'Neal and Davis (2015): 0-healthy foliage, 1-chlorosis and/or necrotic margins on leaves, 2-slight wilt (<15\% wilting foliage) with no or slight defoliation $(<15 \%)$, 3-moderate wilt (15 to $<50 \%$ wilting foliage with no or slight defoliation (<15\%), 4-severe wilt (50 to $100 \%$ wilting foliage with no or slight defoliation $(<15 \%)$, 5 - 
moderate defoliation (15 to $<50 \%$ ), 6-severe defoliation (50 to 90\%), 7-very severe defoliation (90 to $100 \%$ ) with epicormic sprouting, 8-dead.

To further assess the internal impact of $V$. nonalfalfae inoculations on tree health, 23 tree cores were excised from Ailanthus trees spanning the previously defined rating categories. Health status at time of coring was based on the 2017 end of year rating since trees were dormant in March 2018 at time of core extraction. Cores were extracted at DBH (diameter at breast height) with the use of a Haglöf 18" 2-thread 12mm increment borer (Haglof Inc., Madison, MS, USA) in May of 2018. Since it was suspected that the land-use history could be contributing to disease progression and radial growth response, additional Ailanthus trees were cored at the West Virginia University Organic Farm, to act as controls. The WVU Organic Farm has largely been managed as farm or forest lands for over 100 years (Nesius 1988).

Extracted cores were air-dried inside straws for 3-7 days, glued into routed wooden blocks and taped to secure cores for additional drying. Following removal of tape, cores were sanded with 220- and 320-grit paper with an orbital sander. Once sanded, cores were observed under a dissecting scope to observe radial growth and vessel occlusion patterns as well as sap wood characteristics. Photos were taken to permit comparisons between the WILDS and control cores. Tree-level factors including age, years with vascular discoloration, and patterns of radial growth anomalies were recorded.

Sections of select duplicate tree cores with prominent vascular discoloration, indicative of previous Verticillium spp. infections, were surface sterilized with $10 \%$ bleach for four minutes and plated on potato dextrose agar amended with tetracycline hydrochloride (Fisher BioReagents, Pittsburgh PA) and streptomycin sulfate (Sigma-Aldrich Chemical company, St. Louis, MO) (PDA + A) in an attempt to recover Verticillium spp. 


\section{Evaluation of outward symptoms following 2018 re-inoculation with $V$. nonalfalfae}

In May 2018, 9 of 21 Ailanthus trees that were previously inoculated in 2015 and had 2017 ratings ranging from 0-7 (i.e. diseased but still alive) were re-inoculated with $V$. nonalfalfae strain $\mathrm{VnOH} 1$. Ailanthus trees at each site were inoculated using a hack and squirt method where $1 \mathrm{ml}$ of inoculum $\left(10^{7}\right.$ conidia $\mathrm{ml}^{-1}$ in sterile distilled water) were dispersed into a freshly hatchet-wound at the base of the main stem (Kasson et al. 2014). The volume of inoculum delivered depended on stem diameter, with plants $>7.6 \mathrm{~cm}$ diameter receiving $3 \mathrm{ml} / \mathrm{stem}$, plants 2.5 to $7.6 \mathrm{~cm}$ diameter receiving $2 \mathrm{ml} / \mathrm{stem}$ and plants $<2.5 \mathrm{~cm}$ diameter receiving $1 \mathrm{ml} / \mathrm{stem}$ (Kasson et al. 2015). In August 2018, stems were revisited and rated using the previously described rating system.

\section{Elemental assessment of Ailanthus radial cores using X-ray fluorescence (XRF) spectrometry}

Portable X-ray fluorescence (P-XRF) spectrometry is a proximal sensor system which has been used successfully to provide multi-elemental quantification in contaminated soils over the last two decades (Argyraki et al. 1997, Weindorf et al. 2012). More recently these same approaches have been successfully adopted for plant-based materials including grains, leaf tissues, and powdered vegetation (McGladdery et al. 2018, McLaren et al. 2011, Paltridge et al. 2012, Sacristan et al. 2016, Towett et al. 2015). Although these techniques have not been previously tested on extracted radial cross-sections of wood, P-XRF has shown utility in detecting arsenic (Block et al. 2007) and copper (Zielenkiewicz et al. 2012) in treated wood. To utilize this technique, cores were sectioned into $2 \mathrm{~cm}$ lengths and placed in water for 12 hours to remove wood glue. After 12 hours, the cores were removed from the mount, glue was wiped off with a paper towel, and sections were allowed to dry at room temperature for 24 hours, after which the cores were lightly sanded with a 180-grit sand paper to remove any remaining glue. 
Cores were analyzed for selected metals with a Bruker tracer X-ray fluorescence (P-XRF) handheld instrument (Bruker, Billerica, MA, USA) to evaluate if elements commonly associated with strip mining were present in the sampled tissues. Magnesium, aluminum, silicon, sulfur, chlorine, potassium, manganese, iron, copper, and zinc were selected for qualitative data collection in the Bruker XRF software based on the previous studies, especially those related to the fitness of Verticillium spp. (Jaeckel et al. 2005).

Tree cores sections were placed on the platform and covered the entirety of the x-ray window. The Bruker Tracer XRF was run for 40 seconds on samples and qualitative data based off of counts / second for each metal was obtained. Spectrum output was not calibrated against a standard since there is no established plant calibration specifically for wood. No vacuum was run during the x-ray exposure as it is standard protocol to not run the vacuum on plant samples due to their high concentration of organic compounds (Towett et al. 2015). Widths of the sanded tree cores were uniform at $\sim 4 \mathrm{~mm}$. Qualitative data and presence of distinct peaks were used to differentiate elemental content in Ailanthus cores from the WILDS versus those from the WVU organic farm. The number of counts of element-specific fluorescent X-ray energies received in an XRF instrument detector allows for creation of a XRF raw spectrum data for an individual sample. Spectrum graphs allow visualization of the sample constituents and are considered qualitative data. Spectrums show peaks where element-specific fluorescent energies are detected. High peaks represent more counts where a particular energy was detected. However, these relative abundances are not exact and cannot be quantified. This method of sample analysis allows for comparisons of the raw spectrum which creates a peak only when fluorescent energy is captured. Spectra were analyzed and compared on Bruker's Artax Software (Bruker, Billerica, 
MA, USA). Spectra were not normalized in accordance with the Bruker Artax manual and all samples followed a scale not requiring normalization.

Spectral comparisons from Artax is presented as qualitative data based on relative abundance (x 1E3 pulses or counts) with a maximum range of 40 on the y-axis. The $\mathrm{x}$-axis represents element-specific fluorescent energies, which for this study, spanned from 0 to $12 \mathrm{keV}$ as all the metals of interest are below that level. Specifically, $6.4 \mathrm{keV}$ is a fluorescent energy that is specific to iron. If two samples are analyzed and one has a higher peak than the other in regards to normalized other base peaks, the sample with the higher peak contains more of that particular element.

\section{Growth and Conidiation of $\boldsymbol{V}$. nonalfalfae across an Iron Gradient}

To independently assess the interaction between iron and growth/conidiation of $V$. nonalfalfae, 4-mm diameter fungus-colonized plugs of $V$. nonalfalfae strain VnAa140 were plated on PDA + A amended with varying concentrations of Sequestrene 138, a water-soluble chelated iron product (PlantMedia, Dublin, OH USA). Treatments included a negative control, with no added iron and six gradually increasing treatments ranging from $0.25 \mathrm{mgs}$ of Sequestrene 138 / $500 \mathrm{ml}$ of water to the highest concentration of $100 \mathrm{mg}$ Sequestrene 138 / 500 $\mathrm{ml}$ water. Plates were permitted to grow for three weeks, after which mean colony diameter and conidial yield were measured/quantified. Colony diameter was measured at one, two and three weeks post-placement of the excised fungal plug. Additionally, the morphological difference of percent of aerial mycelium present was recorded across treatments. This difference was rated on a $25 \%$ gradient and was averaged over the entire treatment.

After three weeks, plates were measured, photographed, and rinsed with $10 \mathrm{ml}$ of sterile water to quantify mean conidial production across treatments. After loosening hyphae and 
condiophores with a sterile metal spatula, the suspension was filtered through a KenAg nongauze milk filter to remove hyphal fragments and permit quantification via a hemocytometer. An average was taken of the number of conidia on plates included in each treatment.

Separate from the treatment-level quantification, the plate exhibiting the least aerial hyphae and the plate with the most aerial hyphae from each treatment were processed individually to compare conidial viability based on serial dilution plating and CFU counts following quantification using a hemocytometer. Approximately $500 \mu \mathrm{L}$ of the final conidial spore suspension was aliquoted to a PDA + A plate and allowed to grow for three days before colony counts were tallied.

\section{Iron Inundation to Suppress Verticillium wilt in Ailanthus seedlings}

Based on the combined results of the XRF spectrometry and the iron amended media, we sought to test whether concentrations capable of reducing fungal sporulation in culture were also capable of delaying/inhibiting progression of wilt. To test this, potted Ailanthus seedlings were subjected to one of three treatments prior to inoculation, water negative control, low concentration $(0.1 \mathrm{~g} / \mathrm{gal}$ of water) or high concentration ( $0.4 \mathrm{~g} / \mathrm{gal}$ water) of Sequestrene 138. Ailanthus seedlings were planted in Sun Gro Potting mix (Sun Gro Horticulture, Agawam, MA) and permitted to grow in the absence of pathogens in separate pots for two weeks prior to inoculation with $V$. nonalfalfae strain VnAa140 while being watered with the different treatments. This two-week period allowed for adequate iron accumulation in the soil and in the plants through root uptake. Sample size was six plants per treatment for iron supplemented plants and five plants for water controls. After two weeks, plants were gently uprooted and root dip inoculated with a conidial spore suspension of $V$. nonalfalfae with a concentration of $1 \times 10^{7}$ conidia/ml and replanted in their respective individual treatment pots. Starting at four weeks when the first wilt symptoms appeared, percent wilt was recorded on a biweekly basis until eight 
weeks post-inoculation. Once plants experienced $\geq 80 \%$ wilt, height of the seedling was recorded and the seedling was destructively sampled to fulfill Koch's Postulates. Destructively sampled seedlings were surface sterilized in $10 \%$ bleach for four minutes and aseptically placed on a PDA + A plate. Upon emergence from stem tissues, fungi were aseptically subcultured onto new PDA + A plates and allowed to grow to confirm colony identity. Additionally, $2.5 \mathrm{ml}$ of soil from near the base of the infected seedling was sampled and distributed on to three replicate plates of PDA + A to assess survival of fungi in iron and water treated soil. Upon emergence of distinguishable fungal growth from the plated soil particles, fungi were subcultured and allowed to grow to confirm colony species identity. At the end of the eight-week period, any remaining seedlings showing no symptoms of vascular wilt were also destructively sampled and plated in the same manner as symptomatic plants on PDA + A. Soil around the asymptomatic seedlings' root collars was also plated on PDA + A to confirm presence or absence of $V$. nonalfalfae.

\section{Statistical Analysis}

A one-way analysis of variance (ANOVA) and student t-test was used to determine if any statistically significant differences occurred between the means of the growth of $V$. nonalfalfae on the iron augmented PDA + A plates, the conidia produced on these plates. A nonparametric ANOVA was performed on aerial mycelial growth to account for the percentile scale.

Statistical analysis of survivorship was performed using the "Survival/Reliability" function in JMP 13.1.0 (SAS Institute Inc., Cary, NC). Post-hoc pairwise comparisons to the control treatment were performed for treatments that reached at least $80 \%$ mortality by the end of the trial. Survival data analysis overview using Kaplan-Meier estimates were used to understand survivorship through both log-rank and Wilcoxon tests. Log-rank tests score mortality at all time points evenly, while Wilcoxon tests score early mortality more heavily. 


\section{Results}

Two-year evaluation of outward symptoms and radial growth responses following artificial inoculation with $V$. nonalfalfae strain VnOH1

August 2017 disease ratings of 21 Ailanthus trees originally inoculated in 2015 and two additional trees infected via natural spread revealed some outcomes that deviated significantly from all previous Ailanthus inoculations using isolates from $\mathrm{OH}, \mathrm{PA}, \mathrm{VA}$ and Europe. Of these trees, seven had typical disease progression resulting in death over the two-year period and three additional trees showed increased disease severity over the same window but at much slower rates compared to the other seven trees. However, eight trees that showed initial symptoms with ratings $>3$ (mean of 6 across all trees), exhibited a decrease in symptom severity over the next two growing seasons decreasing to a mean of 2.7 , indicating that the trees had recovered. Some of these individual trees had no outward symptoms 27 months post-inoculation. An additional three trees initially developed symptoms but disease never progressed beyond the 2015 ratings. One of the trees showed symptoms in 2017 but in 2018 the canopy had fully recovered back to a rating of 0 .

Distinct growth differences were noticed in Ailanthus stems from the WILDS site when compared to cores from Ailanthus stems from the WVU Organic farm (Figure 4-1). Nineteen out of 23 tree cores from the WILDS displayed compressed rings with a majority showing radial growth decline beginning in the late 1990s. Rings occurring in the outermost rings were on average $<1 \mathrm{~cm}$ in width compared to earlier growth which ranged from 2-4 cm annually. There was no clear association between trees with diminished radial growth and disease ratings, although three of the four trees lacking this suppressed radial growth were tolerant to Verticillium wilt (Table 4-1). Vascular discoloration was noted in 15 of 23 tree cores from the 
WILDS. However, trees continued to grow normally after a previous infection, with five of those 15 tree cores showing multiple years of distinct and separate Verticillium infections (Table 4-1). Not surprisingly, all of these trees that showed evidence of overcoming a previous infection were rated as tolerant trees. Most of the vascular discoloration occurred in annual growth rings associated with the first inoculation in 2015 with only a few earlier occurrences including 1989 , 1996, and several the early 2000s. Eight trees did not have vascular discoloration, seven of which were rated 8 in 2018 .

\section{Evaluation of outward symptoms following 2018 re-inoculation with $V$. nonalfalfae}

Of the nine tolerant May 2018 re-inoculated trees, only one showed an increase in symptoms when rated in August of 2018. The remaining seven of those tolerant trees kept their same tolerant ratings or even showed less symptoms than the summer of 2017 (Table 4-1). There were no compressed tree rings or symptoms of vascular discoloration in the tree cores form the WVU Organic Farm. Additionally, these Ailanthus trees showed no external symptoms of wilt when they were sampled.

No Verticillium colonies were isolated from the plated tree cores indicating that the fungus was no longer living in the woody substrate.

\section{Elemental assessment of Ailanthus radial cores using X-ray fluorescence (XRF) spectrometry}

Distinct peaks of iron were present in Ailanthus sampled from the WILDS compared with the five control trees cores from the WVU Organic Farm. There were noticeable trends between high peaks in iron in tolerant tree cores (rating of 0-1) when compared to susceptible trees with a rating of 7-8 from the WILDS (Figure 4-2). Relative abundance for the control trees at the WVU Organic Farm was much lower than trees at the WILDS ranging from 4.5 to 8 , and never 
surpassed 8 pulses (Figure 4-3). Additionally, the tolerance and susceptibility of the trees at the WILDS appeared to be dependent on the concentration of iron in the tree core tissues (Figure 43). When separated from the moderately tolerant trees which still show some external symptoms, the most extremes cases of tolerance and susceptibility, are very evident. Iron peaks for the most tolerant trees at the WILDS with ratings of 0 showed a max peak pulse of 32 (range $6-32$ ) compared to the most susceptible trees at the WILDS with ratings of 8 that showed max peak of 12 (range 6 and 12) (Figure 4-4).

\section{Growth and Conidiation of $\boldsymbol{V}$. nonalfalfae across an Iron Gradient}

A distinct morphological phenotype was noted in plates containing the highest concentration of Sequestrene 138 compared to iron-free media (Figure 4-5, Figure 4-6). Although no differences in colony diameter were detected across the seven treatments, colony morphology on high concentrations of Sequestrene 138 appeared mucilaginous and lacked aerial hyphae typical of V. nonalfalfae (Inderbitzin et al. 2011). Estimated aerial mycelium was 37\%, $43 \%$, and $58 \%$ for the three highest iron treatments, $25 \mathrm{mg} / 0.5 \mathrm{~L}, 50 \mathrm{mg} / 0.5 \mathrm{~L}$ and $100 \mathrm{mg} /$ $0.5 \mathrm{~L}$, respectively. This compared to $92.8 \%$ aerial mycelium for control and $77 \%, 89 \%, 70 \%$ for three lowest iron treatments, $0.25 \mathrm{mg} / 0.5 \mathrm{~L}, 0.5 \mathrm{mg} / 0.5 \mathrm{~L}$ and $0.1 \mathrm{mg} / 0.5 \mathrm{~L}$, respectively. A nonparametric ANOVA on the production of aerial hyphae resulted in a significant difference between treatments, particularly in iron treatments versus the control ( $p>F<0.0001) /$ Wilcoxin test (chi square $<0.001$ ). The nonparametric multiple comparisons Steel test showed that when compared against the non-iron containing control, only the high iron treatments had statistically significant differences in aerial hyphae production (high half -0.0050 , sigh full 0.0081 , high extra 0.0339). 
Radial growth rate of hyphae was different in the high iron treatment plates from the control in the first two weeks for growth, but did not result in a significant difference at the end of three weeks (Table 4-2). The oneway ANOVA for the three weeks produced statistically significant p-values for the first two weeks but not for the third week $(<0.0001,<0.0001$, $<0.2427)$.

Conidiation was statistically significantly $(\mathrm{p}<0.001)$ decreased on the high iron treatment plates when compared to the control (Dunnet's method) (Figure 4-7). Plates with low iron treatments produced a similar amount of spores as the control, alluding to a threshold of iron levels that impacts conidia production. Viability of conidia between the plate with the most aerial hyphae and the least aerial hyphae did not differ, indicating that although overall conidiation was impacted, viability of produced condiospores was not impacted (Table 4-2).

\section{Iron Inundation to Suppress Verticillium wilt in Ailanthus seedlings}

Five of five control seedlings showed severe (68\%) wilt symptoms by four weeks postinoculation (P.W.I.), while three of six low iron seedlings and two of the six high iron seedings showed symptoms at this same time point averaging $27 \%$ and $55 \%$ wilt, respectively.

At eight-weeks post-inoculation, all five controls and six of six low iron seedlings averaged $81 \%$ wilt plants, while six of the high iron seedlings exhibited wilt, averaging $79 \%$. By eight-weeks, the only remaining plants alive were a seedling in the low iron treatment and one in the high iron treatment, with $50 \%$ and $10 \%$ wilt respectively.

Verticillium nonalfalfae was successfully re-isolated from all symptomatic plants, regardless of treatment. Soil was also found to contain viable $V$. nonalfalfae propagules in at least two instances per treatment (Table 4-3). From the two asymptomatic plants at the end of 
the experiment, Verticillium colonies were recovered from both the stems and soil when plated on $\mathrm{PDA}+\mathrm{A}$.

Although symptoms progressed at different rates across the three treatments, results from the statistical analysis using the Survival Curve Kaplan-Meier Estimates revealed that the three treatments were not statistically significantly different from each other (tests between groups Log-rank $\mathrm{p}<0.1760$ and Wilcoxon $\mathrm{p}<0.1650)$. The results of this pathogenicity assay indicated that iron did not have a statistically significant impact on the efficacy of $V$. nonalfalfae at varying levels of concentration in the soil and presumably accumulated in the plant, although mortality of seedlings occurred at different times depending on treatment (Figure 4-5).

\section{Discussion}

The results of this study provide the first conclusive evidence for induced tolerance of Ailanthus to the vascular wilt pathogen $V$. nonalfalfae, which is attributed to iron hyperaccumulation that limits disease severity despite colonization. The results help explain the impacts of excess iron to fungi but fail to directly explain suspected impacts on plant growth. However, compressed rings were noted in 19 of 23 trees at the WILDS which occurred after a period of normal growth, a phenomenon possibly explained by the trees' taproot penetrating the layer of the top soil applied during reclamation and encountering the metal contaminated substrate beneath.

Since $V$. nonalfalfae was never recovered from tree cores taken from the WILDS, possibly trees are more able to rapidly occlude vessels and thereby stop the spread of infectious propagules due to the increased vigor from the high iron. This has been reported in American elm in response to inoculations with $V$. albo-atrum, which triggers the tree's natural defense 
systems and prevents infection by the devastating Ophiostoma ulmi, the causal agent of Dutch elm disease (Scheffer et al. 2008).

An imbalance of iron levels in the tree cores from the WILDS may help explain the compressed rings of Ailanthus since iron plays an important role in formation of lignin (Hasanuzzaman et al. 2017). However, compressed rings were common across a majority of evaluated trees and their presence did not relate to high levels of susceptibility or tolerance to the pathogen. Therefore, it is likely that the compressed rings are an effect of another metal present in high occurrence at the wilds, such as Cadmium (Cd). Cadmium has been shown to have an effect on the primary and secondary growth in aspen hybrids (Populus tremula x P. alba L.) and inhibiting net photosynthetic rate (Durand et al. 2010). The same study found that Cd was responsible for the differential allocation of $\mathrm{Fe}^{2+}, \mathrm{Zn}^{2+}, \mathrm{Ca}^{2+}, \mathrm{Mg}^{2+}$ and $\mathrm{K}^{+}$, indicating an interaction between $\mathrm{Cd}$ and Fe. The compressed rings in the Ailanthus tree cores coupled with the iron data presented here suggest that $\mathrm{Cd}$ also is playing an unknown role in the tolerance of Ailanthus to $V$. nonalfalfae.

The inhibition of Verticillium wilt in a number of trees at the reclaimed mine site is likely due to the presence of iron at levels attributed to mining activities. Unfortunately, due to the complex nature of site capping, soils could not be directly tested since the contaminated soils are likely many feet below the current soil line. The abrupt change in ring growth patterns once trees had reached a certain age (and presumed height) supports the following hypothesis. Roots developed and expanded until finally penetrating the clean soil cap, after which radial growth was reduced.

While hyphae of $V$. nonalfalfae were still able to grow at a rate similar to control plates with no Sequestrene 138 in the agar they were not able to produce conidia similar to the control 
plates. Since clogging of the vessels by conidia are the main mode of action of vascular wilt disease, including Verticillium wilt, a reduction in conidia could explain less severe wilt symptoms (Ospina-Giraldo et al. 2003, Schall and Davis 2009). Perhaps iron is a valuable resource in initial development but too much iron accumulates in the tissues of the fungus and begins to cause deleterious effects to growth and conidial production. There may be a bellcurved threshold for iron levels within fungal tissues that allow for optimal performance.

Considering that $V$. nonalfalfae was re-isolated from the soil in the highest iron concentration treated soil as well as from seedlings, confirms that $V$. nonalfalfae is not completely inhibited by high iron levels. This suggests combination of sub-lethal effects on the fungus combined with increased plant vigor that may explain the tolerance observed over the course of this study. Whatever the case, this environmentally-acquired tolerance only reinforces excluding Ailanthus reclamation plantings. On the other hand, this presumed interaction between heavy metals and delayed/arrested disease progression could allow land managers with oversight of reclaimed lands to monitor for intrusion of capped soils.

The long-term implications of reclamation practices that utilize invasive species in an effort to quickly establish an organic soil layer are potentially expediting species invasions in neighboring forests. The biocontrol method of $V$. nonalfalfae may work well in forests adjacent to the polluted sites, but with forests of tolerant Ailanthus trees producing seed nearby, there will continuously be a reservoir depositing seed into potentially ecologically sensitive areas.

Allowing invasive species to thrive and continue to be the dominant forest ecotype at the WILDS is not only deleterious for the establishment and reforestation by native species of the property containing the invasive, but also for the neighboring properties that are susceptible to infestation 
by the reservoir of invasive species due to their high fecundity of more than one million seeds annually and impressive seed dispersal methods (Wickert et al. 2017).

\section{Conclusions}

The remarkable success of Ailanthus as an invasive species in the U.S. is due in part to its ability to grow in nutrient poor sites and tolerate heavy metals. In this study, it was hypothesized that Ailanthus was not succumbing to the vascular wilt pathogen $V$. nonalfalfae due to the high relative abundance of iron at the WILDS. Tolerant trees at the WILDS showed higher comparative iron peaks analyzed with X-ray florescence than Ailanthus trees that had succumbed to the disease at the WILDS as well as to control trees from the WVU organic farm, which lacked a surface mining history. Thus, Ailanthus growing in reclaimed mine sites may have an advantage against the biocontrol fungus. Land managers of reclaimed mine sites should be diligent in removing Ailanthus before the roots have time to grow through the top soil fill and reach the heavy metal containing mine soil, which leads them to becoming tolerant/resistant to $V$. nonalfalfae, forcing land managers to rely on more expensive, time and labor consuming methods of chemical herbicides to control Ailanthus. 


\section{Acknowledgements}

Joanne Rebeck and Joan Jolliff made this experiment and publication possible, by noticing a potential tolerance of Ailanthus at the WILDS. Thank you to the WILDS for allowing US Forest Service officials and myself to collect samples from their property for this publication. Thank you to Chansotheary Dang for offering advice based from her expertise in reclaimed mine properties and biochemistry. The authors would like to thank Dr. Louis McDonald for the use of his Bruker X-ray fluorescence instrument and his knowledge of soil science. The exceptional customer service of Bruker, especially from their representative Andrew Lee, was incredibly valuable during the analysis of the data from this project. Thank you to Dr. Jim Kotcon for describing and providing tests pertaining to the WVU Organic Farm history. Funding support was provided by the USDA Forest Service, FHP and FHTET to Dr. Matthew Kasson and Kristen Wickert. 


\section{Tables}

Table 4-1: Disease ratings of tolerant and susceptible Ailanthus trees from the WILDS, a wildlife conservation center built on a reclaimed surface mine site in Southeastern Ohio. Details of Ailanthus tree cores: include age, years with vascular discoloration indicating previous Verticillium infections and years of abnormal compressed annual growth rings. Rating scale is taken from O'Neal and Davis 2015 and follows a 0-8 scale: 0-healthy foliage, 1-chlorosis and/or necrotic margins on leaves, 2 -slight wilt ( $<15 \%$ wilting foliage) with no or slight defoliation $(<15 \%)$, 3-moderate wilt ( 15 to $<50 \%$ wilting foliage with no or slight defoliation $(<15 \%)$, 4 severe wilt (50 to $100 \%$ wilting foliage with no or slight defoliation $(<15 \%)$, 5-moderate defoliation ( 15 to $<50 \%$ ), 6-severe defoliation (50 to 90\%), 7-very severe defoliation (90 to $100 \%$ ) with epicormic sprouting, 8-dead.

\begin{tabular}{|c|c|c|c|c|c|c|c|c|c|c|c|c|}
\hline Site & Tree ID & $\begin{array}{c}2015 \\
\text { Inoculation }\end{array}$ & $\begin{array}{c}2018 \\
\text { Inoculation }\end{array}$ & $\begin{array}{c}\text { Ring } \\
\text { Count }\end{array}$ & $\begin{array}{c}\text { Years with } \\
\text { Vascular } \\
\text { discolouration }\end{array}$ & $\begin{array}{c}\text { Year } \\
\text { Condensed } \\
\text { Rings Start }\end{array}$ & 2018 Status & $\begin{array}{c}2015 \\
\text { Rating }\end{array}$ & $\begin{array}{c}2016 \\
\text { Ratings }\end{array}$ & $\begin{array}{c}2017 \\
\text { Rating }\end{array}$ & $\begin{array}{c}2018 \\
\text { Rating }\end{array}$ & $\begin{array}{l}\text { Plated for Re- } \\
\text { isolation of } \\
\text { Verticillium } \\
\text { nonalfalfae }\end{array}$ \\
\hline W2 & 7 & yes & no & 31 & - & 1997 & Susceptible & 7 & 7 & 8 & - & - \\
\hline W2 & 502 & yes & no & 30 & - & 1998 & Susceptible & 3 & 8 & 7 & - & - \\
\hline W2 & 511 & yes & no & 28 & - & 1989 & Susceptible & 8 & 7 & 8 & - & - \\
\hline W2 & 3 & yes & yes & 35 & 2010 & 1998 & Tolerant & 3 & 5 & 4 & 5 & yes \\
\hline W2 & 501 & yes & yes & 19 & 2015 & - & Tolerant & 4 & 2 & 0 & 0 & yes \\
\hline W2 & 503 & yes & yes & 30 & 2015 & 2012 & Tolerant & 6 & 5 & 4 & 4 & yes \\
\hline W2 & 505 & yes & yes & 15 & 2015,2016 & - & Tolerant & 7 & 7 & 2 & 2 & yes \\
\hline W2 & 517 & yes & yes & 29 & 2004,2015 & 2004 & Tolerant & 7 & 7 & 2 & 7 & yes \\
\hline W3 & 509 & yes & no & 29 & - & 2007 & Susceptible & 8 & 8 & 8 & - & - \\
\hline W3 & 512 & yes & no & 27 & - & 2009 & Susceptible & 7 & 8 & 8 & - & - \\
\hline W3 & 14 & yes & yes & 28 & 2015 & 2010 & Tolerant & 2 & 0 & 5 & 0 & yes \\
\hline W3 & 506 & yes & yes & 42 & - & - & Tolerant & 2 & 3 & 5 & 0 & - \\
\hline W4 & 521 & yes & no & 12 & - & - & Susceptible & 7 & 7 & 8 & - & - \\
\hline W4 & 522 & yes & no & 36 & 2009,2016 & 1996 & Tolerant & 5 & 4 & 5 & - & yes \\
\hline W4 & 514 & yes & no & 30 & 2012,2016 & 2016 & Tolerant & 7 & 6 & 5 & - & yes \\
\hline W4 & 518 & yes & no & 29 & 2006 & 2009 & Tolerant & 3 & 2 & 4 & - & yes \\
\hline W4 & 536 & yes & no & 22 & 2008 & 2011 & Tolerant & 3 & 4 & 6 & - & yes \\
\hline W5 & 16 & yes & no & 37 & - & 1991 & Susceptible & 7 & 7 & 8 & - & - \\
\hline W5 & 21 & yes & yes & 39 & 1989 & 1995 & Tolerant & 4 & 0 & 2 & 1 & yes \\
\hline W5 & 22 & yes & yes & 39 & 2005 & 1997 & Tolerant & 4 & 3 & 2 & 1 & yes \\
\hline W5 & 100 & no & no & 24 & 2015 & 2015 & Tolerant & - & - & - & 6 & yes \\
\hline W5 & 513 & yes & no & 47 & 2015 & 1987 & Tolerant & 7 & 5 & 5 & - & yes \\
\hline W5 & $O-2 X$ & no & no & 37 & 1996,2009 & 1995 & Tolerant & - & - & 2 & 0 & yes \\
\hline
\end{tabular}

( - ) indicates not present or recorded 


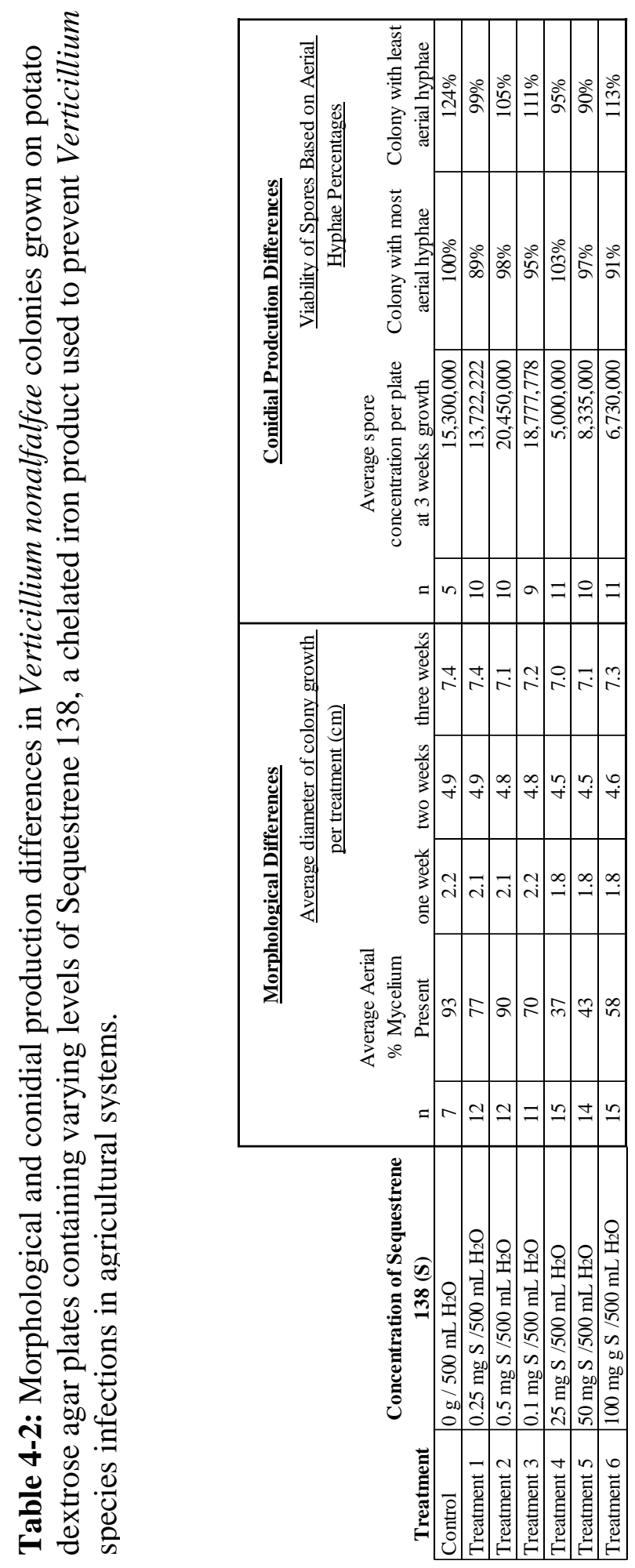




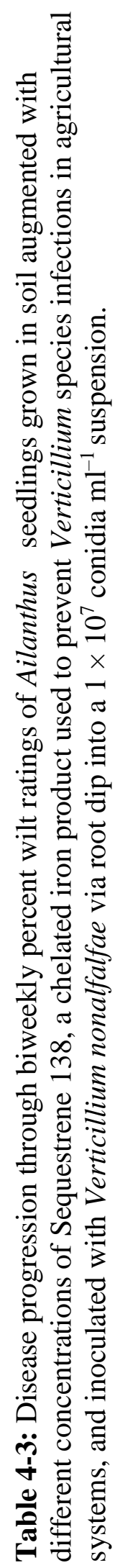
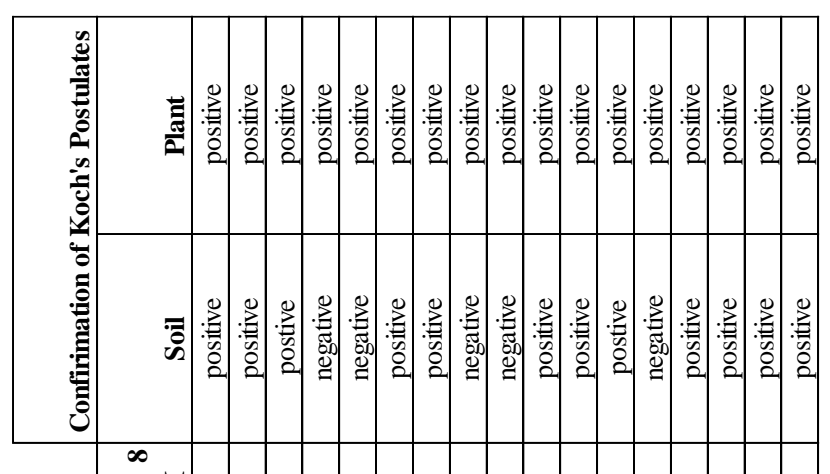

$\infty$
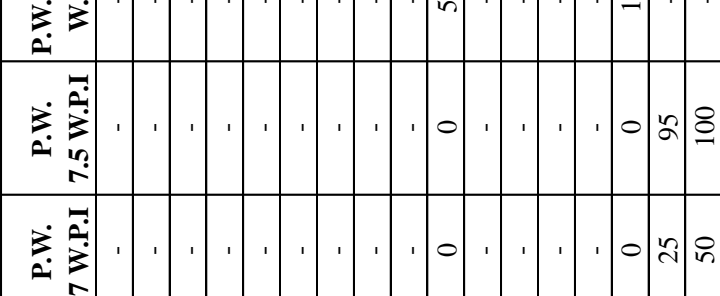

غे

a

ํ.

in

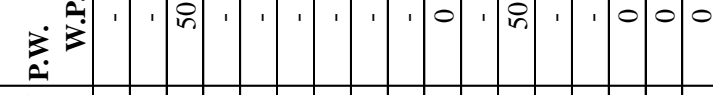

n

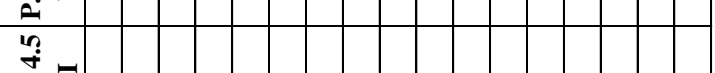

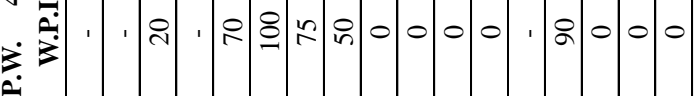

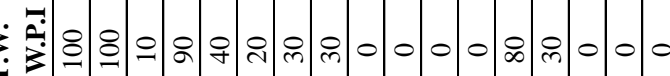

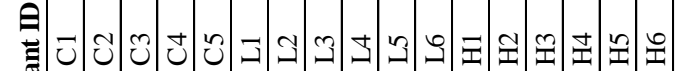

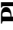

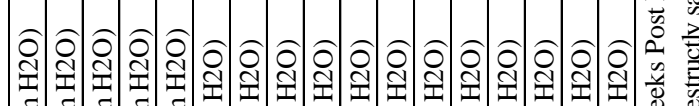

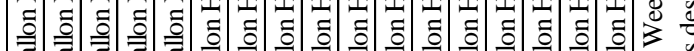

$=100$

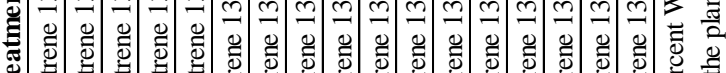

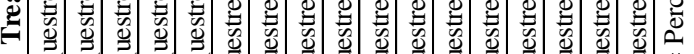

ఫั้

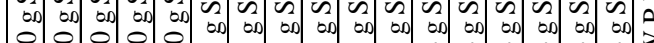




\section{Figures}
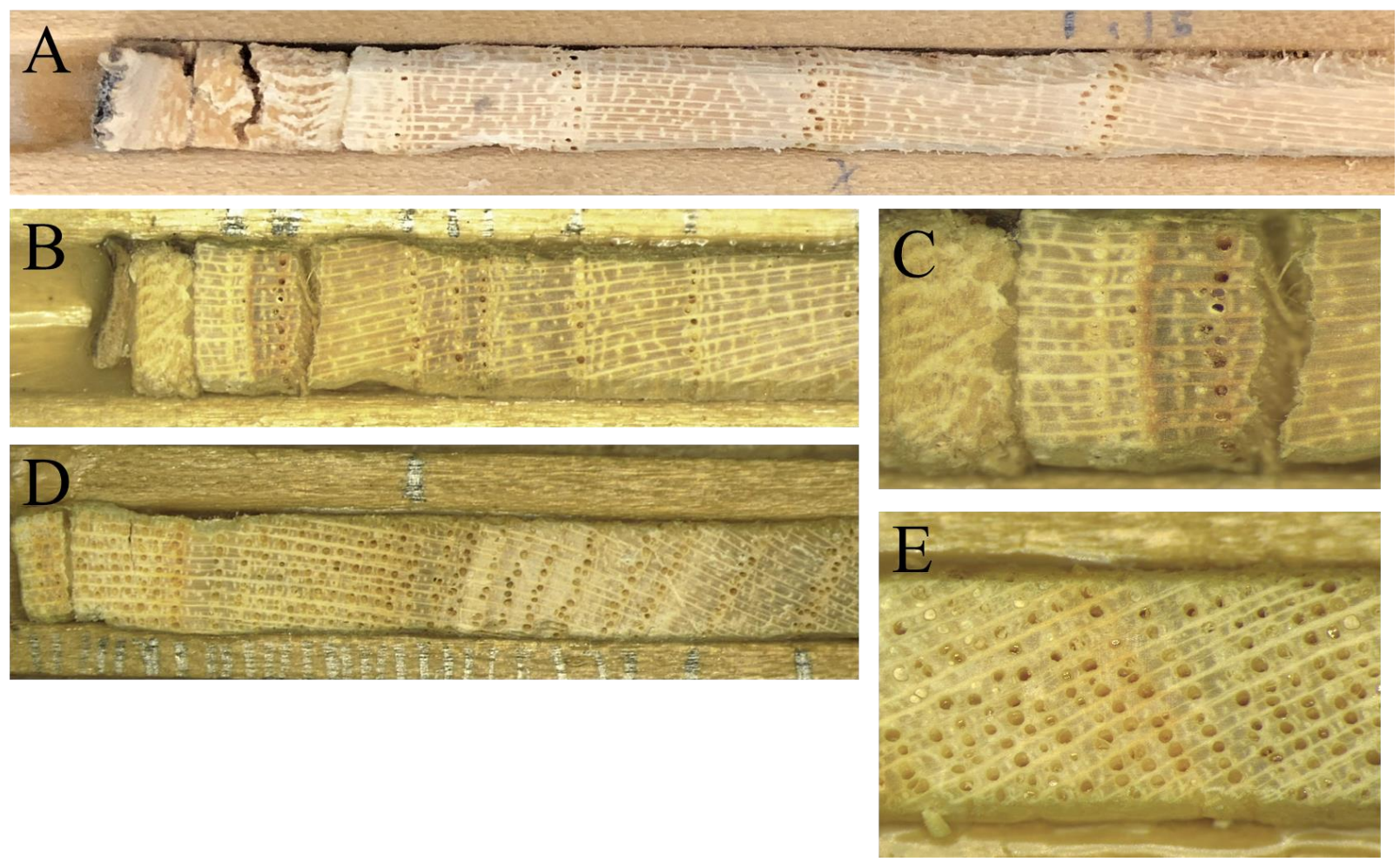

Figure 4-1: (A) Example Ailanthus tree core from the West Virginia University organic farm (which served as a control) displaying normal growth patterns with average spacing between individual growth rings. (B) An Ailanthus tree core displaying a ring of yellow vascular discoloration and continued growth that overcame infection by a Verticillium species. (C) Close up of vascular discoloration in photo B. (D) An Ailanthus tree core displaying an occurrence only noticed at the WILDS of compressed rings. (E) Close up of ring compression with seemingly lacking evidence of annual late wood hypothesized to be due to heavy metal accumulation and subsequent toxicity. 


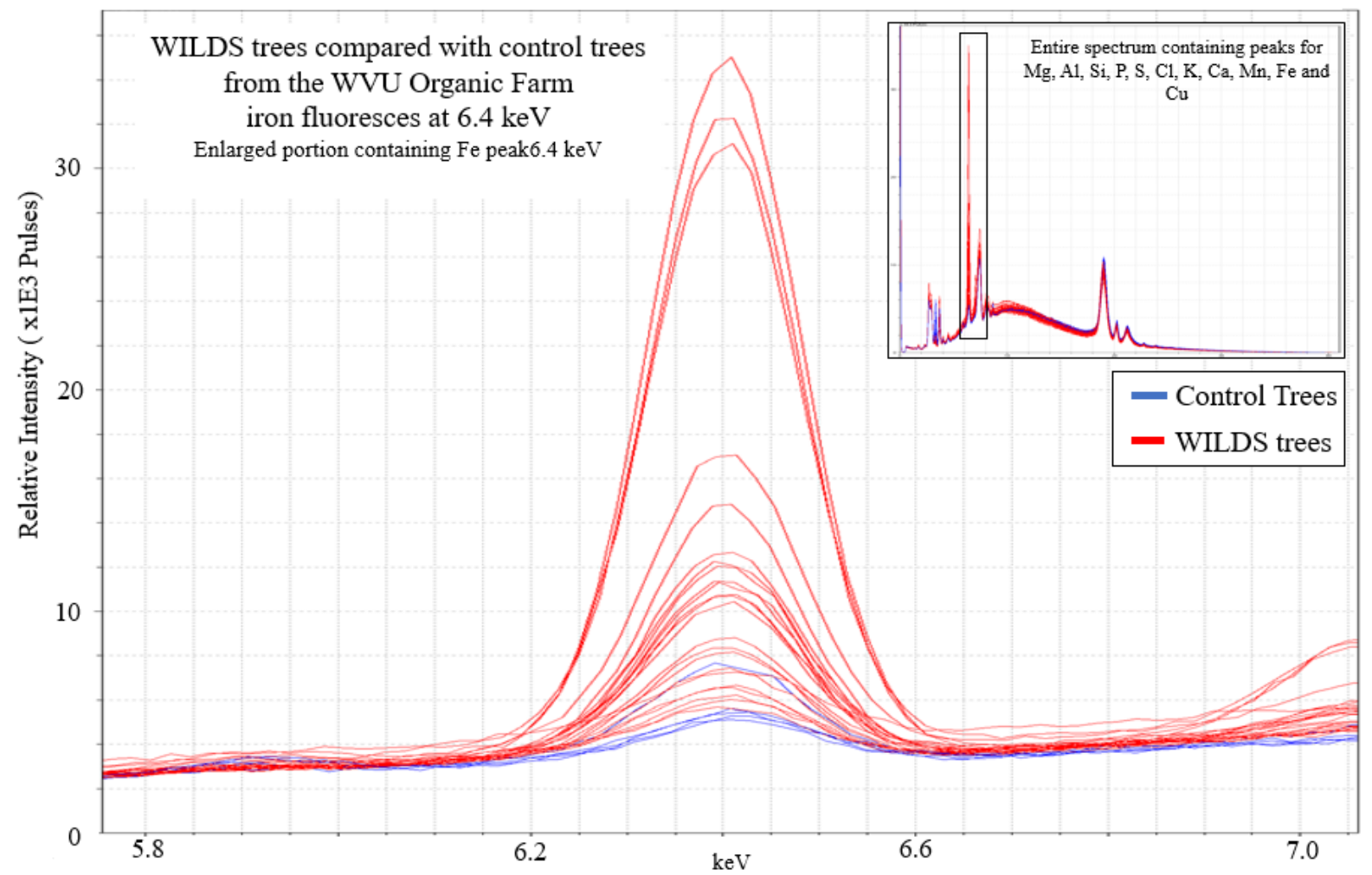

Figure 4-2: Qualitative iron peaks for Ailanthus tree cores from the WILDS and from the West Virginia University Organic Farm. 


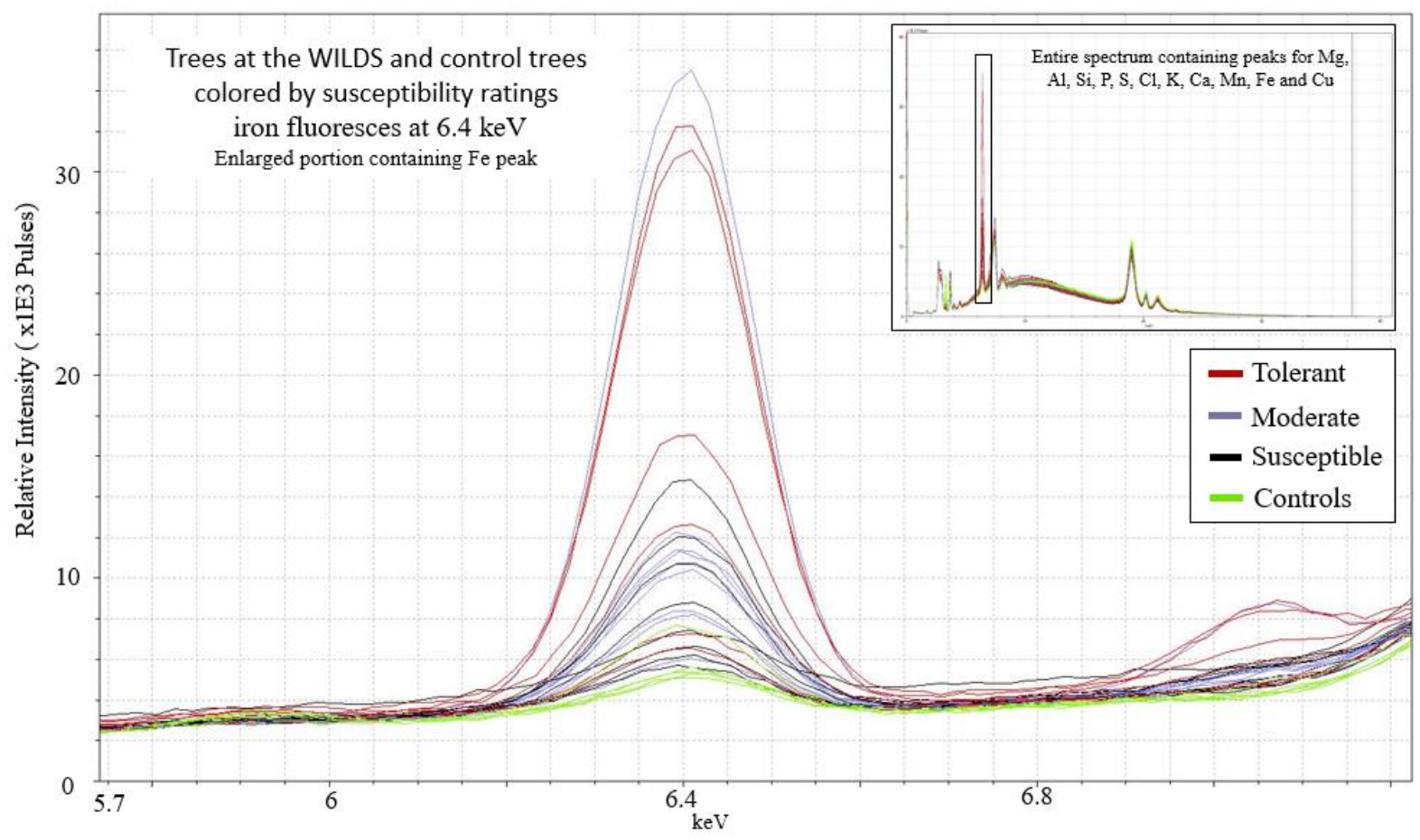

Figure 4-3: Qualitative iron peaks for Ailanthus tree cores from the WILDS and from the West Virginia University Organic Farm colored according to tolerance and susceptibly ratings. 

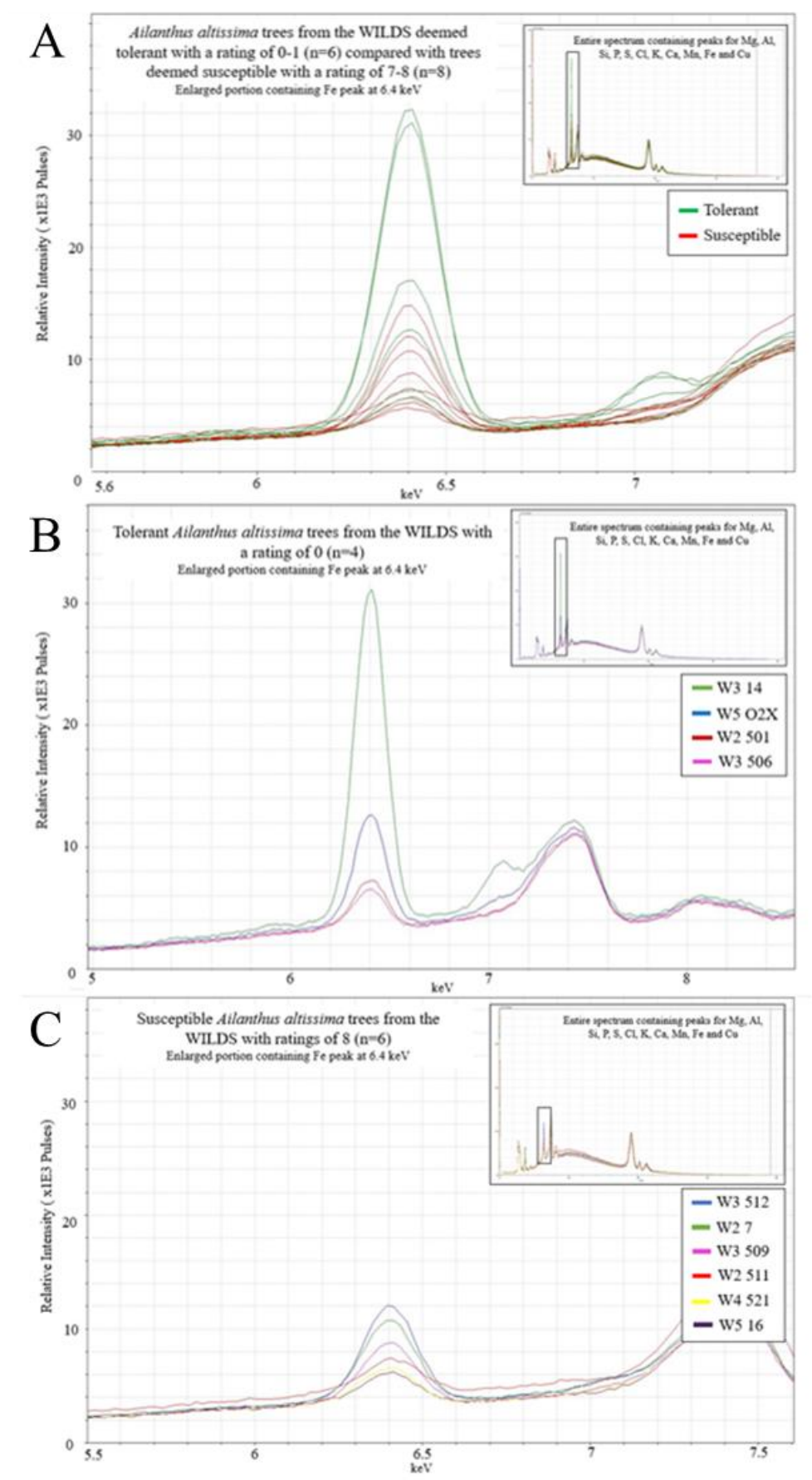

Figure 4-4: (A) Qualitative iron peaks for Ailanthus tree cores from the WILDS colored by susceptible and tolerant ratings. (B) Iron peaks for the most tolerant trees at the WILDS with ratings of 0 , meaning they displayed no external symptoms after being inoculated with the vascular wilt pathogen Verticillium nonalfalfae two times. (C) Iron peaks for the most susceptible trees at the WILDS with ratings of 8, meaning they displayed no external symptoms after being inoculated with the vascular wilt pathogen $V$. nonalfalfae once in 2015. 


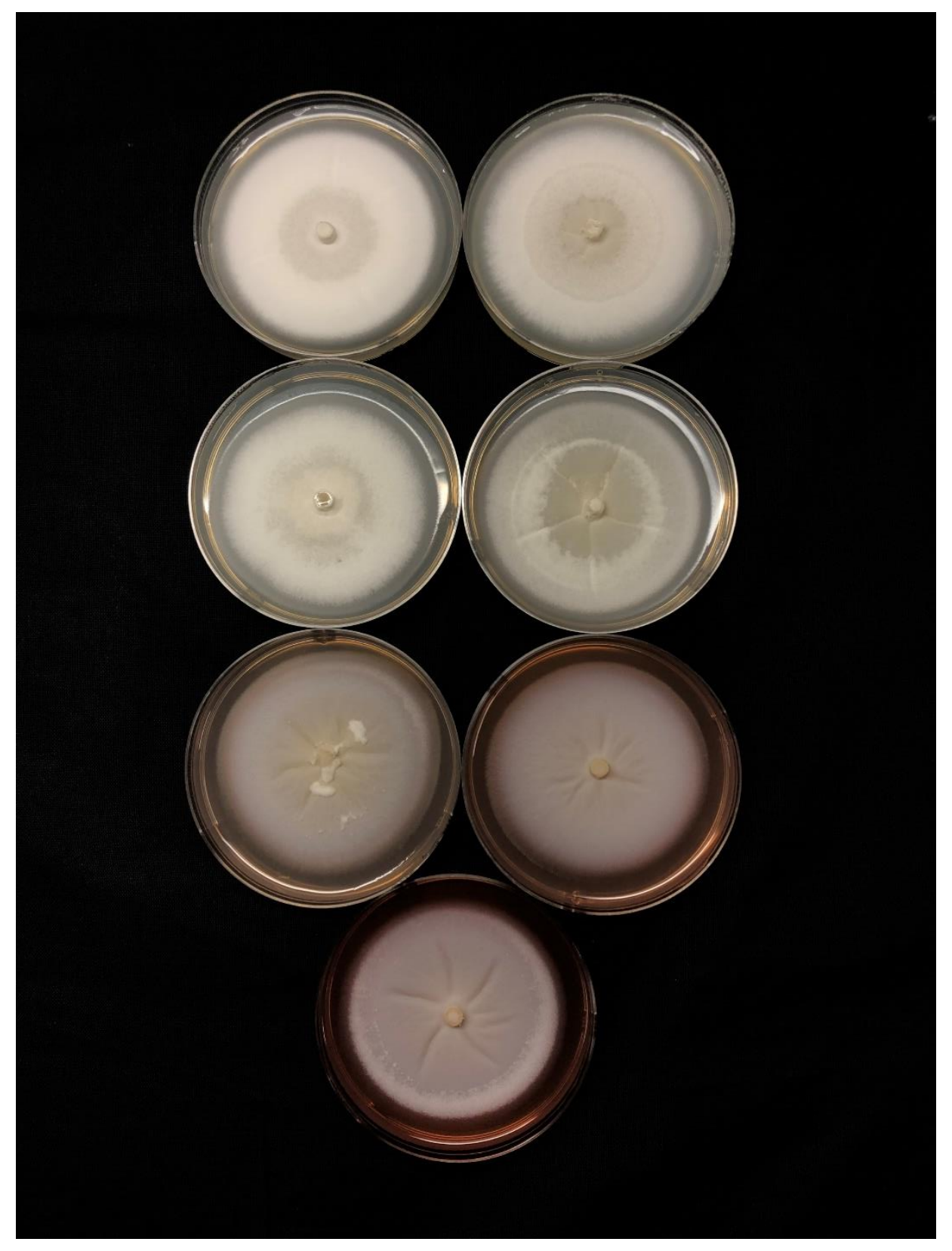

Figure 4-5: Seven treatments of gradually increasing iron concentrations in the form of Sequestrene 138 added to potato dextrose agar plates with pure cultures of $V$. nonalfalfae placed in the center of the plate after being excised with a sterile $4 \mathrm{~mm}$ cork borer. Measurements of growth, conidial production and viability occurred after 3 weeks of growth at ambient room temperature. 

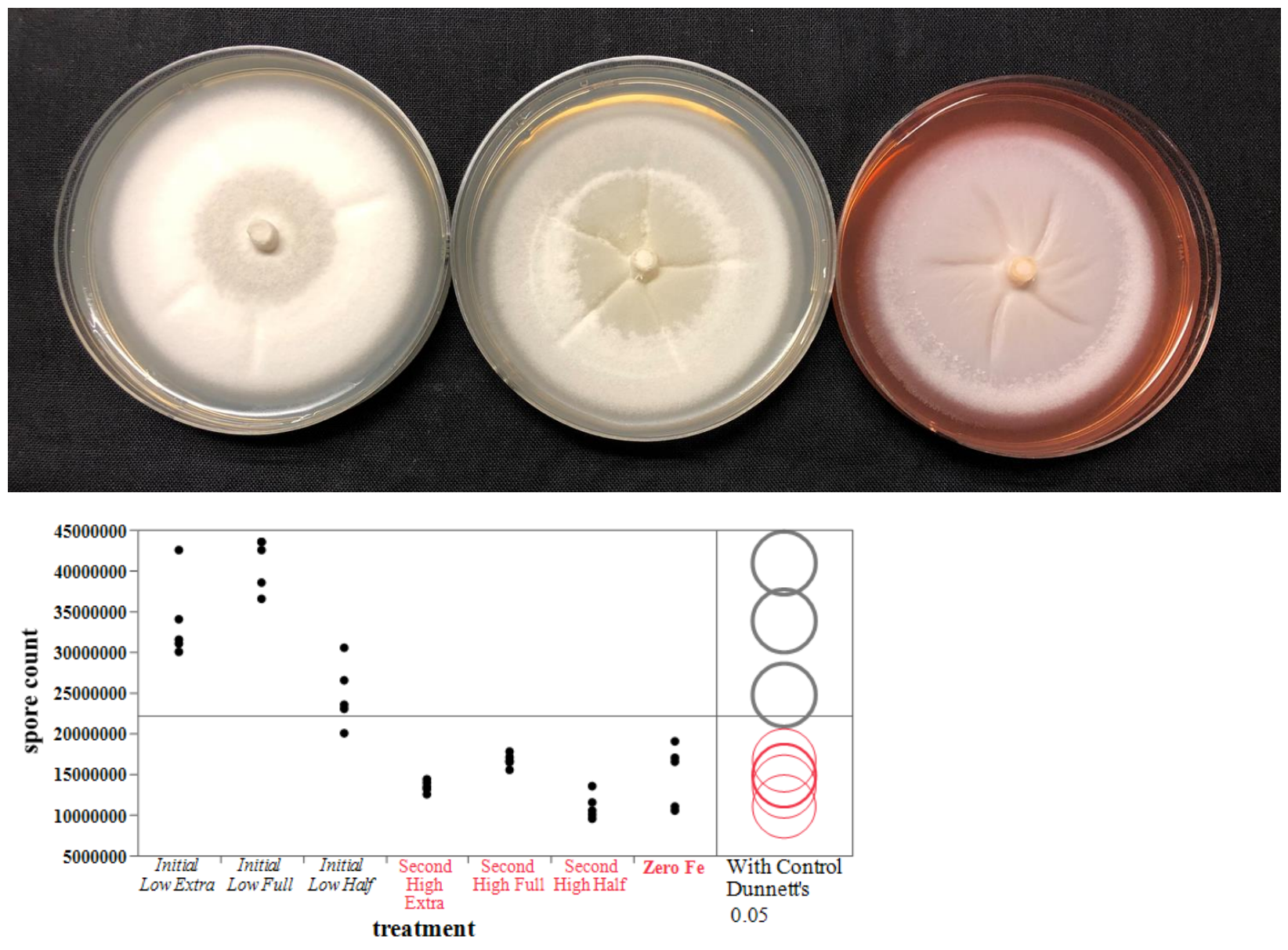

Figure 4-6: A comparison showing the reduction of aerial hyphae of $V$. nonalfalfae produced with increasing intensity of iron concentrations in PDA plates. From left to right are treatments of control PDA + A with no added iron, $0.001 \mathrm{~g}$ Sequestrene/500 $\mathrm{mL} \mathrm{H}_{2} \mathrm{O} / 19 \mathrm{~g}$ PDA and $0.1 \mathrm{~g}$ Sequestrene/500 $\mathrm{mL} \mathrm{H}_{2} \mathrm{O} / 19 \mathrm{~g}$ PDA. 

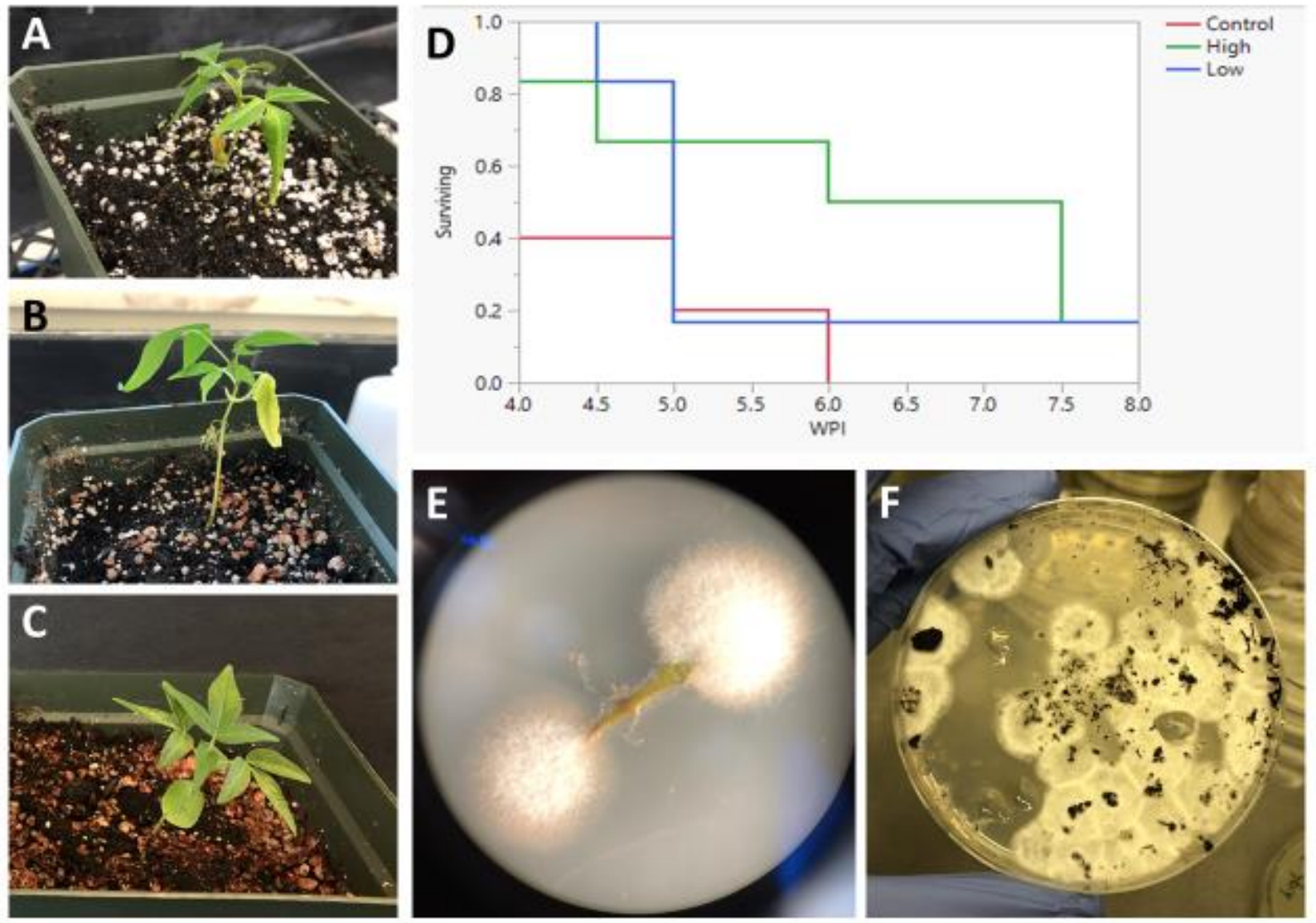

Figure 4-7: (A) An Ailanthus seedling grown in soil containing no iron additions showing severe symptomatic wilting after being root dip inoculated with $V$. nonalfalfae (B) An Ailanthus seedling grown in soil containing $0.1 \mathrm{~g} / \mathrm{gallon}$ of Sequestrene 138 showing milt symptomatic wilting and chlorosis after being root dip inoculated with $V$. nonalfalfae (C) An asymptomatic Ailanthus seedling grown in soil containing $0.4 \mathrm{~g} / \mathrm{gallon}$ of Sequestrene 138 amended soil after being root dip inoculated with $V$. nonalfalfae (D) Survival curve for Ailanthus seedlings after being grown in Sequestrene 138 augmented soil low $(n=6)$ and high $(n=6)$ concentrations and a control $(n=5)$ containing no iron and being root dip inoculated with $V$. nonalfalfae conidial suspension. WPI = weeks post inoculation $(\mathrm{E}-\mathrm{F}) \mathrm{V}$. nonalfalfae was successfully isolated from both symptomatic tissues and soil of all three treatments. 


\section{References}

Aldrich, P. R., Briguglio, J. S., Kapadia, S. N., Morker, M. U., Rawal, A., Kalra, P., Huebner, C.D. \& Greer, G. K. (2010). Genetic structure of the invasive tree Ailanthus in eastern United States cities. Journal of Botany.

Argyraki, A., Ramsey, M. H., \& Potts, P. J. (1997). Evaluation of portable X-ray fluorescence instrumentation for in situ measurements of lead on contaminated land. Analyst, 122(8), 743749.

Bååth, E. (1989). Effects of heavy metals in soil on microbial processes and populations (a review). Water, Air, and Soil Pollution, 47(3-4), 335-379.

Barash, I. (1990). Iron, siderophores and plant-pathogen interactions. Phytoparasitica, 18(3), 183-188.

Barash, I., Zion, R., Krikun, J., \& Nachmias, A. (1988). Effect of iron status on Verticillium wilt disease and on in vitro production of siderophores by Verticillium dahliae. Journal of Plant Nutrition, 11(6-11), 893-905.

Block, C. N., Shibata, T., Solo-Gabriele, H. M., \& Townsend, T. G. (2007). Use of handheld Xray fluorescence spectrometry units for identification of arsenic in treated wood. Environmental Pollution, 148(2), 627-633.

Brusa, A., \& Holzapfel, C. (2018). Population structure of Ailanthus altissima (Simaroubaceae): The role of land-use history and management. The Journal of the Torrey Botanical Society, 145(1), 55-69.

Byrd, S. M., Cavender, N. D., Peugh, C. M., \& Bauman, J. M. (2012). Sustainable landscapes: evaluating strategies for controlling autumn olive (Elaeagnus umbellata) on reclaimed surface mineland at the wilds conservation center in southeastern Ohio. Journal of the American Society of Mining and Reclamation, 193.

Cavender, N., Byrd, S., Bechtoldt, C. L., \& Bauman, J. M. (2014). Vegetation communities of a coal reclamation site in southeastern Ohio. Northeastern Naturalist, 21(1), 31-46.

Chibuike, G. U., \& Obiora, S. C. (2014). Heavy metal polluted soils: effect on plants and bioremediation methods. Applied and Environmental Soil Science.

Đunisijević Bojović, D., Đukić, M., Maksimović, V., Skočajić, D., \& Suručić, L. (2012). The effects of iron deficiency on lead accumulation in Ailanthus altissima (Mill.) Swingle seedlings. Journal of Environmental Quality, 41(5), 1517-1524.

Durand, T. C., Hausman, J. F., Carpin, S., Albéric, P., Baillif, P., Label, P., \& Morabito, D. (2010). Zinc and cadmium effects on growth and ion distribution in Populus tremula $\times$ Populus alba. Biologia Plantarum, 54(1), 191-194.

Goldweber, S. (1975). The use of a chelated iron to restore normal vigor to Verticillium wilt infected mango trees. Florida State Horticultural Society. 
Guerra, D., \& Anderson, A. J. (1985). The effect of iron and boron amendments on infection of bean by Fusarium solani. Phytopathology, 75(9), 989-991.

Hasanuzzaman, M., Nahar, K., Rahman, A., Al Mahmud, J., Hossain, S., Alam, K., Oku, H., \& Fujita, M. (2017). Actions of biological trace elements in plant abiotic stress tolerance. In Essential Plant Nutrients (pp. 213-274). Springer, Cham.

Hiremath, S., Lehtoma, K., \& Bauman, J. M. (2013). Survey for the presence of Phytophthora cinnamomi on reclaimed mined lands in Ohio chosen for restoration of the American Chestnut. Journal of the American Society of Mining and Reclamation, 68.

Illick, J.S.; Brouse, E.F. (1926) The Ailanthus tree in Pennsylvania; Pennsylvania Department of Forests and Waters: Harrisburg, PA, USA,

Inderbitzin, P., Bostock, R. M., Davis, R. M., Usami, T., Platt, H. W., \& Subbarao, K. V. (2011). Phylogenetics and taxonomy of the fungal vascular wilt pathogen Verticillium, with the descriptions of five new species. PloS One, 6(12), e28341.

Jaeckel, P., Krauss, G. J., \& Krauss, G. (2005). Cadmium and zinc response of the fungi Heliscus lugdunensis and Verticillium cf. albo-atrum isolated from highly polluted water. Science of the Total Environment, 346(1-3), 274-279.

Kasson, M. T., Davis, M. D., \& Davis, D. D. (2013). The invasive Ailanthus altissima in Pennsylvania: a case study elucidating species introduction, migration, invasion, and growth patterns in the northeastern US. Northeastern Naturalist, 20(m10), 1-60.

Kasson, M. T., O’Neal, E. S., \& Davis, D. D. (2015). Expanded host range testing for Verticillium nonalfalfae: potential biocontrol agent against the invasive Ailanthus altissima. Plant Disease, 99(6), 823-835.

Kasson, M. T., Short, D. P. G., O'Neal, E. S., Subbarao, K. V., \& Davis, D. D. (2014). Comparative pathogenicity, biocontrol efficacy, and multilocus sequence typing of Verticillium nonalfalfae from the invasive Ailanthus altissima and other hosts. Phytopathology, 104(3), 282292.

Kieu, N. P., Aznar, A., Segond, D., Rigault, M., Simond-Côte, E., Kunz, C., Soulie M. C., Expert, D., \& Dellagi, A. (2012). Iron deficiency affects plant defense responses and confers resistance to Dickeya dadantii and Botrytis cinerea. Molecular Plant Pathology, 13(8), 816-827.

Kowarik, I., \& Säumel, I. (2007). Biological flora of central Europe: Ailanthus altissima (Mill.) swingle. Perspectives in Plant Ecology, Evolution and Systematics, 8(4), 207-237.

Macur, R. E., Mathre, D. E., \& Olsen, R. A. (1991). Interactions between iron nutrition and Verticillium wilt resistance in tomato. Plant and Soil, 134(2), 281-286.

Maschek, O., \& Halmschlager, E. (2016). First report of Verticillium wilt on Ailanthus in Europe caused by Verticillium nonalfalfae. Plant Disease, 100(2), 529-529. 
Maschek, O., \& Halmschlager, E. (2017). Natural distribution of Verticillium wilt on invasive Ailanthus in eastern Austria and its potential for biocontrol. Forest Pathology, 47(5), e12356.

Maschek, O., \& Halmschlager, E. (2018). Effects of Verticillium nonalfalfae on Ailanthus and associated indigenous and invasive tree species in eastern Austria. European Journal of Forest Research, 137(2), 197-209.

McAvoy, T. J., Snyder, A. L., Johnson, N., Salom, S. M., \& Kok, L. T. (2012). Road survey of the invasive tree-of-heaven (Ailanthus altissima) in Virginia. Invasive Plant Science and Management, 5(4), 506-512.

McGladdery, C., Weindorf, D. C., Chakraborty, S., Li, B., Paulette, L., Podar, D., Pearson, D., Kusi, N.Y.O., \& Duda, B. (2018). Elemental assessment of vegetation via portable X-ray fluorescence (PXRF) spectrometry. Journal of Environmental Management, 210, 210-225.

McLaren, T. I., Guppy, C. N., \& Tighe, M. K. (2012). A rapid and nondestructive plant nutrient analysis using portable x-ray fluorescence. Soil Science Society of America Journal, 76(4), 1446-1453.

Miller, G. W., Huang, I. J., Welkie, G. W., \& Pushnik, J. C. (1995). Function of iron in plants with special emphasis on chloroplasts and photosynthetic activity. In Iron nutrition in soils and plants (pp. 19-28). Springer, Dordrecht.

Miller, J. H. (1990). Ailanthus altissima (Mill.) Swingle Ailanthus. Silvics of North America, 2, 101-104.

Morgan, T. J., George, A., Boulamanti, A. K., Álvarez, P., Adanouj, I., Dean, C., ... \& Andersen, L. K. (2015). Quantitative X-ray Fluorescence Analysis of Biomass (Switchgrass, Corn Stover, Eucalyptus, Beech, and Pine Wood) with a Typical Commercial Multi-Element Method on a WD-XRF Spectrometer. Energy \& Fuels, 29(3), 1669-1685.

Morton, V. and Staub, T. 2008 A Short History of Fungicides. Online, APSnet Features. doi: 10.1094/APSnetFeature-2008-0308.

Nesius, E. J. (1988). The first 100 years: a history of the West Virginia Agricultural and Forestry Experiment Station. West Virginia University, Agricultural and Forestry Experiment Station.

O’Neal, E. S., \& Davis, D. D. (2015). Intraspecific root grafts and clonal growth within Ailanthus altissima stands influence Verticillium nonalfalfae transmission. Plant Disease, 99(8), 1070-1077.

Ospina-Giraldo, M. D., Mullins, E., \& Kang, S. (2003). Loss of function of the Fusarium oxysporum SNF1 gene reduces virulence on cabbage and Arabidopsis. Current Genetics, 44(1), 49-57.

Paltridge, N. G., Milham, P. J., Ortiz-Monasterio, J. I., Velu, G., Yasmin, Z., Palmer, L. J., Guild, G. \& Stangoulis, J. C. (2012). Energy-dispersive X-ray fluorescence spectrometry as a tool for zinc, iron and selenium analysis in whole grain wheat. Plant and Soil, 361(1-2), 261-269. 
Peugh, C. M., Bauman, J. M., \& Byrd, S. M. (2013). CASE STUDY: Restoring Remnant Hardwood Forest Impacted by Invasive tree-of-heaven (Ailanthus altissima). Journal American Society of Mining and Reclamation, 2(2), 99-112.

Plass, W. T. (1975). An evaluation of trees and shrubs for planting surface-mine spoils. Res. Pap. NE-317. Upper Darby, PA: US Department of Agriculture, Forest Service, Northeastern Forest Experiment Station. 8p., 317.

Prasad, M. N. V. (Ed.). (2013). Heavy metal stress in plants: from biomolecules to ecosystems. Springer Science \& Business Media.

Pushnik, J. C., Miller, G. W., \& Manwaring, J. H. (1984). The role of iron in higher plant chlorophyll biosynthesis, maintenance and chloroplast biogenesis. Journal of Plant Nutrition, 7(1-5), 733-758.

Rahman, M., \& Punja, Z. K. (2006). Influence of iron on Cylindrocarpon root rot development on ginseng. Phytopathology, 96(11), 1179-1187.

Ranieri, E., Fratino, U., Petrella, A., Torretta, V., \& Rada, E. C. (2016). Ailanthus altissima and Phragmites Australis for chromium removal from a contaminated soil. Environmental Science and Pollution Research, 23(16), 15983-15989.

Rebbeck, J., Malone, M. A., Short, D. P. G., Kasson, M. T., O'Neal, E. S., \& Davis, D. D. (2013). 678701. First Report of Verticillium wilt Caused by Verticillium nonalfalfae on Tree-ofHeaven (Ailanthus altissima) in Ohio. Plant Disease, 97(7), 999-999.

Reidinger, S., Ramsey, M. H., \& Hartley, S. E. (2012). Rapid and accurate analyses of silicon and phosphorus in plants using a portable X-ray fluorescence spectrometer. New Phytologist, 195(3), 699-706.

Sacristán, D., Rossel, R. A. V., \& Recatalá, L. (2016). Proximal sensing of Cu in soil and lettuce using portable X-ray fluorescence spectrometry. Geoderma, 265, 6-11.

Sahu, M. P., Sharma, D. D., Jain, G. L., \& Singh, H. G. (1987). Effects of growth substances, sequestrene 138-Fe and sulphuric acid on iron chlorosis of garden peas (Pisum sativum L.). Journal of Horticultural Science, 62(3), 391-394.

Schall, M. J., \& Davis, D. D. (2009). Ailanthus altissima wilt and mortality: etiology. Plant Disease, 93(7), 747-751.

Scheffer, R. J., Voeten, J. G. W. F., \& Guries, R. P. (2008). Biological control of Dutch elm disease. Plant Disease, 92(2), 192-200.

Snyder, A. L., Kasson, M. T., Salom, S. M., Davis, D. D., Griffin, G. J., \& Kok, L. T. (2013). First report of Verticillium wilt of Ailanthus altissima in Virginia caused by Verticillium nonalfalfae. Plant Disease, 97(6), 837-837. 
Snyder, A. L., Salom, S. M., \& Kok, L. T. (2014). Survey of Verticillium nonalfalfae (Phyllachorales) on tree-of-heaven in the southeastern USA. Biocontrol Science and Technology, 24(3), 303-314.

Towett, E. K., Shepherd, K. D., Sila, A., Aynekulu, E., \& Cadisch, G. (2015). Mid-infrared and total X-ray fluorescence spectroscopy complementarity for assessment of soil properties. Soil Science Society of America Journal, 79(5), 1375-1385.

Vorwieger, A., Gryczka, C., Czihal, A., Douchkov, D., Tiedemann, J., Mock, H. P., Jakoby, M., Weisshaar, B., Saalbach, I. \& Bäumlein, H. (2007). Iron assimilation and transcription factor controlled synthesis of riboflavin in plants. Planta, 226(1), 147-158.

Weindorf, D. C., Zhu, Y., Chakraborty, S., Bakr, N., \& Huang, B. (2012). Use of portable X-ray fluorescence spectrometry for environmental quality assessment of peri-urban agriculture. Environmental Monitoring and Assessment, 184(1), 217-227.

Wickert, K. L., O’Neal, E. S., Davis, D. D., \& Kasson, M. T. (2017). Seed production, viability, and reproductive limits of the invasive Ailanthus altissima (tree-of-heaven) within invaded environments. Forests, 8(7), 226.

Zielenkiewicz, T., Radomski, A., \& Zawadzki, J. (2012). XRF examination of matrix uniqueness in chosen deciduous wood species. European Journal of Wood and Wood Products, 70(6), 845849 . 


\title{
Chapter 5
}

\section{Resolving inter- and intra-species boundaries in phytopathogenic Verticillium spp. by MALDI-TOF mass spectrometry}

\author{
Kristen Wickert
}

\begin{abstract}
Verticillium nonalfalfae has the potential to be used as a biocontrol for the invasive tree-ofheaven (Ailanthus altissima), however there are concerns over its widespread utilization due to discrepancies in host range of different species of Verticillium and different strains within $V$. nonalfalfae. Verticillium isolates from eggplant, a member of the Solanaceae family, caused higher disease ratings on tomatoes which are also in Solanaceae but did not cause severe disease on Ailanthus, a tree species in the very distant family Simaroubaceae. Previous multi-locus phylogenetic analyses have failed to resolve host-level differences within $V$. nonalfalfae. While phylogenetics may not be appropriate for resolving host associations; investigating the expressed proteome of closely related Verticillium isolates may lead to a better understanding of functional differences and host selectivity. The proteomes of specific isolates could compliment classic pathogenicity tests which allude to host selectivity. Matrix assisted laser desorption ionization time of flight - mass spectrometry (MALDI-TOF-MS) may be able to help create a more in depth proteomic analysis to identify specific proteins. Cultures of 32 isolates of $V$. nonalfalfae, $V$. alfalfae, $V$. dahliae, and $V$. albo-atrum originally isolated from 12 distinct plant host species were analyzed using MALDI-MS biotyping. Unlike the previously reported phylogenic and genomic data, this analysis yielded unique protein profiles for Verticillium species and specific isolates that corresponded to their host origin, which complemented previous pathogenicity studies. The results of this study provide the first evidence that proteomics could help regulatory agencies confirm they are utilizing the Ailanthus host specific $V$. nonalfalfae isolate to control for Ailanthus without posing a threat to neighboring crops or forest trees that are susceptible to strains of $V$. nonalfalfae from other plant hosts.
\end{abstract}




\section{Introduction}

Tree-of-heaven (Ailanthus altissima (Mill.) Swingle) was introduced to the United States in 1784 in Philadelphia, PA and since then it has spread to most of the conterminous U.S. states and locations in and Europe, where it is considered a highly invasive species (Kowarik and Säumel 2007, Aldrich et al. 2010, Kasson et al. 2013). Throughout the early 2000's a new vascular wilt disease was found killing Ailanthus across Ohio, Virginia, and Pennsylvania (Rebbeck et al. 2013, Schall and Davis 2009, Snyder et al. 2013, Kasson et al. 2014). The causal agent of this disease was confirmed as Verticillium albo-atrum Reinke \& Berthold, now recognized as $V$. nonalfalfae Inderbitzen. Since its discovery, many experiments have sought to confirm the utility of $V$. nonalfalfae as a potent native biocontrol against Ailanthus. As such, a central determinant for use of biocontrol relates to its host range and any potential non-target impacts. Host specificity of $V$. nonalfalfae was considered a top priority. In 2005 , Schall and Davis (2009), in additional to efficacy studies on Ailanthus (Schall and Davis 2009), conducted host range testing of seven common co-occurring native forest tree species, common in the Mid-Atlantic region. Testing of seedlings of these species occurred in the greenhouse as well as in forests plots where native tree hosts were directly inoculated with $V$. nonalfalfae (Schall and Davis 2009). In both cases, $V$. nonalfalfae was not found to be pathogenic on any of the artificially inoculated hosts except for striped maple (Acer pensylvanicum L.), including all individuals used in both greenhouse and forest studies. However, complimentary studies that sought to evaluate exposure risk of striped maple to Verticillium wilt by $V$. nonalfalfae through natural spread from infected Ailanthus, found that this species experienced $<1 \%$ mortality across the landscape. These results helped emphasize that the actual threat of striped maple succumbing to Verticillium wilt in Verticillium treated tree-of-heaven stands was low (Schall and Davis 2009). 
Between May 2007 and July 2010, Kasson and colleagues (2015) replicated and expanded on Schall and Davis's 2009 host range work and subjected 71 species of forest trees and shrubs to inoculation with $V$. nonalfalfae strain VnAa140, including several species closely related to tree-of-heaven (Simaroubaceae) but are native to areas outside of Pennsylvania. Of the 71 species inoculated, only three native tree host species showed signs of wilt and mortality due to infections via natural spread in inoculated Ailanthus stands: devil's walking stick (Aralia spinose L.), striped maple and staghorn sumac (Rhus typhina L.) at 17\%, 13\% and 16\% wilt incidence respectively (Kasson et al. 2015). However, V. nonalfalfae was never successfully reisolated from the staghorn sumac, therefore Koch's postulates were never fulfilled. These trees also recovered the next season, while Ailanthus continued to suffer from $100 \%$ mortality and no recovery. Low infection rates on a select number of weedy, commercially low-value forest species provided essential baseline data to permit the continued use of $V$. nonalfalfae in successive biocontrol studies. Nevertheless, follow-up studies assessing application and transmission in a forest setting have enhanced our understanding of the utility of $V$. nonalfalfae strain VnAa140 (Kasson et al. 2015, O’Neal and Davis 2015, Snyder et al. 2014). Recent investigations of a newly confirmed strain from Europe has helped to delimit host range and efficacy of $V$. nonalfalfae against European populations of this invasive species. (Maschek and Halmschlager 2016, Maschek and Halmschlager 2017, Maschek and Halmschlager 2018). Members of the Verticillium genus cause a vascular wilt to more than 350 species of both herbaceous and woody plants (Markell et al. 2015, Pegg and Brady 2002). Compared to V. dahliae, $V$. nonalfalfae has a relatively small host range that excludes alfalfa (Medicago sativa L.) as the name suggests, and includes important agronomic crops such as hops (Humulus lupulus L.), kiwifruit (Actinidia chinensis Planch.), members of the nightshade (Solanaceae) 
family, petunia (Petunia spp. Juss.), spinach (Spinacia oleracea L.), and the forest shrub species deer brush (Ceanothus integerrimus Hook. \& Arn.) (Kasson et al. 2014). Despite more than 15 years of investigation of Verticillium wilt of Ailanthus, widespread utilization and commercialization of $V$. nonalfalfae has yet to be fully realized due to several factors: 1) cost associated with registration; 2) regulatory barriers; and 3) incongruence between recent host specificity studies and historic studies that included $V$. nonalfalfae, $V$. albo-atrum sensu stricto and $V$. alfalfae under a single Latin binomial "V. albo-atrum".

A multi-gene phylogeny of $V$. nonalfalfae constructed by Kasson et al. in 2014 included 37 Verticillium isolates from different hosts to try to detect a phylogenetic signal in $V$. nonalfalfae that corresponded to differences in pathogenicity based on comparative pathogenicity assays. This concatenated four-locus alignment failed to resolve clades exhibiting differences in host specificity, with one exception. V. nonalfalfae isolates from kiwifruit in Chile formed a genealogically exclusive clade, or multilocus sequence type (MLST), separate from the clade that includes all other $V$. nonalfalfae isolates from North America and Europe (Kasson et al. 2014).

With the advancement in molecular bioinformatic tools and methods, it is possible to analyze organisms more in-depth than just comparing select loci or even entire genomes, which can provide some level of insight (Kasson et al. 2019). Metabolomics, transcriptomics, and proteomics allow for an organism's entire function to be deciphered with qualitative and/or quantitative measurement of the functional properties that directly affect the function of an organism (Shulaev 2006, Doyle 2011). Proteomic techniques allow us to analyze the complete proteome of an organism (Bhadauria et al. 2007). The study of proteomics involves the identification and quantification of large mostly intact molecule proteins. Matrix assisted laser 
desorption ionization - time of flight - mass spectrometry (MALDI-TOF-MS) has been used to create an intact protein fingerprints as biomarkers for distinct proteins profiles (Pasch and Schrepp 2013). MALDI has a history of being utilized in the medical field including detecting medically important human pathogenic fungi, such as Scytalidium dimidatum (Penz.) Crous \& Slippers, Trichophyton rubrum (Castell.) Sabour and Penicillium marneffei Segretain (Alshawa et al. 2012, Lau et al. 2016). In 2014, use of MALDI-TOF was expanded to the field of plant pathology for the identification of fungi, such as Aspergillus, Fusarium, Penicillium or Trichoderma, inside of plant tissues to the level of genus, species, and even strain (Chalupová et al. 2014).

Investigating the expressed proteome of closely related plant pathogenic Verticillium spp. with the use of MALDI-TOF-MS may lead to a better understanding of the differences in pathogenicity among strains recovered from various plant hosts. The results from a highthroughput proteomics-based approach could provide the resolution needed to address the concerns of regulators and land-use managers.

This study elucidates the incongruence between phylogenetic studies and crosspathogenicity assays of Verticillium species, specifically $V$. nonalfalfae. The objectives are: i) to evaluate the pathogenicity of Verticillium species and strains on Ailanthus using both traditional disease ratings and an independent rating system; and ii) to compare protein fingerprints along Verticillium spp. and intraspecific strains to detect differences that can help clarify relationships among closely related phytopathogenic Verticillium species. 


\section{Materials and Methods \\ Inoculum preparation}

Verticillium cultures were actively maintained on Difco potato dextrose agar (PDA; BD and Co., Franklin Lakes, NJ, USA) amended with streptomycin (Sigma-Aldrich, St. Louis, MO, USA) and tetracycline (Fisher Scientific, Pittsburgh, PA, USA), and grown at ambient temperature following a 16-h light/8-h dark cycle. Inoculum was prepared as previously described by Kasson et al. 2014. Briefly, 2-week-old cultures of V. nonalfalfae isolate VnAa140 were flooded with $5 \mathrm{ml}$ of sterile water and the surface scraped with a sterile disposable cell spreader. The resulting spore suspension was vortexed to dislodge conidia from associated mycelia to homogenize the suspension prior to passage through a sterile milk filter (KenAg, Ashland, $\mathrm{OH}$ ). Conidial concentrations were determined using a hemocytometer and adjusted to $1 \times 10^{7}$ conidia $\mathrm{ml}^{-1}$. Viability of conidia was evaluated by counting CFU from 10 -fold dilutions of suspensions on PDA+A plates. Only inoculum with $>80 \%$ viability was utilized.

\section{Pathogenicity tests of Ailanthus and Tomato}

Previously, Kasson et al. 2014 conducted comparative pathogenicity testing of representative isolates of $V$. alfalfae and $V$. nonalfalfae on Ailanthus. These investigations included six isolates of $V$. nonalfalfae and one isolate of $V$. alfalfae from a combined six hosts tested against growth chamber Ailanthus seedlings for a total of 8 weeks. Upon termination of the experiment, indices developed by Qin et al. (2006) utilized to quantify disease on a scale from 0 to 6 , where $0=$ no symptoms, $1=1$ to $25 \%$ vascular discoloration (VD), $2=26$ to $50 \%$ $\mathrm{VD}, 3=51$ to $75 \% \mathrm{VD}, 4=76$ to $100 \% \mathrm{VD}, 5=4+$ wilt, and $6=5+$ mortality. Mean ratings were calculated based on average ratings of 10 plants per treatment, including the negative control. Isolates yielding a mean disease severity $\geq 2$ were considered pathogenic (Qin et al. 
2006). Identical studies were conducted on tomato by Kasson et al. but never published including the seven isolates inoculated into Ailanthus as well as 12 additional isolates. In addition to assessing disease severity using indices developed by Qin et al. (2006), mean area under the disease progress curve (AUDPC) values (Shall and Davis 2009) were assessed.

\section{Pathogenicity Testing of Verticillium Isolates}

To permit comparisons of pathogenicity of different Verticillium isolates, 80 Ailanthus seedlings (susceptible seed source HPA-62; Wickert et al. 2017) per treatment were planted in Sun Gro Potting mix (Sun Gro Horticulture, Agawam, MA) in individual pots. Sample size was eight plants per treatment and seedlings were subjected to one of ten treatments (Table 5-1). Three Verticillium species were included in pathogenicity comparisons: V. nonalfalfae, V. alboatrum, and V. alfalfae. Verticillium nonalfalfae isolates were originally recovered from four different hosts: Ailanthus, hops, tomato (Solanum lycopersicum L.), and spinach. This builds off a previous study that evaluated pathogenicity of seven isolates recovered from six hosts (Kasson et al. 2015). Verticillium albo-atrum was originally isolated from soil in symptomatic potato fields. Verticillium alfalfae was originally isolated from alfalfa. Seedlings were plants were gently uprooted and root dip inoculated with a conidial spore suspension of their respective Verticillium isolate with a concentration of $1 \times 10^{7}$ conidia/ml and replanted in their respective individual treatment pots. Additionally, there was a control of sterile water. Seedlings were allowed to grow for eight weeks post inoculation. Seedlings were rated on a $0-4$ scale $0-$ healthy, 1 - necrotic margins, 2 - mild wilt and chlorosis, 3- severe wilt, 4 - dead. After 8 weeks, stems were harvested and plated for re-isolation. Destructively sampled seedlings were surface sterilized in $10 \%$ bleach for four minutes and aseptically placed on a PDA plate. Upon emergence from stem tissues, fungi were aseptically subcultured onto new PDA plates and 
allowed to grow to confirm colony identity. For long-term storage, re-isolated cultures were transferred to PDA slants and maintained at $4^{\circ} \mathrm{C}$.

\section{Phylogenetic Resolution via PCR Methods}

To compliment MALDI approaches and independently confirm species' identities for included Verticillium species, a PCR utilizing distinct primers described by Inderbitzen et al. (2013) was utilized. Thirty-two Verticillium fungal strains including four putative Verticillium species derived from 14 different hosts, were included, 11 of which were originally isolated from Ailanthus (Kasson et al. 2014). Fungal isolates were cultured on Difco potato dextrose agar (PDA; BD and Co., Franklin Lakes, NJ, USA) for one week (Table 5-1), after which mycelia was scraped, transferred to Difco potato dextrose broth (PDB; BD and Co., Franklin Lakes, NJ, USA), and incubated for 10 days. Mycelia were harvested, dried between filter papers, and transferred to 1.5-ml Eppendorf tubes. Genomic DNA was extracted using a Wizard kit (Promega, Madison, WI, USA). DNA was suspended in $75 \mu 1$ Tris-EDTA (TE) buffer preheated to $65^{\circ} \mathrm{C}$.

Four different PCR assays were conducted using species specific primers developed by Inderbitzen et al. 2013. All PCRs were performed using primers from IDT (Integrated DNA Technologies, Coralville, IA, USA) and BioLine PCR kits (Bioline USA Inc., Taunton, MA) in 26- $\mu 1$ reaction mixtures containing $1 \mu 1$ genomic DNA, $10 \mu l$ nuclease-free water, and 12.5 BioLine PCR master mix. In all the PCR primer assays, $1 \mu$ of each primer (forward and reverse) was used, whereas in four-primer assays.

Thermal cycling profiles were $94^{\circ} \mathrm{C}$ for 2 minutes, 35 cycles of $94^{\circ} \mathrm{C}$ for 10 seconds, optimized annealing temperatures of $57^{\circ} \mathrm{C}$ for $V$. alfalfae, $64^{\circ} \mathrm{C}$ for $V$. nonalfalfae, $67^{\circ} \mathrm{C}$ for $V$. dahliae and $62^{\circ} \mathrm{C}$ for $V$. albo-atrum for 20 seconds, $72^{\circ} \mathrm{C}$ for 60 seconds, and then a final 
extension of $72^{\circ} \mathrm{C}$ for 7 minutes. For gel electrophoresis, $4 \mu 1$ of $1 \times \mathrm{SYBR}$ gold (Invitrogen, Grand Island, NY, USA) and $4 \mu \mathrm{l}$ of $5 \times$ loading dye (5Prime, Gaithersburg, MD) were added to PCR products, which then were loaded onto a 1.5\%, wt/vol, agarose gel (Amresco, Solon, OH, USA) made with $0.5 \%$ Tris-borate-EDTA buffer (Amresco, Solon, OH, USA). Electrophoresis was performed at $115 \mathrm{~V}$ for 1 to $2 \mathrm{~h}$, and bands were visualized on a $\mathrm{UV}$ transilluminator (Syngene, Frederick, MD, USA). For size comparison, 100-bp and 1-kbp molecular ladders (Omega Bio-tek, Norcross, GA, USA) were included in gels.

\section{MALDI-TOF-MS}

\section{Sample preparation}

Previous multi-locus sequence typing (MLST) of Verticillium spp. showed all $V$.

nonalfalfae isolates formed a single clonal clade, except for kiwifruit from Chile. The inability of MLST to resolve intra-specific variation in the North American and European clade necessitated the use of a more robust methodology to differentiate fungal strains. Thirty-two Verticillium fungal strains including four Verticillium species derived from 14 different plant hosts, including 11 strains originally isolated from Ailanthus were analyzed using MALDI-TOF-MS (Table 5-1). Verticillium cultures were actively maintained on Difco potato dextrose agar (PDA; BD and Co., Franklin Lakes, NJ, USA) amended with streptomycin (Sigma-Aldrich, St. Louis, MO, USA) and tetracycline (Fisher Scientific, Pittsburgh, PA, USA), and grown at ambient temperature following a 16-h light/8-h dark cycle. Five colonies per isolate were plated individually and served as biological replicates. For optimal spectral quality for peptides and proteins, fungal isolates were prepared for MALDI-TOF MS 24 hours prior to analysis and stored overnight at $80{ }^{\circ} \mathrm{C}$. Ten $\mathrm{mg}$ of fungal material was transferred directly from the growth media to a $1.5-\mathrm{ml}$ Eppendorf tube and suspended in $100 \mu \mathrm{l}$ of formic acid-water (70:30 [vol/vol]). After an 
incubation of $10 \mathrm{~min}$ at room temperature, an equal volume of acetonitrile was added. Samples were incubated again at room temperature for $10 \mathrm{~min}$ and subsequently centrifuged.

One microliter of the fungal smear was applied to the polished steel plate (MTP 384 target Plate Ground steel BS, Bruker) which lacked melanized hyphae. This sample was uniformly mixed in $1 \mu 1$ of Synaptic acid (Bruker Daltonik) $(20 \mathrm{mg} / \mathrm{mL}$ in $50 \%$ acetonitrile in $0.1 \%$ trifluoracetic acid) matrix and allowed to dry at room temperature. The matrix absorbs the ultraviolet light from the machinery and converts it to heat energy. The matrix allowed for vaporization of the sample. Synaptic acid matrix was applied over the entire fungal smear tissue section, and mass spectra are acquired across the entire tissue section in an ordered array. Fungal tissue on a conductive steel plate was placed in the source of the MALDI-TOF-MS instrument (Bruker, Billerica, MA) and a laser was fired at the surface to desorb and ionize molecules within the fungal smears at 1000 repetitions per smear. Each individual spot has an associated mass spectrum that is analogous to a pixel in a digital image. One can generate an average spectrum from the entire tissue section to aid in the generation of MS images. These unique methods for fungi were based off of human tissue sample methods described by Seely and Caprioli (2011).

Ions with smaller $\mathrm{m} / \mathrm{z}$ values and higher charges moved faster through the instrument drift space column until they reached the detector which allowed for differences in time of flight to occur. The acquisition and analysis of mass spectra were performed by an UltrafleXtreme MALDI-TOF/TOF mass spectrometer (Bruker Daltonik) using the fleXcontrol software package (version 3.0) with the mass spectrometer operating in linear positive mode with a mass rang of 9,000-30,000 Daltons. Bovine serum albumin and myoglobin (Protea Biosciences) were used for linear mode mass calibration. For each strain, two preparations of sample material were analyzed. Spectral alignment, peak integration, and data quality control was performed using the 
fleXanalysis (version 3.1). Processed spectral files were then transferred to the ClinPro Tools software package for differential analysis, including principal component analysis and ANOVA, in order to identify significantly different intact mass protein peaks.

\section{Statistical Analyses}

Area under the disease curve provides a quantitative summary of disease intensity over time. This method allows for calculation of the average disease intensity between each pair of adjacent time points. Additionally, a contingency analysis of disease rating by treatment was performed. Statistical analysis was performed SAS JMP 13.1.0 (SAS Institute Inc., Cary, NC).

\section{Results}

\section{Pathogenicity Testing of Verticillium Isolates}

Isolates from Ailanthus (S1 and S17) caused the most mortality to Ailanthus seedlings with mean disease ratings of 4.0 and 3.5 respectively. One isolate from Ailanthus (S6) did not have a high mean disease rating (0.5) and caused minimal disease to Ailanthus seedlings. Inoculations with isolates from tomato (S26), hops (S15), and spinach (S27) did not result in any outward symptoms of disease on Ailanthus seedlings (Figure 5-1). Isolates from hops (S28), alfalfa (S2) and potato (S8) caused minimal wilt on Ailanthus seedlings with mean disease ratings of $0,1.3$, and 0 respectively. One seedling in the negative control died likely due to inadequate watering, resulting in the water control having a mean disease rating of 0.75. The area under the disease curve was largest for the two pathogenic Ailanthus isolates (S1 and S17) was 14.65 and 13.5 respectively, with all other isolates having an AUDCP lower than 5.125. When compared in an ANOVA and a student's t-test, the disease ratings caused by the isolates were statistically significantly different from the other with a p-value of 0.01. Interestingly, isolate S2 (V. alfalfae) caused disease on Ailanthus which Kasson et al. 2014 also experienced with this isolate recovered from alfalfa (Figure 5-2). Both sets of 
results including indices developed by Qin et al. (2006) and mean area under the disease progress curve (AUDPC) values indicate the isolates from Ailanthus are the only isolates that cause outward symptoms of disease on Ailanthus, while isolates from tomato and eggplants are the only isolates that cause outward symptoms of disease on tomato. There was a statistically significant difference between the treatments in the pathogenicity testing with a Prob $>$ ChiSq $<0.0001$.

\section{Phylogenetic Resolution via PCR Methods}

Species boundaries for certain isolates were confirmed while others had amplicons for more than one species which either suggests a mixed template or the primer binding site were not as species specific as anticipated based off of previous observations by Inderbitzen et al. 2013. While the PCR methods confirms some isolates' identities, double bands or cloudy bands for two different primer PCR runs for some isolates, suggests that the isolates identity could have some incongruence with specific speciation based off of strain variability.

\section{MALDI-TOF-MS}

Unlike the previously reported phylogenic and genomic data, this analysis yielded unique protein profiles for Verticillium species and specific isolates that corresponded to their host origin. These results support previous pathogenicity studies left unresolved through traditional phylogenetic analyses. Due to the minimization of protein fragmentation, distinct protein peaks for the Verticillium isolates were able to be visualized and averaged from the five replicated fungal smears (Figure 5-3). These results were able to be separated and clustered in several interpretations of principal component analyses (PCA). These PCAs show relative abundance of the protein/peptides on the $\mathrm{Y}$-axis and $\mathrm{m} / \mathrm{z}$ mass-to-charge ratio on the $\mathrm{X}$-axis. Distinct protein peaks are the output which reflects cleavage/breaking of a chemical bond. The height and 
distance between peaks allows to conclude what individual samples are, although at this time many of these peaks are undescribed for non-human pathogenic fungi. At this time, the differences in peaks relative abundance can be compared across many samples allowing for clustering of samples in PCAs (Figure 5-4). The PCA shows isolates of $V$. nonalfalfae from Ailanthus cluster with $V$. nonalfalfae isolates from Acer pennsylvanicum and Actinidia chinensis while separating from isolates from hops and Solanaceous crops (Figure 5-4). An ANOVA and Tukey's Test with 95\% confident grouped clusters that are statistically significant from each other (p-value of 0.05). Verticillium nonalfalfae isolates isolated from Solanaceous crops (potato, tomato, and eggplant) and hops group together, but separate from Ailanthus isolates. $V$. albo-atrum also grouped with the Solanaceous crops and hops isolates. Isolates of $V$. dahliae and V. alfalfae formed their own distinct clusters (Figure 5-4). When each replicate of each isolate has its respective protein abundances highlighted in a heat map, protein expression patterns can be compared across all replicates (Figure 5-5). The high abundance of proteins at specific $\mathrm{m} / \mathrm{z}$ supports the 3D cluster PCAs in that Verticillium nonalfalfae isolates from both Ailanthus and Acer pennsylvanicum have similar protein abundances. All four species of Verticillium additionally have different abundances of proteins throughout their spectra profile. Individual spectra images for the individual species made as an average of all replicates allows for comparisons of similarities and differences between the four Verticillium species included in the analysis (Figure 5-6).

\section{Discussion}

Since 2005, V. nonalfalfae has been utilized as a biocontrol of the invasive Ailanthus. Despite its regional success, widespread release or commercialization has been hampered due to concerns regarding both its native status and host specificity. The results of this study 
provide strong evidence that support clear gene expression differences between Ailanthus isolates and those that impact Solanaceae crops and hops. These results are also supported by cross-pathogenicity assays of $V$. nonalfalfae that show isolates from Ailanthus are more adapted to Ailanthus while isolates from tomato and other Solanaceae crops are more adapted to these hosts. Coupled with low incidence on native hosts, these data provide evidence in support of a native pathogen that showed host specific aggressiveness towards an invasive plant species.

While the results from the MALDI-TOF-MS analysis are straight forward, this type of mass spectrometry has been under-utilized outside of medical microbiology with only a few studies focused on phytopathogenic fungi. Furthermore, this type of proteomics cannot identify which proteins are contributing to pathogenicity of certain strains, only that differences among strains exist. Moreover, fungal protein databases remain underpopulated, which limits our ability to understand the function of the distinct species-specific proteins in high abundance in the different species (Rep 2005). Hydrophobins, a group of small ( 100 amino acids) cysteine-rich proteins, may be one such example of proteins that play a role in differential pathogenicity. Hydrophobins have been studied extensively in the fungus that causes the rice blast disease, Magnaporthe grisea (T.T. Hebert) M.E. Barr (Talbot et al. 1993). Several virulence gene clusters in fungi and the avirulence gene clusters in the plants associated with disease have been described and it is possible to identify the proteins observed in future endeavors (Idnurm and Howelett 2001). Even small differences in these gene clusters can have a profound impact on pathogenicity or result in a non-pathogenic organism. Function of proteins in fungi control constant function demands and more 
specialized processes like invasion of host with the use of effector proteins and defense methods such as melanization (Gomez and Nosanchuk 2003).

Genomes of V. nonalfalfae from Ailanthus allows for continued research to identify the distinct protein peaks which are likely associated with the specialized host specificity of Verticillium species and strains (Kasson et al. 2019). The genome can be compared to the recent genomes of $V$. nonalfalfae from hops and the $V$. dahliae strain described earlier this decade.

This study helps demonstrate that tools long used in medical microbiology can be useful in understanding closely related populations of phytopathogenic fungi. This study paves the way for new and exciting questions in proteomics-based approaches to understanding plant disease.

\section{Conclusions}

Although phylogenetics were previously unable to resolve differences in strains of Verticillium from different hosts, analyzing the proteome of these strains provided distinct protein peaks potentially relating to functions related to host affinity. These peaks need to be analyzed and confirmed in related gene function, however findings from these studies support the utilization of specific strains of $V$. nonalfalfae as a host specific pathogen for Ailanthus. The results of this study provide the first evidence that high-throughput proteomics can help regulatory agencies distinguish populations of closely related pathogens and help confirm they are utilizing the Ailanthus host-specific V. nonalfalfae isolate to control for Ailanthus. 


\section{Acknowledgements}

The author would like to thank Dr. Erin Seeley for providing her expertise in the field of proteomics and for allowing members of the Kasson Lab to utilize the MALDI machine at New River Labs in Morgantown, WV. Funding for this project was provided to Dr. Matthew Kasson and Kristen Wickert through APHIS. 


\section{Tables}

Table 5-1: Verticillium isolates and their original host species used in pathogenicity testing of Ailanthus to create area under the disease curve and MALDI-TOF-MS analysis. PCR column refers to what the isolate showed bands in the PCR analysis. $\mathrm{Vn}=V$. nonalfalfae, $\mathrm{Valf}=V$. alfalfae, $\mathrm{Vd}=V$. dahliae, $\mathrm{Valb}=\mathrm{V}$. albo-atrum, $-=$ no bands were illuminated in gel results. A slash between names indicates that two distinct bands were produced for that isolate in the respective species' PCR.

\begin{tabular}{|c|c|c|c|c|c|}
\hline Isolate ID & Fungal Species & Host of Isolate Origin & Pathogenicity Testing & PCR Results & MALDI -TOF-MS \\
\hline S1 & Verticillium nonalfalfae & Ailanthus altissima & $\mathrm{x}$ & $\mathrm{Vn}$ & $\mathrm{x}$ \\
\hline S2 & Verticillium alfalfae & Medicago sativa & $\mathrm{x}$ & Valf & $\mathrm{x}$ \\
\hline S3 & Verticillium nonalfalfae & Ceanothus integerrimus & & $\mathrm{Vn}$ & $\mathrm{x}$ \\
\hline S4 & Verticillium nonalfalfae & Solanum melongena & & - & $\mathrm{x}$ \\
\hline S5 & Verticillium nonalfalfae & Actinidia chinensis & & $\mathrm{Vn}$ & $\mathrm{x}$ \\
\hline S6 & Verticillium nonalfalfae & Ailanthus altissima & $\mathrm{x}$ & - & $\mathrm{x}$ \\
\hline S7 & Verticillium nonalfalfae & Solanum tuberosum & & $\mathrm{Vn}$ & $\mathrm{x}$ \\
\hline S8 & Verticillium albo-atrum & Solanum tuberosum & $\mathrm{x}$ & - & $\mathrm{x}$ \\
\hline S11 & Verticillium nonalfalfae & Actinidia chinensis & & Vn/Valf & $\mathrm{x}$ \\
\hline $\mathrm{S} 12$ & Verticillium alfalfae & Medicago sativa & & Valf & $\mathrm{x}$ \\
\hline S13 & Verticillium nonalfalfae & Ailanthus altissima & & $\mathrm{Vn}$ & $\mathrm{x}$ \\
\hline S14 & Verticillium nonalfalfae & Ailanthus altissima & & $\mathrm{Vn}$ & $\mathrm{x}$ \\
\hline S15 & Verticillium nonalfalfae & Humulus lupulus & $\mathrm{x}$ & - & $\mathrm{x}$ \\
\hline S16 & Verticillium dahliae & Lactuca sativa & & - & $\mathrm{x}$ \\
\hline S17 & Verticillium nonalfalfae & Ailanthus altissima & $\mathrm{x}$ & Vn/Valf & $\mathrm{x}$ \\
\hline S18 & Verticillium nonalfalfae & Rosa multiflora & & Vn/Valf & $\mathrm{x}$ \\
\hline S19 & Verticillium nonalfalfae & Ailanthus altissima & & $\mathrm{Vn}$ & $\mathrm{x}$ \\
\hline S20 & Verticillium nonalfalfae & Acer pensylvanicum & & $\mathrm{Vn}$ & $\mathrm{x}$ \\
\hline S21 & Verticillium nonalfalfae & Ailanthus altissima & & Vn/Valf & $\mathrm{x}$ \\
\hline S22 & Verticillium nonalfalfae & Actinidia chinensis & & $\mathrm{Vn}$ & $\mathrm{x}$ \\
\hline S23 & Verticillium nonalfalfae & Humulus lupulus & & - & $\mathrm{x}$ \\
\hline S24 & Verticillium alfalfae & Medicago sativa & & - & $\mathrm{x}$ \\
\hline S25 & Verticillium nonalfalfae & Solanum tuberosum & & - & $\mathrm{x}$ \\
\hline S26 & Verticillium nonalfalfae & Solanum lycopersicum & $\mathrm{x}$ & $\mathrm{Vn}$ & $\mathrm{x}$ \\
\hline S27 & Verticillium nonalfalfae & Spinacia oleracea & $\mathrm{x}$ & Vn/Valf & $\mathrm{x}$ \\
\hline S28 & Verticillium nonalfalfae & Humulus lupulus & $\mathrm{x}$ & $\mathrm{Vn}$ & $\mathrm{x}$ \\
\hline S29 & Verticillium nonalfalfae & Pisum sativum & & Valb & $\mathrm{x}$ \\
\hline S30 & Verticillium nonalfalfae & Ailanthus altissima & & $\mathrm{Vn}$ & $\mathrm{x}$ \\
\hline S31 & Verticillium nonalfalfae & Aralia spinosa & & $\mathrm{Vn}$ & $\mathrm{x}$ \\
\hline S32 & Verticillium nonalfalfae & Ailanthus altissima & & $\mathrm{Vn}$ & $\mathrm{x}$ \\
\hline D19 & Verticillium dahliae & Ailanthus altissima & & $\mathrm{Vn} / \mathrm{Vd}$ & $\mathrm{x}$ \\
\hline D46 & Verticillium dahliae & Ailanthus altissima & & $\mathrm{Vd}$ & $\mathrm{x}$ \\
\hline
\end{tabular}


Table 5-2: Comparisons of the AUDCP and Qin ratings for isolates in previous studies and this study.

\begin{tabular}{|c|c|c|c|c|c|c|c|c|}
\hline \multirow[b]{2}{*}{ Verticillium sp. } & \multirow[b]{2}{*}{ MALDI ID } & \multirow{2}{*}{$\begin{array}{c}\text { MALDI } \\
\text { PCA }\end{array}$} & \multirow[b]{2}{*}{ Isolate ID } & \multirow[b]{2}{*}{ Plant host } & \multicolumn{2}{|c|}{ Ailanthus } & \multicolumn{2}{|c|}{ Tomato } \\
\hline & & & & & Qin rating & AUDPC & Qin rating & AUDPC \\
\hline V. nonalfalfae & S27 & I & VnSo1855 & Spinacia oleracea & 0.0 & $0.0 \mathrm{c}$ & 1.1 & $3.5 \mathrm{c}$ \\
\hline V. nonalfalfae & S15 & II & VnHl1 & Humulus lupulus & 0.0 & $0.0 \mathrm{c}$ & 3.0 & $1.6 \mathrm{c}$ \\
\hline V. nonalfalfae & S7 & II & VnSt462 & Solanum tuberosum & 0.3 & & 2.9 & $3.6 \mathrm{c}$ \\
\hline V. nonalfalfae & $\mathrm{S} 4$ & II & VaSm621 & Solanum melongera & 0.4 & & 5.2 & $13.0 \mathrm{a}$ \\
\hline V. nonalfalfae & S11 & I & VnAc4 & Actinidia chinensis & 0.8 & & 1.6 & $0.1 \mathrm{c}$ \\
\hline V. nonalfalfae & S26 & II & VnS1179 & Solanum lycopersicum & 1.1 & $0.0 \mathrm{c}$ & 4.3 & \\
\hline V. nonalfalfae & & & VnCi21 & Ceanothus integerrimus & 1.2 & & 1.4 & $1.3 \mathrm{c}$ \\
\hline V. nonalfalfae & S28 & II & $\mathrm{VnHI} 2$ & Humulus lupulus & 1.5 & $2.0 \mathrm{c}$ & 1.0 & $1.1 \mathrm{c}$ \\
\hline V. nonalfalfae & S6 & $\mathrm{I}$ & VnAa100 & Ailanthus altissima & $5.3 / 0.0$ & $0.5 \mathrm{c}$ & 3.8 & $5.7 \mathrm{~b}$ \\
\hline V. nonalfalfae & S17 & I & PSU171 & Ailanthus altissima & 5.5 & $13.5 \mathrm{a}$ & & \\
\hline V. nonalfalfae & $\mathrm{S} 1$ & $\mathrm{I}$ & VnAa140 & Ailanthus altissima & $5.1 / 5.8$ & $14.6 \mathrm{a}$ & 3.6 & $5.1 \mathrm{~b}$ \\
\hline V. nonalfalfae & S25 & II & VnSt1856 & Solanum tuberosum soil & & & 2.3 & $1.3 \mathrm{c}$ \\
\hline V. nonalfalfae & $\mathrm{S} 13$ & $\mathrm{I}$ & VnAa172 & Ailanthus altissima & & & & $6.0 \mathrm{~b}$ \\
\hline V. alfalfae & S2 & III & VaMs 102 & Medicago sativa & $3.6 / 1.1$ & $5.1 \mathrm{~b}$ & 1.1 & $1.6 \mathrm{c}$ \\
\hline V. alfalfae & & III & VaMs781 & Medicago sativa & & & 0.3 & \\
\hline V. alfalfae & & III & $\mathrm{VaCb} 241$ & Catalpa bignonioides & & & 1.0 & $0.9 \mathrm{c}$ \\
\hline V. alfalfae & & III & VaMs8AWS95 & Medicago sativa & & & 1.3 & \\
\hline V. alfalfae & $\mathrm{S} 12$ & III & VaMs62969 & Medicago sativa & & & & $1.0 \mathrm{c}$ \\
\hline V. albo-atrum & S8 & II & VaSt112 & Solanum tuberosum & 0.0 & $0.1 \mathrm{c}$ & 0.0 & $0.1 \mathrm{c}$ \\
\hline$?$ & & & VaHv.HPNP8 & Hordeum vulgare & & & 0.0 & \\
\hline$?$ & S29 & $\mathrm{I}$ & VaPsA1211 & Pisum sativum & & & 0.1 & $0.1 \mathrm{c}$ \\
\hline$?$ & & & Strawberry & Fragaria $\times$ ananassa & & & 0.9 & $0.9 \mathrm{c}$ \\
\hline & & & CONTROL & & $0.0 / 0.0$ & $0.8 \mathrm{c}$ & 0.0 & $0.6 \mathrm{c}$ \\
\hline
\end{tabular}




\section{Figures}
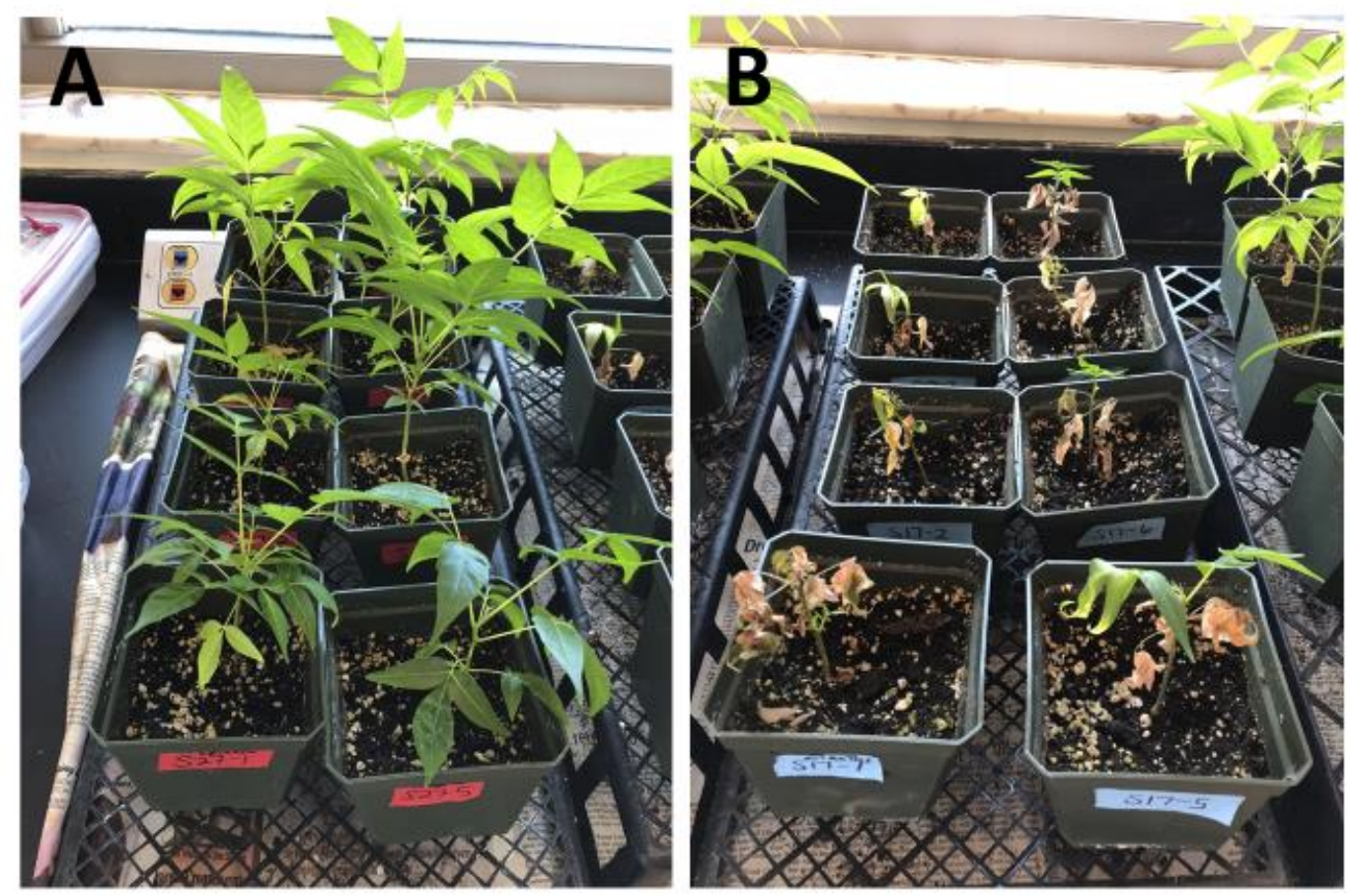

Figure 5-1: (A) Asymptomatic Ailanthus seedlings inoculated with V. nonalfalfae originating from spinach (B) Severely wilted Ailanthus seedlings inoculated with $V$. nonalfalfae originating from Ailanthus 


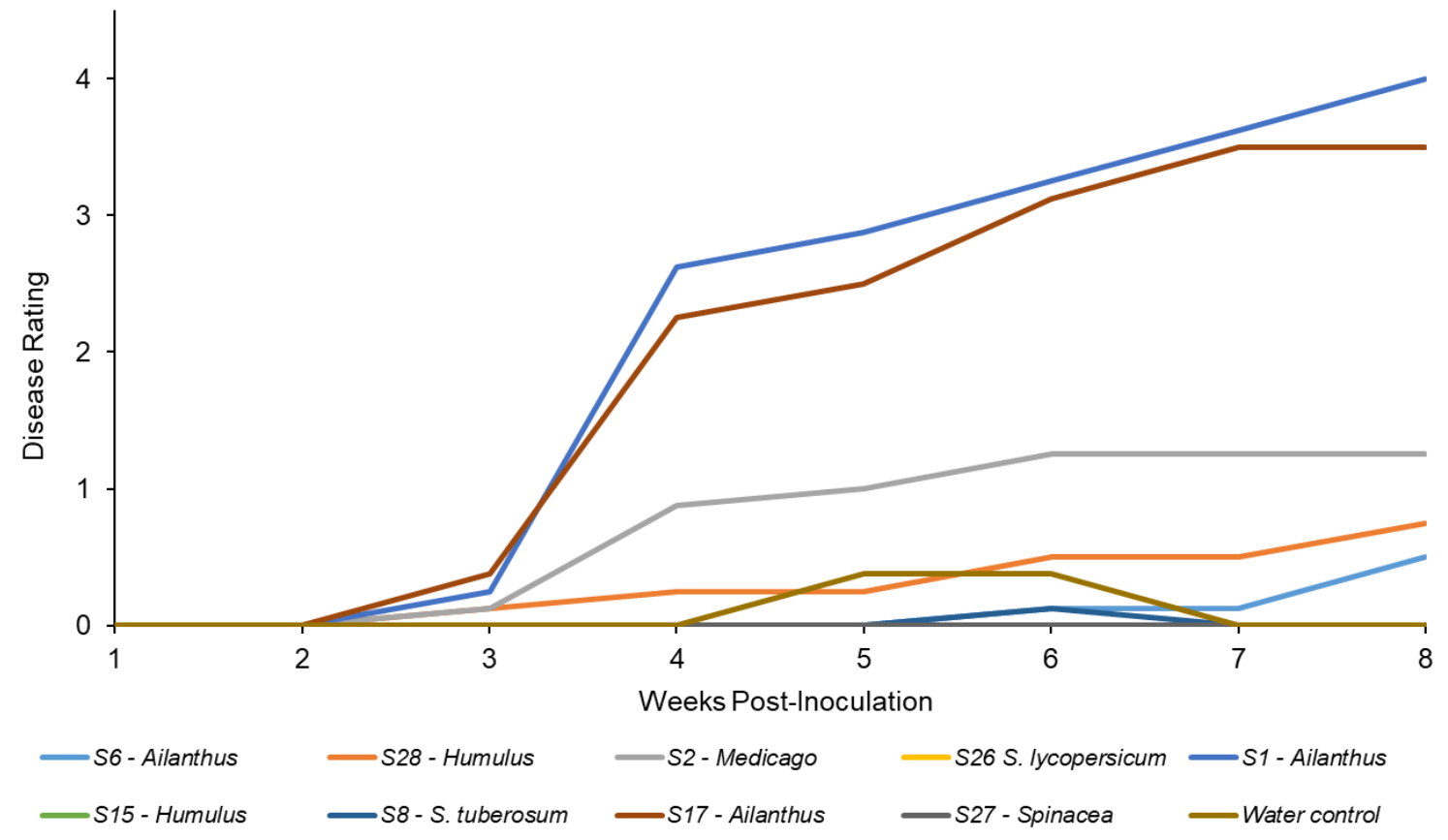

Figure 5-2: Mean disease rating of Ailanthus seedlings inoculated with nine Verticillium strains originally isolated from different plant hosts. An ANOVA and Student's t-test indicate mean disease ratings are statistically significantly different (p-value: 0.01). 


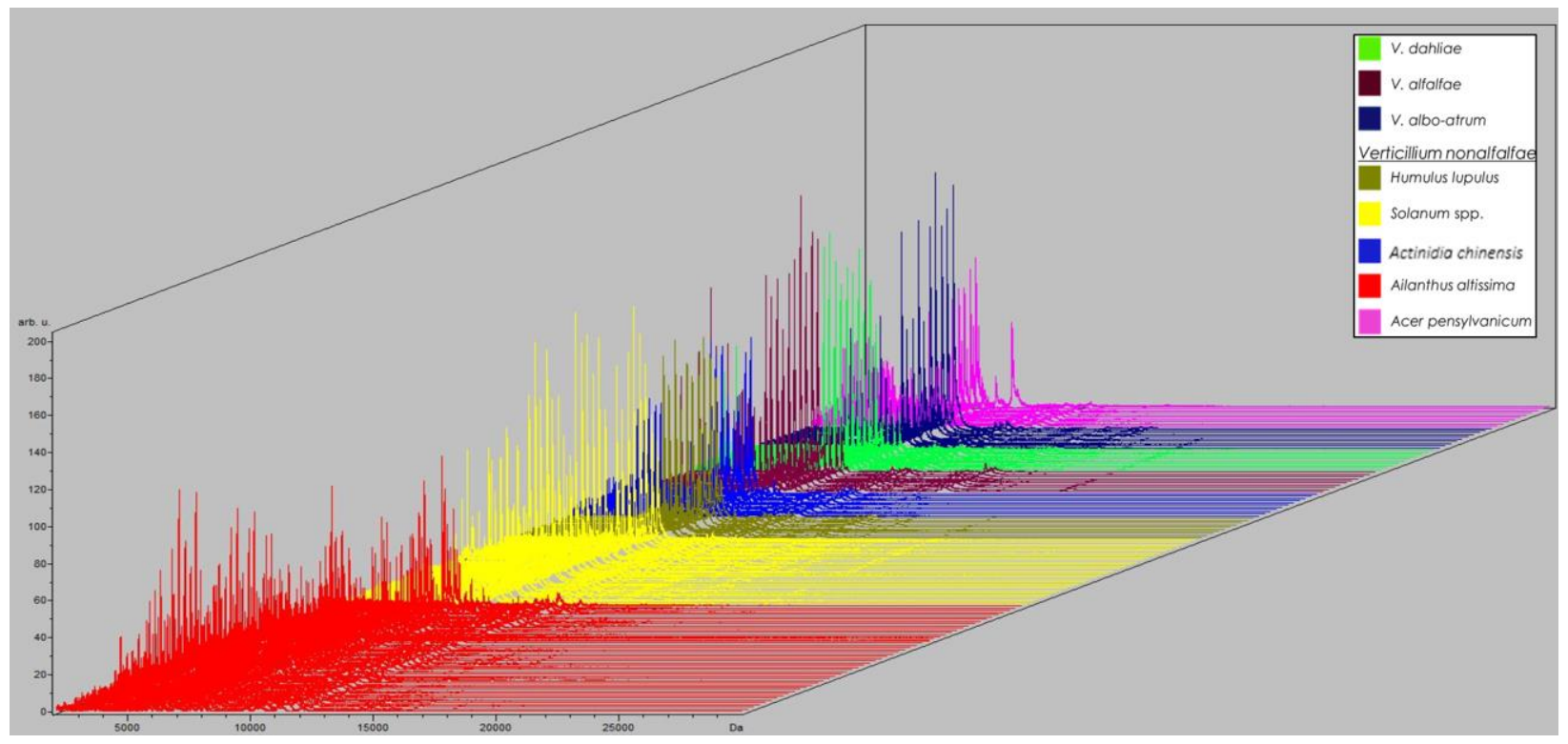

Figure 5-3: Principal component analysis (PCA) plot showing average peaks for all reads of the fungal smear replicates for the 32 isolates. Each line represents a fungal smear of the isolate type grouped in colors representing isolate groups. 


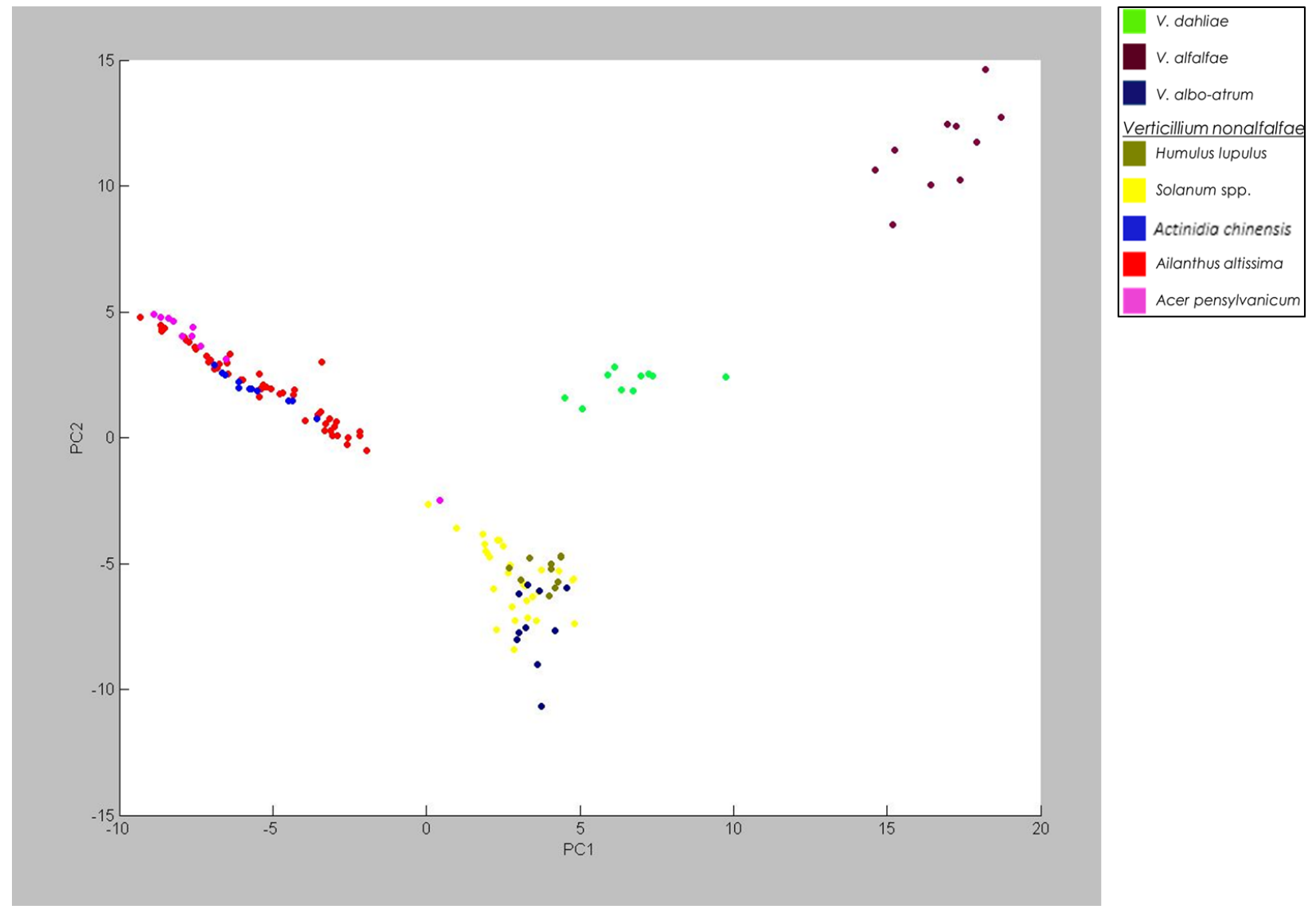

Figure 5-4: A principle component analysis shows isolates of $V$. nonalfalfae from Ailanthus cluster with $V$. nonalfalfae isolates from Acer pennsylvanicum and Actinidia chinensis but separately from and hops and Solanaceous hosts isolates. An ANOVA and Tukey's Test with 95\% confidence interval delineated clusters (see circles) that are statistically significant from each other ( $\mathrm{p}$-value $\leq 0.05)$. 


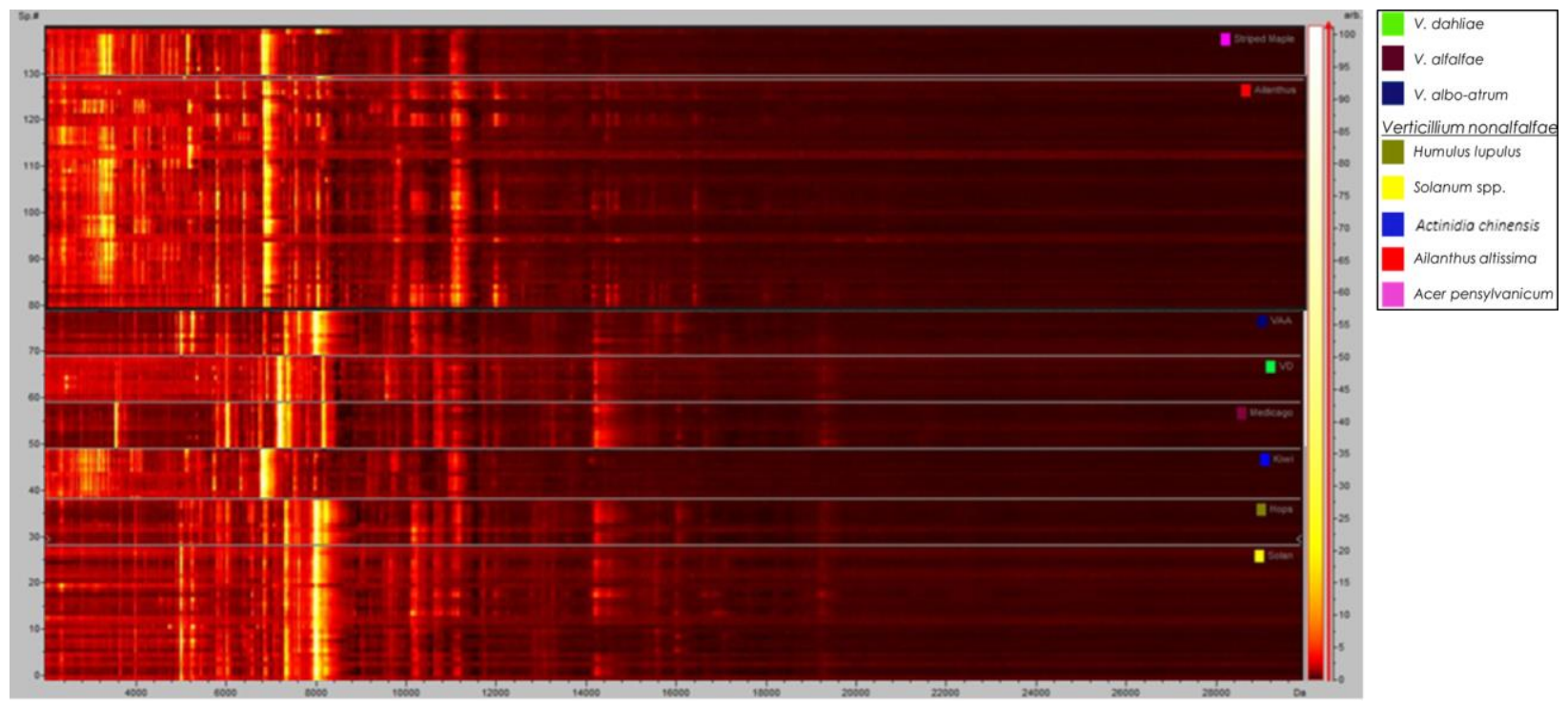

Figure 5-5: Heat map confirms the trends in the PCA plot, showing the separation of the eight groupings of species and host associations into separate clusters. 

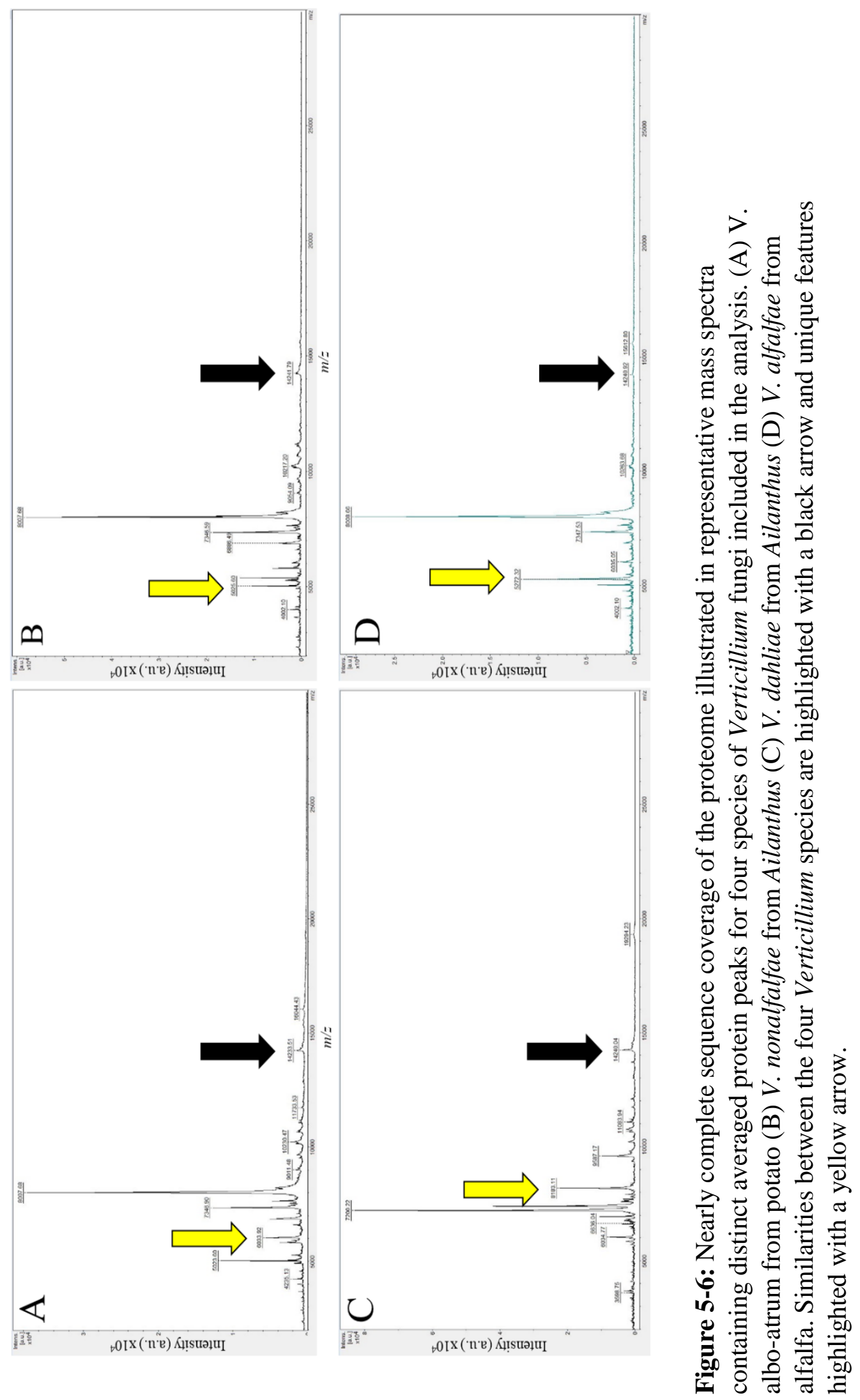


\section{References}

Alshawa, K., Beretti, J. L., Lacroix, C., Feuilhade, M., Dauphin, B., Quesne, G., Hassouni, N. Nassif, X. \& Bougnoux, M. E. (2012). Successful identification of clinical dermatophyte and Neoscytalidium species by matrix-assisted laser desorption ionization-time of flight mass spectrometry. Journal of Clinical Microbiology, 2277-2281.

Aldrich, P.R.; Briguglio, J.S.; Kapadia, S.N.; Morker, M.U.; Rawal, A.; Kalra, P.; Greer, G.K. (2010). Genetic structure of the invasive tree Ailanthus in Eastern United States cities. Journal of Botany.

Bhadauria, V., Popescu, L., Zhao, W. S., \& Peng, Y. L. (2007). Fungal transcriptomics. Microbiological Research, 162(4), 285-298.

Chalupová, J., Raus, M., Sedlářová, M., \& Šebela, M. (2014). Identification of fungal microorganisms by MALDI-TOF mass spectrometry. Biotechnology Advances, 32(1), 230-241.

Doyle, S. (2011). Fungal proteomics: from identification to function. FEMS Microbiology Letters, 321(1), 1-9.

Elliott, M. L. (2005). Survival, growth and pathogenicity of Gaeumannomyces graminis var. graminis with different methods of long-term storage. Mycologia, 97(4), 901-907.

Fournier, E., \& Giraud, T. (2008). Sympatric genetic differentiation of a generalist pathogenic fungus, Botrytis cinerea, on two different host plants, grapevine and bramble. Journal of Evolutionary Biology, 21(1), 122-132.

Gavin, A. C., Bösche, M., Krause, R., Grandi, P., Marzioch, M., Bauer, Schultz, A., Rick, J., Michon, J.M., Cruciat, A.M. \& Remor, M. (2002). Functional organization of the yeast proteome by systematic analysis of protein complexes. Nature, 415(6868), 141.

Giraldo, M. C., \& Valent, B. (2013). Filamentous plant pathogen effectors in action. Nature Reviews Microbiology, 11(11), 800.

Gómez, B. L., \& Nosanchuk, J. D. (2003). Melanin and fungi. Current Opinion in Infectious Diseases, 16(2), 91-96.

Han, Y., Liu, X., Benny, U., Kistler, H. C., \& VanEtten, H. D. (2001). Genes determining pathogenicity to pea are clustered on a supernumerary chromosome in the fungal plant pathogen Nectria haematococca. The Plant Journal, 25(3), 305-314.

Hortin GL. 2006. The MALDI-TOF mass spectrometric view of the plasma proteome and peptidome. Clinical Chemistry 52:1223-1237.

Idnurm, A., \& Howlett, B. J. (2001). Pathogenicity genes of phytopathogenic fungi. Molecular Plant Pathology, 2(4), 241-255.

Inderbitzin, P., \& Subbarao, K. V. (2014). Verticillium systematics and evolution: how confusion impedes Verticillium wilt management and how to resolve it. Phytopathology, 104(6), 564-574. 
Inderbitzin, P., Davis, R. M., Bostock, R. M., \& Subbarao, K. V. (2013). Identification and differentiation of Verticillium species and $V$. longisporum lineages by simplex and multiplex PCR assays. PLoS One, 8(6), e65990.

Kasson MT, Short DPG, O'Neal ES, Subbarao KV, Davis DD. 2014. Comparative pathogenicity, biocontrol efficacy, and multilocus sequence typing of Verticillium nonalfalfae from the invasive Ailanthus and other hosts. Phytopathology 104:282-292.

Kasson, M. T., Kasson, L. R., Wickert, K. L., Davis, D. D., \& Stajich, J. E. (2019). Genome Sequence of a Lethal Vascular Wilt Fungus, Verticillium nonalfalfae, a Biological Control Used Against the Invasive Ailanthus altissima. Microbiology Resource Announcements, 8(4), e0161918.

Kasson, M. T., O’Donnell, K., Rooney, A. P., Sink, S., Ploetz, R. C., Ploetz, J. N., Konkol, J. L., Carrillo, D., Freeman, S., Mendel, Z., Smith, J. A., Black, A.W., Hulcr, J., Bateman, C., Stefkova, K., Campbell, P. R., Geering, A. D., Dann, E. K., Eskalen, A., Mohotti, K., Short, D. P., Aoki, T., Fenstermacher, K. A., Davis, D. D., \& Geiser, D. M. (2013). An inordinate fondness for Fusarium: phylogenetic diversity of fusaria cultivated by ambrosia beetles in the genus Euwallacea on avocado and other plant hosts. Fungal Genetics and Biology, 56, 147-157.

Kasson, M. T., O’Neal, E. S., \& Davis, D. D. (2015). Expanded host range testing for Verticillium nonalfalfae: potential biocontrol agent against the invasive Ailanthus altissima. Plant Disease, 99(6), 823-835.

Kowarik, I., \& Säumel, I. Biological flora of Central Europe: Ailanthus altissima (Mill.) Swingle. Perspect. Plant Ecology. 2007, 8, 207-237.

Lau, S. K., Lam, C. S., Ngan, A. H., Chow, W. N., Wu, A. K., Tsang, D. N., Tse, C.W., Que, T. L., Tang, B.S, \& Woo, P. C. (2016). Matrix-assisted laser desorption ionization time-of-flight mass spectrometry for rapid identification of mold and yeast cultures of Penicillium marneffei. BMC Microbiology, 16(1), 36.

Markell, S. G., Harveson, R. M., Block, C. C., \& Gulya, T. J. (2015). Sunflower diseases. In Sunflower (pp. 93-128). AOCS Press.

Marton K, Flajšman M, Radišek S, Košmelj K, Jakše J, Javornik B, Berne, S. (2018).

Comprehensive analysis of Verticillium nonalfalfae in silico secretome uncovers putative effector proteins expressed during hop invasion. PloS One 13:e0198971.

Maschek, O., \& Halmschlager, E. (2016). First report of Verticillium wilt on Ailanthus in Europe caused by Verticillium nonalfalfae. Plant Disease, 100(2), 529-529.

Maschek, O., \& Halmschlager, E. (2017). Natural distribution of Verticillium wilt on invasive Ailanthus in eastern Austria and its potential for biocontrol. Forest Pathology, 47(5), e12356.

Maschek, O., \& Halmschlager, E. (2018). Effects of Verticillium nonalfalfae on Ailanthus and associated indigenous and invasive tree species in eastern Austria. European Journal of Forest Research, 137(2), 197-209. 
O'Neal, E. S., \& Davis, D. D. (2015). Intraspecific root grafts and clonal growth within Ailanthus stands influence Verticillium nonalfalfae transmission. Plant Disease, 99(8), 10701077.

Osbourn, A., Bowyer, P., Lunness, P., Clarke, B., \& Daniels, M. (1995). Fungal pathogens of oat roots and tomato leaves employ closely related enzymes to detoxify different host plant saponins. MPMI-Molecular Plant Microbe Interactions, 8(6), 971-978.

Pasch, H., \& Schrepp, W. (2013). MALDI-TOF mass spectrometry of synthetic polymers. Springer Science \& Business Media.

Pegg, G. F., \& Brady, B. L. (2002). Verticillium wilts. CABI.

Qin, Q.M., Vallad, G.E., Wu, B.M. \& Subbarao, K.V. (2006). Phylogenetic analyses of phytopathogenic isolates of Verticillium spp. Phytopathology, 96(6), pp.582-592.

Rebbeck, J., Kloss, A., Bowden, M.; Coon, C., Hutchinson, T.F., Iverson, L., \& Guess, G. Aerial detection of seed-bearing female Ailanthus altissima: A cost-effective method to map an invasive tree in forested landscapes. For. Sci. 2015, 61, 1068-1078.

Rep, M. (2005). Small proteins of plant-pathogenic fungi secreted during host colonization. FEMS Microbiology Letters, 253(1), 19-27.

Schall, M. J., \& Davis, D. D. (2009). Ailanthus wilt and mortality: etiology. Plant Disease, 93(7), 747-751.

Schulthess, B., Ledermann, R., Mouttet, F., Zbinden, A., Bloemberg, G. V., Böttger, E. C., \& Hombach, M. (2014). Use of the Bruker MALDI Biotyper for the identification of molds in the clinical mycology laboratory. Journal of Clinical Microbiology, JCM-00049.

Seeley, E. H., \& Caprioli, R. M. (2011). MALDI imaging mass spectrometry of human tissue: method challenges and clinical perspectives. Trends in Biotechnology, 29(3), 136-143.

Shulaev, V. (2006). Metabolomics technology and bioinformatics. Briefings in Bioinformatics, 7(2), 128-139.

Snyder, A. L., Kasson, M. T., Salom, S. M., Davis, D. D., Griffin, G. J., \& Kok, L. T. (2013). First report of Verticillium wilt of Ailanthus in Virginia caused by Verticillium nonalfalfae. Plant Disease, 97(6), 837-837.

Talbot, N. J., Kershaw, M. J., Wakley, G. E., De Vries, O. M., Wessels, J. G., \& Hamer, J. E. (1996). MPG1 encodes a fungal hydrophobin involved in surface interactions during infectionrelated development of Magnaporthe grisea. The Plant Cell, 8(6), 985-999.

Tao, J., Zhang, G., Jiang, Z., Cheng, Y., Feng, J., \& Chen, Z. (2009). Detection of pathogenic Verticillium spp. using matrix-assisted laser desorption/ionization time-of-flight mass spectrometry. Rapid Communications in Mass Spectrometry: An International Journal Devoted to the Rapid Dissemination of Up-to-the-Minute Research in Mass Spectrometry, 23(23), 36473654. 
Tessitore, A., Gaggiano, A., Cicciarelli, G., Verzella, D., Capece, D., Fischietti, M., Zazzeroni, \& Alesse, E. (2013). Serum biomarkers identification by mass spectrometry in high-mortality tumors. International Journal of Proteomics. 


\section{Chapter 6}

\section{Conclusions}

Utilization of the soil borne pathogen Verticillium nonalfalfae as a biocontrol for the invasive Ailanthus is a promising suppression measure in that the fungus is i) hardy across multiple hardiness zones, ii) is not suppressed by other naturally and co-occurring Verticillium fungi in the forest, iii) has the potential to be formulated into methods with high potential for long-term storage, iv) and has a distinct strain which is host selective for Ailanthus. Not being hindered to the point of ineffectiveness by temperature and rainfall differences in hardiness zones 5, 6a, and 6b, shows promise for wide spread utilization of $V$. nonalfalfae in the MidAtlantic region. The interaction of the two Ailanthus pathogenic strains of $V$. dahliae and $V$. nonalfalfae did not affect mortality normally experienced with only $V$. nonalfalfae is present in Ailanthus forests, allowing for land managers to utilize $V$. nonalfalfae in forests already infected by the less aggressive $V$. dahliae without preforming costly and time-consuming assays for the presence of $V$. dahliae. The successful occurrence of wilt and mortality to Ailanthus seedlings, both in the forest and the greenhouse exposed to rye grain and soil infected with $V$. nonalfalfae, further supports the continued study of these two methods as a potential suppression method for Ailanthus regeneration in disturbed timber management sites. Additionally, the ability of the fungus to reside in containers of sterile soil for 8 years provides evidence for potentially affordable commercialization tactics. Although, phylogenetics were previously unable to resolve differences in strains of Verticillium from different hosts, analyzing the proteome of these strains provided distinct protein peaks potentially relating to functions related to specific pathogenicity constraints. These peaks need to be analyzed and confirmed in related gene function, however 
findings from these studies support the utilization of specific strains of $V$. nonalfalfae as a host specific pathogen for Ailanthus. 


\section{Appendix:}

Table S1. Tree-level data for gynoecious Ailanthus included in the study

\begin{tabular}{|c|c|c|c|c|c|c|c|c|c|c|}
\hline ID & Previous IDs & Experiment & $\begin{array}{c}\begin{array}{c}\text { Date } \\
\text { collecte } \\
\text { d }\end{array} \\
\end{array}$ & State & Location details & Environment & $\begin{array}{c}\text { No. } \\
\text { stems } \\
@ \text { dbh } \\
\end{array}$ & $\begin{array}{c}\text { dbh } \\
\text { (cm) }\end{array}$ & $\begin{array}{c}\text { Total } \\
\text { seeds } \\
\text { produce } \\
\text { d } \\
\end{array}$ & $\begin{array}{c}\mathrm{Ag} \\
\mathrm{e}\end{array}$ \\
\hline PA-01 & $\mathrm{N} / \mathrm{A}$ & Seed production & 8.27 .11 & PA & 522 S immediately below Lewistown & roadside & 1 & 7.6 & 594 & 5 \\
\hline PA-02 & $N / A$ & Seed production & 8.27.11 & PA & 522 S near FS01 & roadside & 3 & 6.3 & 24214 & 6 \\
\hline " " " & $"$ & $"$ & $" \quad "$ & $"$ & $"$ & $"$ & & 6.3 & & $"$ \\
\hline " " " & $"$ & " & " " " & $"$ & $"$ & & & 6.5 & & $"$ \\
\hline PA-03 & N/A & Seed production & 8.27.11 & PA & 322 E Port Royal exit ramp & roadside & 1 & 7.3 & 2388 & 4 \\
\hline PA-04 & N/A & Seed production & 8.27.11 & PA & Dauphin Park and Ride & roadside & 1 & 5.5 & 619 & 9 \\
\hline PA-05 & $\mathrm{N} / \mathrm{A}$ & Seed production & 8.27 .11 & PA & $322 \mathrm{~W}$ Thompsontown Exit ramp & roadside & 2 & 5.3 & 28136 & 6 \\
\hline$" \quad "$ & $"$ & $"$ & $" \quad "$ & $"$ & $"$ & & & 4.6 & " " " & $"$ \\
\hline PA-06 & $N / A$ & Seed production & 8.27.11 & PA & $322 \mathrm{~W}$ between Millerstown and Pfoutz Valley Exit & Roadside on shale cli & 1 & 2.1 & 1936 & 7 \\
\hline PA-07 & N/A & Seed production & 8.27.11 & PA & Immediately adjacent to FS06 & Roadside on shale cli & 1 & 2.4 & 135 & 5 \\
\hline PA-08 & N/A & Seed production & 8.27 .11 & PA & 322 W between Millerstown and Pfoutz Valley Exit & Roadside on shale cli & 1 & 3 & 3356 & 9 \\
\hline PA-09 & $\mathrm{N} / \mathrm{A}$ & Seed production & 8.27.11 & PA & $322 \mathrm{~W}$ before Thompsontown Exit & Roadside & 1 & 4 & 6438 & 5 \\
\hline PA-11 & $\mathrm{N} / \mathrm{A}$ & Seed production & 8.27.11 & PA & Immediately adjacent to $\mathrm{FS} 10$ & Roadside on shale cli & 3 & 3.3 & 8175 & 8 \\
\hline$" \quad "$ & $"$ & $"$ & $" \quad "$ & $"$ & $"$ & $"$ & & 3.3 & & $"$ \\
\hline " " & " & " & " " " & $"$ & $"$ & & & 3.1 & & $"$ \\
\hline PA-12 & $N / A$ & Seed production & 9.01 .11 & PA & $99 \mathrm{~S}$ north of Exit 33 & roadside & 2 & 3.1 & 1067 & 10 \\
\hline " " " & $"$ & " & $" \quad "$ & $"$ & " & & & 2.5 & " " & $"$ \\
\hline PA-13 & $\mathrm{N} / \mathrm{A}$ & Seed production & 9.01 .11 & PA & 99 S north of Exit 33 & roadside & 2 & 7.2 & 33751 & 17 \\
\hline " " " & $"$ & $"$ & $" \quad "$ & $"$ & $"$ & & & 5.5 & $" \quad "$ & $"$ \\
\hline PA-14 & $\mathrm{N} / \mathrm{A}$ & Seed production & 9.01 .11 & PA & Rt. $22 \mathrm{E}$ west of $453 \& 45 \mathrm{Jnct}$. Along road & roadside & 1 & 3 & 1087 & 8 \\
\hline PA-15 & N/A & Seed production & 9.01 .11 & PA & Rt. $22 \mathrm{E}$ west of $453 \& 45 \mathrm{Jnct}$. Along road & roadside & 1 & 4.6 & 6147 & 9 \\
\hline PA-16 & $\mathrm{N} / \mathrm{A}$ & Seed production & 9.01 .11 & PA & Rt. 22 E west of $453 \& 45$ Jnct. Along road & roadside & 1 & 3.5 & 82 & 9 \\
\hline PA-17 & $\mathrm{N} / \mathrm{A}$ & Seed production & 9.01 .11 & PA & Rt. 22 E west of $453 \& 45$ Jnct. Along road & roadside & 1 & 4.4 & 3759 & 9 \\
\hline PA-18 & $\mathrm{N} / \mathrm{A}$ & Seed production & 9.02 .11 & PA & entrance ramp $99 \mathrm{~S}$ Exit 31 & Roadside on shale cli & 3 & 4.4 & 19879 & 11 \\
\hline$" \quad "$ & $"$ & $"$ & $" \quad "$ & $"$ & $"$ & $"$ & & 4.2 & $" \quad "$ & $"$ \\
\hline " " " & $"$ & $"$ & $" \quad "$ & $"$ & $"$ & & & 3.7 & & $"$ \\
\hline PA-19 & $\mathrm{N} / \mathrm{A}$ & Seed production & 9.02.11 & PA & entrance ramp $99 \mathrm{~S}$ Exit 31 & Roadside & 2 & 2.8 & 181 & 9 \\
\hline$"$ " " & " & " & " " & $"$ & " & & & 2.7 & $" \quad "$ & $"$ \\
\hline PA-20 & N/A & Seed production & 9.02 .11 & PA & " & Roadside & 1 & 7.3 & 6139 & 10 \\
\hline PA-21 & N/A & Seed production & 9.02 .11 & PA & entrance ramp $99 \mathrm{~S}$ Exit 31 & Roadside & 1 & 4.8 & 10344 & 9 \\
\hline PA-22 & $\mathrm{N} / \mathrm{A}$ & Seed production & 9.13 .11 & PA & ccsp water tower road & roadside & 1 & 5.7 & 4984 & 11 \\
\hline PA-23 & $N / A$ & Seed production & 9.22.11 & PA & SGL1 n.t. Ev symbiont study & forest & 1 & 40.6 & 4441 & 41 \\
\hline PA-24 & $N / A$ & Seed production & 8.8 .12 & PA & PSU UP tree & campus & 1 & 115.1 & 685641 & 112 \\
\hline PA-25 & $N / A$ & Seed production & 9.24 .11 & PA & E. of Arch rock, 322 East bound before herb trt & roadside & 1 & 5 & 12209 & 5 \\
\hline PA-26 & N/A & Seed production & 9.24.11 & PA & E. of Arch rock, 322 East bound before herb trt & roadside & 1 & 10.2 & 24692 & 10 \\
\hline PA-27 & $N / A$ & Seed production & 9.24 .11 & PA & E. of Arch rock, 322 East bound close to herb trt & roadside & 1 & 7.7 & 14722 & 7 \\
\hline PA-28 & $\mathrm{N} / \mathrm{A}$ & Seed production & 9.24 .11 & PA & 322 E., btwn Port Royal and Thompsontown Exit & median, roadside & 3 & 3 & 20645 & 10 \\
\hline$" \quad "$ & $"$ & $"$ & " " " & $"$ & " & " & & 2.4 & & $"$ \\
\hline " " " & $"$ & $"$ & $" \quad "$ & $"$ & $"$ & " & & 1.8 & $" \quad "$ & $"$ \\
\hline PA-29 & $N / A$ & Seed production & 9.24 .11 & PA & 322 E., btwn Port Royal and Thompsontown Exit & median, roadside & 1 & 2 & 2009 & 15 \\
\hline PA-30 & $\mathrm{N} / \mathrm{A}$ & Seed production & 9.24.11 & PA & 322 E., btwn Port Royal and Thompsontown Exit & roadside & 1 & 13.8 & 108278 & 8 \\
\hline PA-31 & $\mathrm{N} / \mathrm{A}$ & Seed production & 9.24 .11 & PA & 322 W., btwn Port Royal and Thompsontown Exit & roadside & 1 & 3.4 & 426 & 9 \\
\hline PA-32 & $N / A$ & Seed production & 9.24 .11 & PA & 322 W., btwn Port Royal and Thompsontown Exit & roadside & 1 & 2.5 & 176 & 10 \\
\hline PA-33 & $\mathrm{N} / \mathrm{A}$ & Seed production & 9.24 .11 & PA & 322 E., btwn Arch Rock and Mifflintown Exit & cliff & 2 & 4 & 2703 & 12 \\
\hline$" \quad "$ & $"$ & $"$ & $" \quad "$ & $"$ & $"$ & $"$ & & 5.1 & $" \quad "$ & $"$ \\
\hline PA-34 & $N / A$ & Seed production & 9.24.11 & PA & 322 E., btwn Arch Rock and Mifflintown Exit & median, roadside & 1 & 5.5 & 12463 & 13 \\
\hline PA-35 & $\mathrm{N} / \mathrm{A}$ & Seed production & 7.14.12 & PA & 322 E., btwn Lewistown and Arch Rock Exit & roadside & 1 & 6.5 & 861 & 4 \\
\hline PA-36 & $\mathrm{N} / \mathrm{A}$ & Seed production & 7.14 .12 & PA & 322 W., btwn Mifflintown and Arch Rock Exit & median, roadside & 1 & 4.5 & 265 & 7 \\
\hline PA-37 & $N / A$ & Seed production & 7.14.12 & PA & 322 W., btwn Mifflintown and Arch Rock Exit & median, roadside & 1 & 3.2 & 167 & 7 \\
\hline PA-38 & $\mathrm{N} / \mathrm{A}$ & Seed production & 7.14.12 & PA & east of SGL1 by about $150 \mathrm{ft}$ & forest & 1 & 14.1 & 3894 & 10 \\
\hline PA-39 & $N / A$ & Seed production & 7.14 .12 & $\mathrm{PA}$ & west of SGL1, by thistle inoc & forest & 1 & 7 & 40 & 5 \\
\hline
\end{tabular}


Table S1. Tree-level data for gynoecious Ailanthus included in the study (cont.)

\begin{tabular}{|c|c|c|c|c|c|c|c|c|c|c|}
\hline PA-40 & $\mathrm{N} / \mathrm{A}$ & Seed production & 7.14 .12 & PA & west of SGL1, by symbiont study & forest & 1 & 7.2 & 4769 & 10 \\
\hline PA-41 & $\mathrm{N} / \mathrm{A}$ & Seed production & 7.14 .12 & PA & Dauphin, PA, rt $225 \mathrm{~S}$, half mile from 322 & roadside & 1 & 5.2 & 2643 & 9 \\
\hline PA-42 & N/A & Seed production & 7.14 .12 & PA & Rt. 22 E west of $453 \& 45$ Jnct. Along road & roadside & 1 & 6.5 & 4983 & 9 \\
\hline PA-43 & $\mathrm{N} / \mathrm{A}$ & Seed production & 7.25 .12 & PA & Below RLK 1 near smaller field & forest & 1 & 22.5 & 70849 & 46 \\
\hline $\mathrm{PA}-44$ & $\mathrm{~N} / \mathrm{A}$ & Seed production & 7.26 .12 & PA & SGL211 next to a 3rd landing & forest & 1 & 10.8 & 7554 & 8 \\
\hline PA-45 & N/A & Seed production & 7.26 .12 & PA & SGL211 in old clearcut next to road that passes SG & al forest & 1 & 8.2 & 5467 & 5 \\
\hline PA-46 & $\mathrm{N} / \mathrm{A}$ & Seed production & 7.26 .12 & PA & SGL1 near Sumac inoc by landing & forest & 1 & 9 & 6879 & 7 \\
\hline PA-47 & $\mathrm{N} / \mathrm{A}$ & Seed production & 7.26 .12 & PA & Lewistown Exit Rt 22 Business & roadside & 1 & 7.5 & 1989 & 5 \\
\hline PA-48 & N/A & Seed production & 7.26 .12 & PA & Lewistown Exit Rt 22 Business & roadside & 1 & 4.6 & 1359 & 8 \\
\hline PA-49 & $N / A$ & Seed production & 7.27.12 & PA & RLK1 along field & forest, field edge & 1 & 25.2 & 73703 & 40 \\
\hline PA-50 & $\mathrm{N} / \mathrm{A}$ & Seed production & 7.27 .12 & PA & RLK1 along field & forest, field edge & 1 & 13 & 46567 & 9 \\
\hline $\mathrm{PA}-51$ & N/A & Seed production & 8.3.12 & PA & Below RLK 1, near June inoc. & forest & 1 & 47.5 & 68627 & 45 \\
\hline PA-52 & $\mathrm{N} / \mathrm{A}$ & Seed production & 8.3.12 & PA & RLK1, near Sept. inoc & forest & 1 & 15 & 22487 & 21 \\
\hline PA-53 & $\mathrm{N} / \mathrm{A}$ & Seed production & 8.3.12 & PA & RLK1, near Sept. inoc & forest & 1 & 25.3 & 142502 & 46 \\
\hline PA-54 & $N / A$ & Seed production & 8.3.12 & PA & RLK1 near Soil form. Inoc & forest & 1 & 20.7 & 89704 & 37 \\
\hline PA-55 & $N / A$ & Seed production & 8.3.12 & PA & RLK1 near Soil form. Inoc & forest & 1 & 25 & 72815 & 40 \\
\hline PA-56 & $N / A$ & Seed production & 8.3.12 & PA & RLK1 near Soil form. Inoc & forest & 1 & 24.3 & 40664 & 34 \\
\hline PA-57 & $\mathrm{P} 30^{\mathrm{a}}$ & Seed germination & 7.30 .10 & PA & Gettysburg & highway & $\mathrm{n} / \mathrm{a}$ & $\mathrm{n} / \mathrm{a}$ & $\mathrm{n} / \mathrm{a}$ & $n / a$ \\
\hline PA-58 & S38 & Seed germination & 10.09 .09 & PA & Buchannan State Forest, Site BSF2 & forest & $\mathrm{n} / \mathrm{a}$ & $\mathrm{n} / \mathrm{a}$ & $\mathrm{n} / \mathrm{a}$ & $n / a$ \\
\hline PA-59 & $S 9^{b}$ & Seed germination & 9.04 .08 & PA & Monongalia County airport & roadside & $\mathrm{n} / \mathrm{a}$ & $\mathrm{n} / \mathrm{a}$ & $\mathrm{n} / \mathrm{a}$ & $\mathrm{n} / \mathrm{a}$ \\
\hline PA-60 & $\mathrm{HSAa} 23^{\mathrm{a}, \mathrm{b}}$ & Seed germination & 9.15 .08 & PA & $\begin{array}{l}\text { On the campus of Penn State University adjacent } \\
\text { to Old Main }\end{array}$ & campus & $\mathrm{n} / \mathrm{a}$ & $\mathrm{n} / \mathrm{a}$ & $\mathrm{n} / \mathrm{a}$ & 98 \\
\hline WV-01 & Mon. Co. Airport & Seed germination & 8.09 .17 & WV & Monongalia County airport & roadside & $\mathrm{n} / \mathrm{a}$ & $\mathrm{n} / \mathrm{a}$ & $\mathrm{n} / \mathrm{a}$ & 52 \\
\hline WV-02 & $\begin{array}{l}\text { Organic Farm Tree } \\
\# 1\end{array}$ & $\begin{array}{c}\text { Seed } \\
\text { germination / }\end{array}$ & 8.18.17 & WV & WVU Organic Farm, Tree \#1 & field & $\mathrm{n} / \mathrm{a}$ & $\mathrm{n} / \mathrm{a}$ & $\mathrm{n} / \mathrm{a}$ & 20 \\
\hline WV-03 & $\begin{array}{l}\text { Organic Farm Tree } \\
\# 2\end{array}$ & Seed germination & 8.18 .17 & WV & WVU Organic Farm, Tree \#2 & field & $\mathrm{n} / \mathrm{a}$ & $\mathrm{n} / \mathrm{a}$ & $\mathrm{n} / \mathrm{a}$ & 12 \\
\hline WV-04 & WVU1 & Seed germination & 8.11 .17 & WV & WVU Evansdale Campus, Evans dale Drive & roadside & $\mathrm{n} / \mathrm{a}$ & $\mathrm{n} / \mathrm{a}$ & $\mathrm{n} / \mathrm{a}$ & 45 \\
\hline WV-05 & Farmhouse & Seed germination & 8.16 .17 & WV & Cedarstone Drive, Morgantown, WV & yard & $\mathrm{n} / \mathrm{a}$ & $\mathrm{n} / \mathrm{a}$ & $\mathrm{n} / \mathrm{a}$ & 16 \\
\hline PA-61 & $\begin{array}{l}\text { East Finley } \\
\text { Township, PA }\end{array}$ & $\begin{array}{c}\text { Seed } \\
\text { germination / }\end{array}$ & 8.31 .16 & PA & Rural road & roadside & $\mathrm{n} / \mathrm{a}$ & $\mathrm{n} / \mathrm{a}$ & $\mathrm{n} / \mathrm{a}$ & 7 \\
\hline PA-62 & HSAa23 $3^{\mathrm{a}, \mathrm{b}}$ & $\begin{array}{c}\text { Seed } \\
\text { germination / }\end{array}$ & 10.29 .16 & PA & $\begin{array}{l}\text { On the campus of Penn State University adjacent } \\
\text { to Old Main }\end{array}$ & campus & $\mathrm{n} / \mathrm{a}$ & $\mathrm{n} / \mathrm{a}$ & $\mathrm{n} / \mathrm{a}$ & 104 \\
\hline IB1 & - & Seed production & - & $\mathrm{PA}$ & See Illick and Brouse 1926 & See location details & - & 30.5 & 995995 & $29^{c}$ \\
\hline IB2 & - & Seed production & - & PA & $"$ & $"$ & - & 20.3 & 879580 & $21^{\mathrm{c}}$ \\
\hline FRA1 & - & Seed production & - & PA & See Bory and Clair-Maczulajtys 1980 & $"$ & - & 1.2 & 240 & $4^{c}$ \\
\hline FRA2 & - & Seed production & - & France & $"$ & $"$ & - & 2.5 & 900 & $5^{c}$ \\
\hline FRA3 & - & Seed production & - & France & $"$ & $"$ & - & 16.0 & 88200 & $18^{\mathrm{c}}$ \\
\hline FRA4 & - & Seed production & - & France & $"$ & $"$ & - & 11.0 & 22500 & $13^{\mathrm{c}}$ \\
\hline FRA5 & - & Seed production & - & France & $"$ & $"$ & - & 25.0 & 240000 & $25^{\mathrm{c}}$ \\
\hline FRA6 & - & Seed production & - & France & $"$ & $"$ & - & 21.0 & 78000 & $21^{\mathrm{c}}$ \\
\hline FRA7 & - & Seed production & - & France & $"$ & $"$ & - & 11.0 & 45000 & $13^{c}$ \\
\hline FRA8 & - & Seed production & - & France & $"$ & $"$ & - & 17.0 & 110000 & $19^{c}$ \\
\hline FRA9 & - & Seed production & - & France & $"$ & $"$ & - & 11.0 & 58000 & $13^{c}$ \\
\hline FRA10 & - & Seed production & - & France & $"$ & $"$ & - & 9.0 & 28000 & $12^{\mathrm{c}}$ \\
\hline FRA11 & - & Seed production & - & France & $"$ & $"$ & - & 17.0 & 54000 & $19^{c}$ \\
\hline FRA12 & - & Seed production & - & France & $"$ & $"$ & - & 19.0 & 190000 & $20^{\mathrm{c}}$ \\
\hline FRA13 & - & Seed production & - & France & $"$ & $"$ & - & 30.0 & 325000 & $29^{c}$ \\
\hline FRA14 & - & Seed production & - & France & $"$ & $"$ & - & 16.0 & 122000 & $18^{c}$ \\
\hline FRA15 & - & Seed production & - & France & $"$ & $"$ & - & 11.0 & 81000 & $13^{c}$ \\
\hline FRA16 & - & Seed production & - & France & $"$ & $"$ & - & 18.0 & 125000 & $19^{c}$ \\
\hline FRA17 & - & Seed production & - & France & $"$ & $"$ & - & 12.0 & 51000 & $14^{\mathrm{c}}$ \\
\hline FRA18 & - & Seed production & - & France & $"$ & $"$ & - & 5.0 & 85000 & $8^{c}$ \\
\hline FRA19 & - & Seed production & - & France & $"$ & $"$ & - & 6.5 & 36000 & $9^{c}$ \\
\hline FRA20 & - & Seed production & - & France & $"$ & $"$ & - & 10.0 & 14000 & $13^{\mathrm{c}}$ \\
\hline FRA21 & - & Seed production & - & France & $"$ & $"$ & - & 5.5 & 55000 & $4^{c}$ \\
\hline
\end{tabular}

${ }^{a}$ See Appendix 5 and/or Table 1 in Kasson et al. 2013 for additional information.

${ }^{b}$ See Supplemental Table 1 in Kasson et al. 2015 for additional information.

${ }^{\mathrm{C}}$ Ages were estimated using Fig. 4 age-DBH regression. 